\title{
Soil Cycles of Elements simulator for Predicting TERrestrial regulation of greenhouse gases: SCEPTER v0.9
}

\author{
Yoshiki Kanzaki ${ }^{1}$, Shuang Zhang ${ }^{2}$, Noah J. Planavsky ${ }^{3}$, Christopher T. Reinhard ${ }^{1}$ \\ ${ }^{1}$ School of Earth and Atmospheric Sciences, Georgia Institute of Technology, Atlanta, GA 30332, USA \\ $5 \quad{ }^{2}$ Department of Oceanography, Texas A\&M University, College Station, TX 77843, USA \\ ${ }^{3}$ Department of Earth and Planetary Sciences, Yale University, New Haven, CT 06511, USA
}

Correspondence to: Yoshiki Kanzaki (ykanzaki3@gatech.edu)

\begin{abstract}
Regulation of anthropogenic carbon dioxide $\left(\mathrm{CO}_{2}\right)$ is an urgent issue-continuously increasing atmospheric $\mathrm{CO}_{2}$ from burning fossil fuels is leading to significant warming and acidification of the surface ocean. Timely and effective measures to curb $\mathrm{CO}_{2}$ increases are thus needed in order to mitigate the potential degradation of natural ecosystems, food security, and livelihood caused by anthropogenic release of $\mathrm{CO}_{2}$. Enhanced rock weathering (ERW) on croplands and hinterlands may be one of the most economically and ecologically effective ways to sequester $\mathrm{CO}_{2}$ from the atmosphere, given that these soil environments generally favor mineral dissolution and because amending soils with crushed rock can result in a number of co-benefits on plant growth and crop yield. However, quantitative evaluation of $\mathrm{CO}_{2}$ capture by ERW

15 in terrestrial soil systems to date has been conducted with tools that are mechanistically very simplified and/or allow limited flexibility. With the goal of working towards a more mechanistically grounded understanding of the geoengineering potential of terrestrial ERW, we developed new 1D reactive transport model - SCEPTER. The model is designed to: (1) mechanistically simulate natural weathering, including dissolution/precipitation of minerals along with uplift/erosion of solid phases, advection plus diffusion of aqueous phases and diffusion of gas phases; (2) allow targeted addition of solid phases at

20 the soil-atmosphere interface, including multiple forms of organic matter (OM) and crushed mineral/rock feedstocks; (3) implement a range of soil mixing regimes as catalyzed by soil surface fauna (e.g., bioturbation) or humans (e.g., various forms of tilling); and (4) enable calculation of solid mineral surface area based on controlled initial particle size distributions coupled to a shrinking core framework. Here we describe the model structure and intrinsic thermodynamic/kinetic data, provide a series of idealized simulations to demonstrate the basic behavior of the code, and evaluate the computational and mechanistic performance of the model against observational data. We also provide selected example applications to highlight model features particularly useful for future prediction of $\mathrm{CO}_{2}$ sequestration by ERW in soil systems.
\end{abstract}

\section{Introduction}

Continuously increasing emissions of $\mathrm{CO}_{2}$ and other greenhouse gases (GHGs) from fossil fuel consumption and land use change have resulted in large changes to atmospheric chemistry and global temperature since the beginning of the industrial era (e.g., Le Quéré et al., 2018), and are expected to lead to significant climate perturbation and environmental degradation 
in the coming century (IPCC, 2006). Although reducing anthropogenic GHG emissions must be the lynchpin for mitigating degradation of surface environments (e.g., Rogelj et al., 2018), all current pathways delineated by the Intergovernmental Panel on Climate Change (IPCC, 2006, 2018) as potentially limiting global warming to below $1.5^{\circ} \mathrm{C}$ by 2100 require carbon dioxide removal (CDR) on the order of $10^{2}-10^{3}$ gigatons of $\mathrm{CO}_{2}\left(\mathrm{GtCO}_{2}=10^{15} \mathrm{gCO}_{2}\right)$ over the course of the next century (IPCC, 2018), and less severe $\mathrm{CO}_{2}$ regulation trajectories will also likely require active CDR. As a result, various modes of $\mathrm{CO}_{2}$ capture will likely be critical for achieving climate targets set by the international community (e.g., Fuss et al., 2014; Gasser et al., 2015; IPCC, 2018).

Enhanced rock weathering (ERW) at Earth's surface is one potential means of executing CDR on a gigaton scale (e.g., Köhler et al., 2010; Taylor et al., 2016; Beerling et al., 2020). Broadly, this class of CDR strategies involves the 40 sequestration of atmospheric $\mathrm{CO}_{2}$ as dissolved inorganic carbon (DIC) through reaction with silicate or carbonate minerals. In principle, this could be achieved across a range of marine (Rau et al., 2007; Köhler et al., 2013; Renforth and Henderson, 2017) and terrestrial (Köhler et al., 2010; Hartmann et al., 2013; Beerling et al., 2020) environments. However, terrestrial ERW in agricultural settings, in particular, has received significant recent attention as a potentially cost-effective strategy for CDR with a range of possible co-benefits including increasing crop yields and neutralization of ongoing surface ocean 45 acidification (Minx et al., 2018; Strefler et al., 2018; Beerling et al., 2020). Numerical tools will be essential to chart a path forward with $\mathrm{CO}_{2}$ capture by ERW given environmental and economic constraints. Following more developed modeling fields (e.g., CMIP6; e.g., Liddicoat et al., 2021), the most robust estimates of CDR potential and operational cost will require an ensemble of traceable models that are optimized for addressing the feedbacks between soil systems and ERW intervention.

To help facilitate robust prediction of the $\mathrm{CO}_{2}$ capture efficiency, environmental impacts, and operational costs of ERW in terrestrial soil systems, we have developed a new 1D reactive-transport model - SCEPTER. The model is designed for quantification of interactions between accelerated dissolution of applied rock/mineral powders and background natural weathering including soil respiration and particle mixing by surface soil fauna. Soil mixing is implemented by adapting a transition matrix method, which allows the user to define their own transfer function for desired mixing regime. We track surface area differences between background rocks/soils and applied mineral/rock powders by tracking porosity evolution caused by addition of mineral/rock powders and/or by tracking size distributions of particles with an adapted shrinking particle model. Increased surface areas from milled grains can be retained or annealed with reaction progress. First, we describe the theoretical background and numerical implementation of SCEPTER (Section 2). Then, a series of idealized simulations are presented in order to illustrate the basic capability of the code as a natural weathering simulator and the

60 utility of model components specifically designed to interrogate the impact of ERW (Section 3.1). Finally, we compare model results to soil depth profiles of $\mathrm{pH}$ and $\mathrm{OM}$ from gridded U.S. soil data (Section 3.2). 


\section{Model description}

\subsection{Overview}

The basic framework of SCEPTER is derived from previous models designed to simulate reactive transport and weathering

65 in natural soil systems, with a focus on pyrite and organic matter oxidation (Kanzaki and Kump, 2017) and silicate mineral transformation (Kanzaki et al., 2020). SCEPTER can currently simulate up to 39 minerals and different classes of soil organic matter (SOM; currently configured with 3 classes), 10 independent aqueous species along with 48 dependent aqueous species, and 4 independent gas species (Tables 1-5). Reaction kinetics, especially dissolution/precipitation, are explicitly implemented for individual solid species and are fully coupled with the temporal and spatial evolution of aqueous

70 and gas species (e.g., Table 2). One can further add/remove a series of additional reactions to the system associated with solid, aqueous, and/or gaseous species (referred to as 'extra' reactions, e.g., Table 6). Particular features of SCEPTER designed to interrogate ERW in terrestrial soil systems include: (1) implementation of bio-mixing in the upper soil layers using a transition matrix approach; (2) time-dependent application of crushed rock feedstock to the soil surface; (3) options for time-varying boundary conditions including porosity and advection rates of solids and porewater; and (4) a range of user

75 options for calculation and specification of the surface area of solid species. These features of the model are specifically designed for aiding in robust prediction of enhanced weathering on terrestrial ecosystems, including croplands and hinterlands (e.g., Hartmann et al., 2013; Taylor et al., 2016; Beerling et al., 2020; Goll et al., 2021).

In the following we describe the theoretical framework of the model (Section 2.2), its numerical implementation (Section 2.3), and the user input in relation to model initialization and boundary conditions (Section 2.4). The model code is

80 written in Fortran90 (see Code Availability).

\subsection{Theoretical framework}

\subsubsection{Tracing solid, aqueous, and gas species in soils}

SCEPTER is based on previous models designed to represent fundamental aspects of natural weathering (e.g., Bolton et al., 2006; Brantley and Lebedeva, 2011; Li et al., 2014; Steefel et al., 2015; Kanzaki et al., 2020). Solid minerals are transported

85 upward by continental uplift and eroded at the surface while reacting with solutes in porewater whose transport is dominated by molecular diffusion plus advection caused by downward infiltration. Some solutes are derived from the gas phase present in soil pore space whose composition is controlled by diffusive transport plus consumption/production through reactions within soil including dissolution into and degassing from porewater.

In addition to the above basic description of the model's framework as a natural soil/rock weathering simulator,

90 SCEPTER implements bio-mixing of solid particles in soils and a rain of solid particles onto the soil surface (Section 2.1). Including these additional supply and mixing effects, a solid species $\theta$ is simulated according to the following generalized equation (cf. Boudreau, 1997; Kanzaki et al., 2020, 2021): 
$\frac{\partial m_{\theta}}{\partial t}=\frac{\partial w m_{\theta}}{\partial z}-R_{\theta}-\sum_{\kappa}^{n_{\mathrm{xxn}}} \gamma_{\kappa, \theta} R_{\kappa}+J_{\theta}-m_{\theta} \int_{0}^{z_{\mathrm{m}}} E_{\theta}\left(z, z^{\prime}\right) d z^{\prime}+\int_{0}^{z_{\mathrm{ml}}} m_{\theta}\left(z^{\prime}\right) E_{\theta}\left(z^{\prime}, z\right) d z^{\prime}$

where $m_{\theta}$ is the mole amount of solid species $\theta$ per unit bulk soil/rock volume $\left(\mathrm{mol} \mathrm{m}^{-3}\right), t$ is time (yr), $z$ is the depth of weathering profile $(\mathrm{m}), w$ is the advection rate of solid phases $\left(\mathrm{m} \mathrm{yr}^{-1}\right), R_{\theta}$ and $J_{\theta}$ are the net dissolution and rain rates of solid species $\theta$, respectively ( $m o l \mathrm{~m}^{-3} \mathrm{yr}^{-1}$ ), $R_{\kappa}$ denotes the rate of $\kappa$-th extra reaction $\left(\mathrm{mol} \mathrm{m}^{-3} \mathrm{yr}^{-1}\right.$ ) whose stoichiometry with respect to consumption of $\theta$ is defined by $\gamma_{\kappa, \theta}, n_{\mathrm{xrxn}}$ is the total number of extra reactions, $E_{\theta}\left(z, z^{\prime}\right)$ is the rate of particle transfer between locations at $z$ and $z^{\prime}$ by bio-mixing $\left(\mathrm{m}^{-1} \mathrm{yr}^{-1}\right)$ and $z_{\mathrm{ml}}$ is the mixed layer depth $(\mathrm{m})$ within which bio-mixing occurs. The exchange function $E_{\theta}\left(z, z^{\prime}\right)$ expresses bio-mixing rate in a generalized continuous form, whose discretized counterpart can be formulated with a transition matrix (e.g., Boudreau, 1997; Shull, 2001; Kanzaki et al., 2021). Various biomixing styles and corresponding transition matrices are elaborated in Section 2.2.5. As described above, SCEPTER also allows flexible addition of many additional reactions (with example 'extra' reactions given in Table 6 and discussed in Section 2.2.2) beyond those parameterized with the thermodynamic and kinetic constants in Tables 1 and 2. See the following subsections for more details on individual transport and reaction terms.

When an element with a given redox state dissolves in porewater and is not sourced from soil atmosphere, the element is regarded as an aqueous species in the model. The total amount of all dissolved forms of the element per unit porewater volume is traced as an independent variable for modeling solutes in porewater. Specific chemical forms (e.g., hydrolyzed forms and complexes with other ions) are assumed to be in equilibrium and their concentrations are calculated based on the tracked total concentrations of individual dissolved elements and thermodynamics of association/dissociation reactions (Table 3, Section 2.2.2). For each dissolved element, all associated chemical forms are assumed to be transported uniformly (i.e., the same diffusion coefficients are applied to various aqueous forms of a dissolved element; Table 5, Section 2.2.4) and thus the governing equation for a dissolved element is given as follows:

$$
\frac{\partial \phi \sigma \ell c_{\varsigma}}{\partial t}=-\frac{\partial \phi \sigma \ell v c_{\varsigma}}{\partial z}+\frac{\partial}{\partial z}\left(\phi \sigma \ell \tau_{\mathrm{aq}} D_{\varsigma} \frac{\partial c_{\varsigma}}{\partial z}\right)+\sum_{\theta}^{n_{\mathrm{sdd}}} \gamma_{\theta, \varsigma} R_{\theta}+\sum_{\kappa}^{n_{\mathrm{xxn}}} \gamma_{\kappa, \varsigma} R_{\kappa}
$$

where $c_{\varsigma}$ is the porewater concentration of dissolved element $\varsigma\left(\mathrm{mol} \mathrm{L}^{-1}\right), \phi$ is the porosity, $\sigma$ is the water saturation ratio, $\ell$ is 115 a unit conversion factor $\left(10^{3} \mathrm{~L} \mathrm{~m}^{-3}\right), v$ is the porewater advection rate $\left(\mathrm{m} \mathrm{yr}^{-1}\right), \tau_{\mathrm{aq}}$ is the tortuosity factor for solute diffusion in porewater, $D_{\varsigma}$ is the diffusion coefficient of dissolved element $\varsigma\left(\mathrm{m}^{2} \mathrm{yr}^{-1}\right), n_{\text {sld }}$ is the total number of simulated solid species, $\gamma_{\theta, \zeta}$ is the mole amount of $\varsigma$ released upon dissolution of 1 mole of mineral $\theta$ and $\gamma_{\kappa, \zeta}$ is the stoichiometry of $\varsigma$ production in $\kappa$-th extra reaction.

A gas species is introduced into the model when it is produced/consumed by aqueous and/or solid species. In the 120 current version of SCEPTER, soil $\mathrm{CO}_{2}, \mathrm{O}_{2}, \mathrm{NH}_{3}$ and $\mathrm{N}_{2} \mathrm{O}$ can be included as gas species. The independent variable is taken to be the soil partial pressure for a given gas species and concentrations of all dissolved forms derived from the gas species 
are taken to be dependent variables. Transport occurs via diffusion for a gas species and via diffusion plus porewater advection for its dependent dissolved forms (Section 2.1). The governing equation for a gas species is accordingly given by:

$$
\frac{\partial \alpha_{\varepsilon} p_{\varepsilon}}{\partial t}=-\frac{\partial \phi \sigma \ell v H_{\varepsilon} p_{\varepsilon}}{\partial z}+\frac{\partial}{\partial z}\left(D_{\varepsilon}^{\mathrm{eff}} \frac{\partial p_{\varepsilon}}{\partial z}\right)+\sum_{\theta}^{n_{\mathrm{sd}}} \gamma_{\theta, \varepsilon} R_{\theta}+\sum_{\kappa}^{n_{\mathrm{xxn}}} \gamma_{\kappa, \varepsilon} R_{\kappa}
$$

125 where $p_{\varepsilon}$ is the partial pressure of soil gas $\varepsilon(\mathrm{atm}), \gamma_{\theta, \varepsilon}$ is the mole amount of $\varepsilon$ released upon dissolution of 1 mole of solid species $\theta, H_{\varepsilon}$ is the total solubility of $\varepsilon\left(\mathrm{mol} \mathrm{L}^{-1} \mathrm{~atm}^{-1}\right)$ and $\gamma_{\kappa, \varepsilon}$ is the stoichiometry of $\varepsilon$ production in $\kappa$-th extra reaction. In Eq. (3), $\alpha_{\varepsilon}$ and $D_{\varepsilon}^{\text {eff }}$ are the unit conversion factor $\left(\mathrm{mol} \mathrm{m}^{-3} \mathrm{~atm}^{-1}\right)$ and effective diffusion coefficient $\left(\mathrm{m}^{2} \mathrm{yr}^{-1}\right)$ for soil gas $\varepsilon$, respectively, to include the reactive transport of dependent dissolved forms of $\varepsilon$ (e.g., Elberling and Nicholson, 1996):

$\alpha_{\varepsilon}=\eta \phi(1-\sigma) \ell+\phi \sigma \ell H_{\varepsilon}$

$D_{\varepsilon}^{\mathrm{eff}}=\eta \phi(1-\sigma) \ell \tau_{\mathrm{gas}} D_{\varepsilon}^{\mathrm{gas}}+\phi \sigma \ell H_{\varepsilon} \tau_{\mathrm{aq}} D_{\varepsilon}^{\mathrm{aq}}$

where $\eta$ is the unit conversion from atm to molarity $\left(=\Re^{-1} T^{-1}\right.$, where $\mathfrak{R}$ is the gas constant, $0.08205 \mathrm{~L} \mathrm{~atm} \mathrm{~mol}^{-1} \mathrm{~K}^{-1}$, and $T$ is the temperature in $\mathrm{K}), \tau_{\text {gas }}$ is the tortuosity factor for gas diffusion in pore air space and $D_{\varepsilon}^{\text {gas }}$ and $D_{\varepsilon}^{\text {aq }}$ are the diffusion coefficients $\left(\mathrm{m}^{2} \mathrm{yr}^{-1}\right)$ for gas and aqueous phases of $\varepsilon$, respectively. Individual reaction and transport terms are discussed below.

\subsubsection{Reactions}

Dissolution/precipitation of a solid species $\theta\left(R_{\theta}\right)$ is formulated as a function of saturation state of the species in porewater $\left(\Omega_{\theta}\right)$, rate coefficient $\left(k \theta, \mathrm{mol} \mathrm{m}^{-2} \mathrm{yr}^{-1}\right)$ and surface area of the species per unit bulk soil/rock volume available to porewater $\left(S_{\theta}, \mathrm{m}^{2} \mathrm{~m}^{-3}\right)$ :

$R_{\theta}=S_{\theta} k_{\theta}\left(1-\Omega_{\theta}\right)$

140 Here, $k_{\theta}$ is a function of porewater $\mathrm{pH}$ and soil $\mathrm{CO}_{2}$ (for carbonates) according to Palandri and Kharaka (2004) (Table 2) and $S_{\theta}$ is related to $m_{\theta}$, with a number of potential scaling options (see Section 2.2.6). The saturation state $\Omega_{\theta}$ is calculated based on thermodynamic data for solid species (Table 1). When decomposition of solid species occurs as a redox reaction, e.g., pyrite oxidation and SOM decomposition, $\Omega_{\theta}$ is defined kinetically. For instance, pyrite oxidation proceeds according to, e.g., Williamson and Rimstidt (1994):

$145 R_{\mathrm{py}}=S_{\mathrm{py}} k_{\mathrm{py}} p_{\mathrm{O}_{2}}^{0.5}$

where $p_{\mathrm{O}_{2}}$ is the partial pressure of soil $\mathrm{O}_{2}(\mathrm{~atm})$. We conventionally define saturation state for pyrite $\left(\Omega_{\mathrm{py}}\right)$ as:

$\Omega_{\mathrm{py}}=1-p_{\mathrm{O}_{2}}^{0.5}$

so that Eq. (6) can be applied to all solid species (Tables 1 and 2). In addition to the dissolution/precipitation reactions specific to individual solid species, one can add extra reactions to the system whose kinetics are explicitly considered. Currently implemented extra reactions and their kinetic laws are listed in Table 6. 
All dependent aqueous species are calculated assuming that they are in equilibrium and satisfy the mass balance and charge balance in porewater at any model timestep and at all model depths (cf. Steefel et al., 2015). Generally, the mass balance for dependent aqueous species derived from a given dissolved element is given as:

$$
c_{\varsigma}=\sum_{i}^{n_{\varsigma}} c_{\varsigma}^{i}
$$

155 where $c_{\zeta}^{i}$ is the porewater concentration of $i$-th dependent aqueous species derived from dissolved element $\varsigma\left(\operatorname{mol~L}^{-1}\right)$ and $n_{\varsigma}$ is the total number of dependent aqueous species of $\varsigma$. Note that the current version of the model does not include any polymers (e.g., $\mathrm{Si}_{2} \mathrm{O}(\mathrm{OH})_{6}$ ) as aqueous species and thus 1 mole of dependent aqueous species of dissolved element $\varsigma$ contains 1 mole of $\varsigma$ as assumed in Eq. (9). We define the first dependent species of a given dissolved element as the free dissolved form, except for $\mathrm{Si}$ whose first dependent species is defined as $\mathrm{H}_{4} \mathrm{SiO}_{4}$, and the other species as products formed via reactions of the first dependent species with other aqueous species in porewater, given respectively by:

$$
\begin{aligned}
& c_{\varsigma}^{1}=c_{\varsigma}\left\{1+\sum_{i=2}^{n_{\varsigma}} K_{\zeta, i}\left[\mathrm{H}^{+}\right]^{\gamma_{\zeta, i, \mathrm{p}}} \prod_{\varsigma^{\prime} \neq \varsigma}^{n_{\mathrm{aq}}}\left(c_{\zeta^{\prime}}^{1}\right)^{\gamma_{\zeta, i, \zeta^{\prime}}} \prod_{\varepsilon}^{n_{\mathrm{gas}}}\left(p_{\varepsilon}\right)^{\gamma_{\zeta, i, \varepsilon}}\right\}^{-1} \\
& c_{\zeta}^{i \neq 1}=c_{\zeta}^{1} K_{\zeta, i \neq 1}\left[\mathrm{H}^{+}\right]^{\gamma_{\zeta, i \neq 1, \mathrm{p}}} \prod_{\varsigma^{\prime} \neq \zeta}^{n_{\mathrm{aq}}}\left(c_{\zeta^{\prime}}^{1}\right)^{\gamma_{\zeta, i \neq 1, \zeta}} \prod_{\varepsilon}^{n_{\mathrm{gas}}}\left(p_{\varepsilon}\right)^{\gamma_{\zeta, i \neq 1, \varepsilon}}
\end{aligned}
$$

where $K_{\zeta, i}$ is the thermodynamic constant for production of $i$-th dependent aqueous species of dissolved element $\varsigma,\left[\mathrm{H}^{+}\right]$is the porewater $\mathrm{H}^{+}$concentration $\left(\mathrm{mol} \mathrm{L}^{-1}\right), \gamma_{\varsigma, i \mathrm{p}}, \gamma_{\varsigma, i, \zeta^{\prime}}$ and $\gamma_{\varsigma, i, \varepsilon}$ are the stoichiometry of $\mathrm{H}^{+}$, dissolved element $\varsigma^{\prime}$ and gas species $\varepsilon$, respectively, in the reaction that produces $i$-th dependent aqueous species of $\varsigma$, and $n_{\text {aq }}$ and $n_{\text {gas }}$ are the total numbers of independent aqueous and gas species, respectively.

Any aqueous species derived from a gas species is also assumed to be in equilibrium with the gas in soil pore space:

$$
c_{\varepsilon}^{j}=p_{\varepsilon} K_{\mathrm{H}, \varepsilon} K_{\varepsilon, j}\left[\mathrm{H}^{+}\right]^{\gamma_{s, j p \mathrm{p}}} \prod_{\varsigma}^{n_{\mathrm{aq}}}\left(c_{\varsigma}^{1}\right)^{\gamma_{\varepsilon, j, \zeta}}
$$

where $c_{\varepsilon}^{j}$ is the porewater concentration of $j$-th dependent aqueous species derived from soil gas $\varepsilon\left(\mathrm{mol} \mathrm{L}^{-1}\right), K_{\mathrm{H}, \varepsilon}$ is Henry's constant for soil gas $\varepsilon\left(\mathrm{mol} \mathrm{L}^{-1} \mathrm{~atm}^{-1}\right), K_{\varepsilon, j}$ is the thermodynamic constant for production of $j$-th dependent aqueous species of $\varepsilon, \gamma_{\varepsilon, j, \mathrm{p}}$ and $\gamma_{\varepsilon, j, \zeta}$ are the stoichiometry of $\mathrm{H}^{+}$and dissolved element $\varsigma$, respectively, in the reaction that produces $j$-th dependent aqueous species of $\varepsilon$. The total solubility of $\varepsilon\left(H_{\varepsilon}\right.$, Eq. (3)) is then be given by:

$$
H_{\varepsilon} \equiv \sum_{j}^{n_{\varepsilon}} c_{\varepsilon}^{j} / p_{\varepsilon}=K_{\mathrm{H}, \varepsilon} \sum_{j}^{n_{\varepsilon}} K_{\varepsilon, j}\left[\mathrm{H}^{+}\right]^{\gamma_{\varepsilon, j \mathrm{p}}} \prod_{\varsigma}^{n_{\mathrm{aq}}}\left(c_{\varsigma}^{1}\right)^{\gamma_{\varepsilon, j, \zeta}}
$$

Finally, porewater $\mathrm{pH}$ is obtained based on charge balance:

$175\left[\mathrm{H}^{+}\right]-\left[\mathrm{OH}^{-}\right]+\sum_{\varsigma}^{n_{\mathrm{aq}}} \sum_{i}^{n_{\zeta}} Z_{\varsigma}^{i} c_{\varsigma}^{i}+\sum_{\varepsilon}^{n_{\mathrm{gas}}} \sum_{j}^{n_{\varepsilon}} Z_{\varepsilon}^{j} c_{\varepsilon}^{j}\left(\neq c_{\varsigma^{\prime}}^{i^{\prime}}\right)=0$ 
where $Z_{\varsigma}^{i}$ and $Z_{\varepsilon}^{j}$ are the charges of $i$-th and $j$-th dependent aqueous species derived from aqueous species $\varsigma$ and gas species $\varepsilon$, respectively, and $\left[\mathrm{OH}^{-}\right]$is the porewater $\mathrm{OH}^{-}$concentration $\left(\mathrm{mol} \mathrm{L}^{-1}\right)$. Note that double counting of dependent aqueous species is avoided in Eq. (14). Porewater concentrations of $\mathrm{H}^{+}$and $\mathrm{OH}^{-}$are related to one another via thermodynamic constant of water dissociation $K_{\mathrm{w}}\left(\mathrm{mol}^{2} \mathrm{~L}^{-2}\right)$ :

$180 K_{\mathrm{w}}=\left[\mathrm{H}^{+}\right]\left[\mathrm{OH}^{-}\right]$

Once $p_{\varepsilon}$ and $c_{\varsigma}$ are known, Eqs. (9)-(15) can be solved to obtain porewater concentrations of all dependent aqueous species including $\left[\mathrm{H}^{+}\right]$or $\mathrm{pH}$.

\subsubsection{Porosity and advection of solids and porewater}

Temporal and spatial evolution of porosity is calculated based on Eq. (1) and the constraint of volume conservation:

$185 \sum_{\theta}^{n_{\text {sdd }}} m_{\theta} V_{\theta}=(1-\phi)$

where $V_{\theta}$ is the molar volume of solid species $\theta\left(\mathrm{m}^{3} \mathrm{~mol}^{-1}\right)$ (Table 1). Summing Eq. (1) (multiplied with $V_{\theta}$ for all the considered solid species in the model) and using Eq. (16) yields:

$\frac{\partial(1-\phi)}{\partial t}=\frac{\partial(1-\phi) w}{\partial z}+\sum_{\theta}^{n_{\mathrm{sd}}} V_{\theta}\left\{-R_{\theta}-\sum_{\kappa}^{n_{\mathrm{xxn}}} \gamma_{\kappa, \theta} R_{\kappa}+J_{\theta}+m_{\theta} \int_{0}^{z_{\mathrm{mI}}} E_{\theta}\left(z, z^{\prime}\right) d z^{\prime}-\int_{0}^{z_{\mathrm{m}}} m_{\theta}\left(z^{\prime}\right) E_{\theta}\left(z^{\prime}, z\right) d z^{\prime}\right\}$

To satisfy volume conservation (Eq. (16)), porosity $(\phi)$ and advection rate (w) are calculated simultaneously by Eq. (17)

190 assuming a scaling relationship. In the default setting, $w$ is assumed to be constant and independent of $\phi$, but two other user options are available in which $w \phi$ or $w(1-\phi)$ can be assumed to be constant (cf. Wang et al., 2014; Chen et al., 2020).

Advection of porewater is assumed to be caused by steady state porewater flow (e.g., Stonestrom et al., 1998). Thus, advection terms for aqueous species (the first terms on the right-hand side of Eqs. (2) and (3)) are calculated based on a net water flux to the soil system, $q\left(\mathrm{~m} \mathrm{yr}^{-1}\right)$, and a water saturation profile $(\sigma)$ :

$195 q=\phi \sigma v$

By default, SCEPTER fixes the profiles of $q$ and $\sigma$, but these can be changed along model time as a user option. The depth profile of $\sigma$ is assumed to increase linearly from the surface level to the water table where $\sigma=1$, and is thus controlled by two variables - the value of $\sigma$ at the surface and the depth of the water table (cf. Section 2.4; Kanzaki et al., 2020).

\subsubsection{Diffusion}

200 Molecular diffusion becomes slower in porous media because of tortuosity (Clennell, 1997). The tortuosities of pore air- and water-filled spaces are represented by factors $\tau_{\text {gas }}$ and $\tau_{\text {aq }}$, both of which are parameterized with porosity and water content in soils according to Aachib et al. (2003): 
$\tau_{\text {gas }}=\phi^{1.4}(1-\sigma)^{2.4}$

$\tau_{\mathrm{aq}}=\phi^{1.4} \sigma^{2.4}$

205 See Table 5 for the molecular diffusion coefficients for gas and aqueous species where tortuosity factors are not accounted for.

\subsubsection{Bio-mixing}

SCEPTER parameterizes various styles of soil-mixing (bio-mixing) within a transition matrix framework. Here, we provide a short description of the transition matrix framework for parameterization of bio-mixing. For more details, the reader is referred to e.g., Boudreau (1997), Shull (2001), Kanzaki et al. (2021).

The particle transport rate for solid species $\theta$ from layer $i$ to layer $j$ is defined here as $P_{\theta, i j}\left(\mathrm{yr}^{-1}\right)$, given by:

$$
P_{\theta, i j}=\frac{N_{\theta, i j}}{\sum_{j=1}^{n_{\mathrm{ml}}} N_{\theta, i j}} \frac{1}{\tau}
$$

where $N_{\theta, i j}$ is the number of particles of species $\theta$ moved from layer $i$ to layer $j, n_{\mathrm{ml}}$ is the total number of layers within the bio-mixed zone and $\tau$ is the time (yr) required for the particle displacements. Note that the particle transport probability,

215 given as $P_{\theta, i j} \times \tau$, corresponds to components at $(i, j)$ of the transition matrix (Trauth, 1998; Shull, 2001). The time rate of change of soil concentration of solid species $\theta$ at layer $i$ caused by bio-mixing $\left(\left[\partial m_{\theta, i} / \partial t\right]_{\operatorname{mix}}\right)$ can then be described with $P P_{\theta, i j}$ :

$\left[\frac{\partial m_{\theta, i}}{\partial t}\right]_{\text {mix }}=-m_{\theta, i} \sum_{j=1}^{n_{\mathrm{ml}}} P_{\theta, i j}+\sum_{j=1}^{n_{\mathrm{ml}}} \frac{\delta z_{j}}{\delta z_{i}} m_{\theta, j} P_{\theta, j i}$

where $m_{\theta, i}$ is the concentration of $\theta\left(\mathrm{mol} \mathrm{m}^{-3}\right)$ at soil layer $i$ and $\delta z_{i}$ is thickness of layer $i(\mathrm{~m})$ (see Kanzaki et al., 2021, for a more detailed derivation). To simplify Eq. (22), a modified transition matrix for species $\theta$ is introduced, whose components at $(i, j)$ are denoted as $K_{\theta, i j}$ and calculated based on the particle transport rate $P_{\theta, i j}$ :

$K_{\theta, i j}= \begin{cases}\delta z_{i} P_{\theta, i j} / \delta z_{j} & (i \neq j) \\ -\sum_{j \neq i}^{n_{\mathrm{mL}}} P_{\theta, i j} & (i=j)\end{cases}$

From Eqs. (22) and (23), we obtain

$\left[\frac{\partial m_{\theta, i}}{\partial t}\right]_{\mathrm{mix}}=\sum_{j}^{n_{\mathrm{ml}}} m_{\theta, j} K_{\theta, j i}$

Eq. (24) can be regarded as the discretized form of the bio-mixing term shown in Eq. (1).

SCEPTER can implement a range of different transition matrices for parameterizing different soil mixing regimes, including Fickian mixing (e.g., bulk bioturbation), homogeneous mixing (e.g., deep rotary tilling prior to sowing row crops), 
inversion tilling, or particle-tracking automata-based simulators (see Boudreau et al., 2001; Choi et al., 2002; Kanzaki et al., 2019). Simulations shown here implement either Fickian or homogeneous mixing (see below). The transition matrix for Fickian bioturbation (parameterized with a biodiffusion coefficient $D_{\mathrm{b}}$, Goldberg and Koide, 1962), can be expressed by:

$K_{\theta, i j}= \begin{cases}-K_{\theta, i j}(j=i+1) & (i=j=1) \\ -K_{\theta, i j}(j=i+1)-K_{\theta, i j}(j=i-1) & \left(1<i=j<n_{\mathrm{ml}}\right) \\ -K_{\theta, i j}(j=i-1) & \left(i=j=n_{\mathrm{ml}}\right) \\ \left\{\left(1-\phi_{i}\right) D_{\mathrm{b}, i}+\left(1-\phi_{j}\right) D_{\mathrm{b}, j}\right\} /\left\{\delta z_{i}\left(1-\phi_{i}\right)\left(\delta z_{i}+\delta z_{j}\right)\right\} & \left(2 \leq j=i+1 \leq n_{\mathrm{ml}} \text { or } 1 \leq j=i-1 \leq n_{\mathrm{ml}}-1\right) \\ 0 & (\text { else })\end{cases}$

where $D_{\mathrm{b}, i}$ represents the biodiffusion coefficient at soil layer $i$. SCEPTER adopts a depth-independent coefficient by default: $D_{\mathrm{b}}=2 \times 10^{-4} \mathrm{~m}^{2} \mathrm{yr}^{-1}$ (cf. Jarvis et al., 2010; Astete et al., 2016).

The transition matrix for homogeneous mixing is given by:

$K_{\theta, i j}= \begin{cases}\delta z_{i} P_{\mathrm{h}} / \delta z_{j} & \left(i \neq j \text { and } 1 \leq i, j \leq n_{\mathrm{ml}}\right) \\ -\left(n_{\mathrm{ml}}-1\right) P_{\mathrm{h}} & \left(1 \leq i=j \leq n_{\mathrm{ml}}\right) \\ 0 & (\text { else })\end{cases}$

235 where $P_{\mathrm{h}}\left(\mathrm{yr}^{-1}\right)$ is the homogeneous transport rate of solid particles between soil layers. The model assumes $P_{\mathrm{h}}=0.01 \mathrm{yr}^{-1}$ as the default parameterization (cf. Kanzaki et al., 2021).

\subsubsection{Surface area}

Surface areas of solid species $\theta$ available for reaction with porewater $\left(S_{\theta}\right)$ significantly impacts dissolution/precipitation rates of solid phases (Eq. (6)) and thus the parameterization of surface area is of critical importance for predicting the behavior of elements in soils. However, there are significant differences in the parameterization of $S_{\theta}$ between models (e.g., Bolton et al., 2006; Steefel, 2009; Li et al., 2014) and/or between solid species (e.g., minerals vs. SOM; e.g., Jia et al., 2019). SCEPTER provides multiple options for parameterization of $S_{\theta}$.

\subsubsection{Surface area parameterization based on hydraulic radius}

Hydraulic radius of a given porous medium $\left(r_{\mathrm{H}}, \mathrm{m}\right)$ can be defined as the ratio of pore volume against pore surface area

245 (Fanchi, 2018). Conceptually, the value of $r_{\mathrm{H}}$ can be thought of as the average effective radius of particles within weathering/soil system. In this formulation, the overall surface area of pores in a unit bulk soil/rock volume can be described as $\phi / r_{\mathrm{H}}\left(\mathrm{m}^{2} \mathrm{~m}^{-3}\right)$. The area available for mineral phase $\theta$ can then be calculated as the product of the soil volume fraction of mineral $\theta$ and $\phi / r_{\mathrm{H}}$, i.e.,

$$
S_{\theta}=\phi m_{\theta} V_{\theta} r_{\mathrm{H}}^{-1}
$$

250 Eq. (27) is specified as the default option in SCEPTER, following Kanzaki and Kump (2017) and Kanzaki et al. (2020). A linear relationship between $S_{\theta}$ and $m_{\theta}$ as in Eq. (27) is also widely assumed in other models that calculate the surface area 
based on measured specific surface area $\left(\mathrm{m}^{2} \mathrm{~g}^{-1}\right)$, soil concentration $\left(\mathrm{mol} \mathrm{m}^{-3}\right)$ and molar weight $\left(\mathrm{g} \mathrm{mol}^{-1}\right)$ of minerals (Section 2.2.6.4; Brantley and Lebedeva, 2011; Li et al., 2014).

However, several other reactive-transport models assume that the pore surface area available to mineral $\theta$ is not directly proportional to its volume fraction $m_{\theta} V_{\theta}$, but is instead proportional to $\left(m_{\theta} V_{\theta}\right)^{2 / 3}$ with an intension to convert volume fraction to surface area fraction (e.g., Steefel, 2009; see also Bolton et al., 2006, who implemented a similar dependence with a shrinking particle model). To realize this $S_{\theta-m_{\theta}}$ relation, SCEPTER can also adopt an alternative function for $S_{\theta}$ : $S_{\theta}=\phi\left(m_{\theta} V_{\theta}\right)^{2 / 3} r_{\mathrm{H}}^{-1}$

In Eq. (28), the hydraulic radius $r_{\mathrm{H}}$ is still used to specify the total surface area available to minerals.

With the options presented above (Eqs. (27) and (28)), surface area normalized to porosity and mineral fraction (i.e., $\left.1 / r_{\mathrm{H}}\right)$ does not change with time or depth. To enable evolving surface area while using only average effective radius of particles, SCEPTER adopts two optional scaling relationships between surface area and porosity (e.g., Emmanuel and Berkowitz, 2005):

$r_{\mathrm{H}}^{-1} \propto(1-\phi)^{2 / 3}$

$r_{\mathrm{H}}^{-1} \propto \phi^{2 / 3}$

Eq. (29) is adopted as the default option in the current version of SCEPTER.

\subsubsection{Parameterization based on particle size distribution}

The surface area of a porous medium can be explicitly calculated if the shapes of component particles and the particle size distribution (PSD) are known, assuming that aggregation of particles does not reduce the surface area available to porewater (which can occur in natural systems depending on the assumed particle shapes). Tracking the PSD can be facilitated by adopting a shrinking particle model in which all particles maintain their shapes as their volumes change with ongoing dissolution/precipitation (e.g., Nicholson et al., 1990; Safari et al., 2009). For a batch solution system in which minerals only dissolve without being transported, surface area can be calculated relatively easily in a shrinking particle framework (e.g., LeBlanc and Fogler, 1988). For example, Beerling et al. (2020) adopted a shrinking particle model to calculate the particle

275 size distribution and particle surface area in their 'performance' simulations of basalt powder application onto croplands assuming a uniform spherical shape. The problem becomes more complex with solid phase transport (e.g., in 1D), where solid phases not only precipitate/dissolve but are also added at the top of the model domain and transported vertically (e.g., Eq. (1)). To facilitate inter-model comparison and to add flexibility for representing reactive surface area, SCEPTER contains a numerical scheme and corresponding subroutine for explicit PSD tracking within a shrinking particle framework.

The essential framework is provided below while numerical implementation is detailed in Section 2.3.

Particles are all assumed to be spherical (e.g., Beerling et al., 2020) and chemically and mineralogically homogeneous regardless of the size. A shrinking particle scheme is then applied where net dissolution/precipitation occurs within soils. 
First, SCEPTER defines the PSD as $f(r, t, z)$ - the number of particles per unit bulk soil volume for a given radius bin as a function of radius $r$, time $t$ and soil depth $z$. Applying the general equation for solid species to $f(r, t, z)$ yields:

$$
\frac{\partial f(r, t, z)}{\partial t}=\frac{\partial w f(r, t, z)}{\partial z}-\left[\frac{\partial f(r, t, z)}{\partial t}\right]_{\text {diss }}+\left[\frac{\partial f(r, t, z)}{\partial t}\right]_{\text {rain }}-f(r, t, z) \int_{0}^{z_{m 1}} E_{\theta}\left(z, z^{\prime}\right) d z^{\prime}+\int_{0}^{z_{m 1}} f\left(r, t, z^{\prime}\right) E_{\theta}\left(z^{\prime}, z\right) d z^{\prime}
$$

where $[\partial f(r, t, z) / \partial t]_{\text {diss }}$ is the time rate of change in $f(r, t, z)$ caused by net dissolution and $[\partial f(r, t, z) / \partial t]_{\text {rain }}$ is the supply rate of particles at the soil surface with a specified PSD, which satisfies the following:

$$
\begin{aligned}
& \sum_{\theta}^{n_{\text {sdd }}} V_{\theta}\left(R_{\theta}+\sum_{\kappa}^{n_{\text {xxn }}} \gamma_{\kappa, \theta} R_{\kappa}\right)=\int_{0}^{\infty} \frac{4 \pi r^{3}}{3}\left[\frac{\partial f(r, t, z)}{\partial t}\right]_{\text {diss }} d r \\
& \sum_{\theta}^{n_{\text {std }}} V_{\theta} J_{\theta}=\int_{0}^{\infty} \frac{4 \pi r^{3}}{3}\left[\frac{\partial f(r, t, z)}{\partial t}\right]_{\text {rain }} d r
\end{aligned}
$$

Shifts in the particle size distribution caused by net dissolution/precipitation $\left([\partial f(r, t, z) / \partial t]_{\text {diss }}\right)$ can be formulated with a population balance equation (e.g., LeBlanc and Fogler, 1988; Iggland and Mazzotti, 2012):

$$
\left[\frac{\partial f(r, t, z)}{\partial t}\right]_{\text {diss }}=-\frac{\partial g(r, t, z) f(r, t, z)}{\partial r}
$$

where $g(r, t, z)$ is the particle growth rate $\left(\mathrm{m} \mathrm{yr}^{-1}\right)$. Within a shrinking particle framework, the particle growth rate is specified as (e.g., LeBlanc and Fogler, 1988; Safari et al., 2009):

$g(r, t, z)=\frac{\partial r}{\partial t}=-k^{\prime}$

Here, $k^{\prime}$ is the particle dissolution rate in units of $\mathrm{m} \mathrm{yr}^{-1}$. Loss of particles is allowed at the lower boundary, i.e., particles are assumed to be completely dissolved when $r$ becomes smaller than the minimum radius considered in the model. Also, when dissolution (imposed by Eq. (32)) is intense enough to consume all existing particles, particles are allowed to be lost. Meanwhile, particles are not allowed to grow over the maximum radius set by the model. At each time step, Eqs. (32), (34) and (35) are solved at once to obtain the values for $[\partial f(r, t, z) / \partial t]_{\text {diss }}$ that satisfy the volume balance (Section 2.3).

Given a PSD for particles applied at the soil surface, defined here as $f_{\text {rain }}(r)$ that is only a function of radius but not of time or depth, one can obtain a function $k_{\text {rain }}(r, t, z)$ in units of $\mathrm{yr}^{-1}$ satisfying Eq. (33) and the following:

$$
\left[\frac{\partial f(r, t, z)}{\partial t}\right]_{\text {rain }}=k_{\text {rain }}(r, t, z) f_{\text {rain }}(r)
$$

Then, by solving Eqs. (31)-(36) one can obtain the full PSD reflecting both shrinking particles via net precipitation/dissolution and addition/transport of particles. The above scheme generally satisfies the volume balance:

$$
4 \pi / 3 \int_{r=r_{\min }}^{r=r_{\max }} r^{3} f(r, t, z) d r=\sum_{\theta}^{n_{\mathrm{sdd}}} m_{\theta} V_{\theta}
$$

The total surface area is then calculated based on the PSD as follows: 


$$
4 \pi \int_{r=r_{\min }}^{r=r_{\max }} r^{2} f(r, t, z) d r=\phi r_{\mathrm{H}}^{-1}
$$

Here, the total pore surface area per unit soil/rock volume is again represented with hydraulic radius $r_{\mathrm{H}}$ to facilitate comparison with the default surface area calculation where $r_{\mathrm{H}}$ is directly specified as the average effective radius of particles (Section 2.2.6.1). The surface areas for individual solid species $\left(S_{\theta}\right)$ can then be calculated by either Eq. (27) (the default in SCEPTER) or (28). When adopting the PSD-based formulation, the surface area evolves temporally and spatially in a dynamic fashion without any further parameterization.

\subsubsection{Surface roughness}

315 Mineral surfaces are not necessarily smooth and can have complicated geometry and resultant surface roughness that increases the surface area per unit volume/mass (e.g., White and Peterson, 1990). One can introduce a roughness factor $\lambda$ to correct the surface area calculated for a smooth geometry of solid particles with an assumed shape. This additional parameterization is especially useful when one considers a particle size distribution based on ideal shapes (Section 2.2.6.2). The roughness factor is calculated assuming a dependency on particle size following Beerling et al. (2020) (cf. NavarreSitchler and Brantley, 2007):

$$
\lambda=\left(10^{10} r\right)^{0.33}
$$

As a user option, one can include $\lambda$ in the PSD calculation method in Section 2.2.6.2; in this case, the $k^{\prime}$ and $r^{2}$ terms in Eqs. (35) and (38) are replaced with $\lambda k^{\prime}$ and $\lambda r^{2}$, respectively.

Implementation of a roughness factor is of limited use for formulations that calculate surface area directly from hydraulic radius (Eqs. (27)-(30)), because the hydraulic radius should in principle already account for roughness in the pore surface. As a result, in the default surface area calculation (Eqs. (27) and (29)) a roughness factor is not included, although SCEPTER contains a user option to add a roughness term to Eqs. (27)-(30).

\subsubsection{Specific surface area of solid species}

The options for calculating surface area in SCEPTER described above are based on the total surface area of pores and the fractions of individual solid species in soils. These approaches all assume that every patch of pore surface is mineralogically and chemically homogeneous. However, individual solid species can have unique particle size distributions and thus specific surface areas that are different from the surface areas of bulk soil multiplied with solid species fractions. Based on the concept of specific surface areas for individual solid species, SCEPTER includes an additional user option that enables the surface area calculation for individual solid species.

Defining the specific surface area of solid species $\theta$ as $A_{\theta}\left(\mathrm{m}^{2} \mathrm{~g}^{-1}\right)$, the surface area of $\theta$ available to porewater $\left(S_{\theta}, \mathrm{m}^{2}\right.$ $\mathrm{m}^{-3}$ ) can alternatively be represented by (e.g., Brantley and Lebedeva, 2011; Li et al., 2014) 
where $M_{\theta}\left(\mathrm{g} \mathrm{mol}^{-1}\right)$ is the molar weight of solid species $\theta$ (Table 1). To facilitate comparison with the surface area parameterization using hydraulic radius (Eq. (27)), we introduce an apparent hydraulic radius for solid species $\theta$ as $r_{\mathrm{H}, \theta}(\mathrm{m})$ :

$340 \quad r_{\mathrm{H}, \theta}^{-1}=\frac{A_{\theta} \rho_{\theta}}{\phi}$

where $\rho_{\theta}\left(\mathrm{g} \mathrm{m}^{-3}\right)$ is the particle density of solid species $\theta$ and $\rho_{\theta} \equiv M_{\theta} / V_{\theta}$. The apparent hydraulic radius $r_{\mathrm{H}, \theta}(\mathrm{m})$ can be thought of as the average effective radius of particles which are composed solely of solid species $\theta$. SCEPTER has the option to calculate individual surface areas according to Eqs. (40) and (41), with a specified $r_{\mathrm{H}, \theta}$ the evolution of which can be further specified by replacing $r_{\mathrm{H}}$ with $r_{\mathrm{H}, \theta}$ in Eq. (29) or (30).

SCEPTER can evaluate specific surface areas for individual solid phases by tracking PSDs for individual species. The scheme introduced in Section 2.2.6.2 still holds, but in this case the PSD is defined and calculated for individual solid species. Defining the PSD and particle growth and dissolution rates for solid species $\theta$ as $f_{\theta}(r, t, z), g_{\theta}(r, t, z)$ and $k^{\prime} \theta$, respectively, the equations to solve PSD for bulk soil, i.e., Eqs. (31)-(38), can be used to solve $f_{\ell}(r, t, z)$ by replacing $f(r, t, z)$, $g(r, t, z)$ and $k^{\prime}$ with $f_{\theta}(r, t, z), g_{\theta}(r, t, z)$ and $k^{\prime} \theta$, respectively, and dropping summation symbols and notations (i.e., replacing $\sum_{\theta}^{n_{\text {sld }}} V_{\theta}\left(R_{\theta}+\sum_{\kappa}^{n_{\mathrm{rrxn}}} \gamma_{\kappa, \theta} R_{\kappa}\right), \sum_{\theta}^{n_{\text {sld }}} V_{\theta} J_{\theta}$ and $\sum_{\theta}^{n_{\text {sld }}} m_{\theta} V_{\theta}$ with $V_{\theta}\left(R_{\theta}+\sum_{\kappa}^{n_{\mathrm{xrxn}}} \gamma_{\kappa, \theta} R_{\kappa}\right), V_{\theta} J_{\theta}$ and $m_{\theta} V_{\theta}$, respectively). Then, the specific surface area for solid specie $\theta$ can be calculated as:

$$
A_{\theta}=\frac{3 \int_{r=r_{\min }}^{r=r_{\max }} r^{2} f_{\theta}(r, t, z) d r}{\rho_{\theta} \int_{r=r_{\min }}^{r=r_{\max }} r^{3} f_{\theta}(r, t, z) d r}
$$

and the corresponding apparent hydraulic radius can be evaluated as:

$$
r_{\mathrm{H}, \theta}^{-1}=\frac{3 \int_{r=r_{\min }}^{r=r_{\max }} r^{2} f_{\theta}(r, t, z) d r}{\phi \int_{r=r_{\min }}^{r=r_{\max }} r^{3} f_{\theta}(r, t, z) d r}
$$

355 The roughness factor $\lambda$ can further be included by replacing $k^{\prime} \theta$ and $r^{2}$ with $\lambda k^{\prime} \theta$ and $\lambda r^{2}$, respectively, as described for the PSD calculation for bulk soil (Section 2.2.6.3). For instance, ground minerals have been characterized with significant surface roughness based on measured surface areas that are larger than expected from their grain sizes (e.g., Brantley and Mellot, 2000; Renforth, 2012; Renforth et al., 2015).

\subsubsection{Reactions not limited by surface area}

360 Decomposition of some of solid species can proceed without being affected by the surface area available to porewater. In the current version of SCEPTER, 3 classes of SOM are assumed to decay depending on their concentrations but independent of their surface areas (e.g., Jia et al., 2019): 
For all the other solid species, their dissolution/precipitation kinetics are assumed to be dependent on the surface areas which are calculated based on $r_{\mathrm{H}}$ or $r_{\mathrm{H}, \theta}$, either directly specified by the user or calculated from tracked $\operatorname{PSD}(\mathrm{s})$, as described above.

\subsection{Numerical implementation}

Initialization of SCEPTER involves loading input data, including chosen species to be simulated, and initial and boundary conditions (see Section 2.4). In the case of a restart experiment from a previous simulation, initial conditions are overwritten with the final results from the previous (restart) experiment. After initialization, SCEPTER begins time integration of the governing equations (see Section 2.2). For a given time step, the boundary conditions and time step duration can be modified

if the user selects time-varying changes to water flux, temperature, particle rain rate, or water saturation ratio. Time step duration also evolves adaptively depending on the time to convergence in the previous integration step (from $10^{-18}$ up to $10^{3}$ yr). Kinetic and thermodynamic constants are then updated, and the concentrations of all chosen species are solved via Newton-Raphson iteration in a fully coupled way (see below). Finally, porosity, surface area, and advection rate(s) of solid phases are updated. By default, SCEPTER updates porosity, surface area, and advection rates iteratively at each time step as verified by porosity convergence, but there is also a user option to bypass the porosity iteration and simply update porosity, surface area, and advection rate(s) once per time step. The latter option is computationally less expensive and will yield the same solutions when the time step duration is relatively small. The default criterion for numerical convergence is a solution difference of $<10^{-9}\left(\mathrm{~mol} \mathrm{~m}^{-3}\right.$ or $\left.\mathrm{m}^{3} \mathrm{~m}^{-3}\right)$ from the previous iteration in each time-integration step (cf. Steefel, 2009).

The governing equations of SCEPTER are differentiated via a finite difference method. First-order upwind and second-order central differencing schemes are applied to advection and diffusion terms, respectively (Eqs. (1)-(3)). Eq. (24) is used as a difference form of bio-mixing term in Eq. (1). Time derivatives (left-hand side of Eqs. (1)-(3)) are discretized in accord with a Euler backward scheme. The finite difference expressions are then solved via a fully coupled Newton-Raphson method (Steefel and Lasaga, 1994). Parent rock values are enforced below the bottom of the model domain as a boundary condition for solid species. For aqueous and gas species, the bottom of the model domain is assumed to be impermeable with respect to molecular diffusion (i.e., zero concentration-gradient), while the composition of rainwater and overlying atmosphere are enforced as boundary conditions at the top of the model domain on dissolved and gaseous species, respectively. When there is no user input, a value of $10^{-20} \mathrm{~mol} \mathrm{~m}^{-3}$ or $\mathrm{mol} \mathrm{L}^{-1}$ is assumed for the boundary parent-rock or rainwater concentration, respectively, and $0.21,10^{-3.5}, 10^{-9}$, and $2.7 \times 10^{-7}$ atm for atmospheric $\mathrm{O}_{2}, \mathrm{CO}_{2}, \mathrm{NH}_{3}$ and $\mathrm{N}_{2} \mathrm{O}$,

390 respectively. Concentrations of all dependent aqueous species as well as associated rate constants are always updated (Section 2.2.2, Tables 1-4), including during Newton-Raphson iteration.

The calculations of porosity and advection rate of solid species are conducted by differentiating Eq. (17), again using an implicit finite difference method. Because the reaction term (the summation on the right-hand side of Eq. (17)) is fixed by the solution of Eqs. (1)-(3), the discretized equations become linear with respect to porosity and advection rate and thus the 
395 Newton-Raphson method is not used to solve the finite difference form of Eq. (17). Boundary conditions are imposed consistently with those for solid species - e.g., the porosity and uplift rate of the parent rock at the bottom of the model domain.

In the default version of SCEPTER in which PSDs are not tracked, surface area is calculated by combining Eqs. (27)(30), (40) and (41). When PSD tracking is enabled in the surface area calculation the governing equation for PSD (Eq. (31))

400 is discretized by a finite difference method and solved time-implicitly as for the solution of the governing equation for solid species (Eq. (1)). The PSD shifts caused by net volume change by dissolution/precipitation (the second term on the righthand side of Eq. (31)) are enforced from solutions of Eqs. (32), (34) and (35) by the first-order up-wind finite-difference scheme and the Newton-Raphson method. A PSD for parent rock is imposed as the lower boundary condition. This procedure is repeated for individual solid species when calculating species-specific PSDs and surface areas (Section 2.2.6.4).

405 By default SCEPTER considers the PSD calculation converged when the difference in particle number from the previous iteration is less than $10^{-12}$ times the maximum number of particles. The calculated PSD is truncated below one particle per $\mathrm{m}^{3}$ of bulk soil for a given radius bin.

\subsection{User input}

\subsubsection{Independent variables}

410 Solid, aqueous, and gas species to be tracked in a simulation are listed in individual input files (slds.in, solutes. in and gases.in). If a user wants to include reactions other than dissolution/precipitation reactions specified for individual solid species, the ID string of the extra reaction (e.g., fe2o2 in Table 6 for aqueous $\mathrm{Fe}(\mathrm{II})$ oxidation by $\mathrm{O}_{2}$ ) can be specified in another input file (exrxns.in).

\subsubsection{Boundary conditions}

415 Fundamental variables such as grid size, total depth of simulated soil, water flux, water table depth, surface water saturation, mixing layer thickness, application rate of powdered rock feedstock, OM rain flux, temperature, initial/bottom uplift rate, and initial soil porosity etc. are specified in the input file frame.in. Modifying options for, e.g., mixing regime and method of surface area calculation can be made by modifying another input file, switches.in. One can also specify whether to do a re-start experiment in switches.in, and, if doing a re-start experiment, the previous experiment from 420 which the current simulation should be restarted can be specified in frame. in.

Surface area of parent rock is calculated from the average effective radius of particles specified in frame. in. When one chooses to calculate specific surface areas for individual solid species, different average radius values can be assigned to different solid species in the input file sa. in. The particle size distributions for parent rock are calculated assuming lognormal distributions with 1 SD centered at the radius value(s) input from frame. in or sa. in. Currently, the PSD for OM 
rain is assumed to be the same as that for parent rock, while the PSD for rock feedstock needs be specified within the source codes by providing mean radius(es) and standard deviation(s).

Boundary conditions for solid, aqueous, and gas species need to be provided as parent rock, rainwater, and atmospheric concentrations, respectively, in the corresponding input files (parentrock. in, rain.in and atm.in). Compositions of solids being introduced at the soil surface must also be specified using individual input files (dust. in and OM_rain.in, respectively). In the case of time-varying changes to water flux, temperature, and water saturation ratio, a series of additional input files are necessary ( $T_{-}$temp.in, q_temp.in and Wet_temp.in). See full README information included in the code repository for further details (Code availability).

\subsubsection{Initial conditions}

At the beginning of a simulation, concentrations of solid, aqueous and gas species are assumed to be the same as those of

435 parent rock, rainwater, and atmosphere, respectively, which can be specified by the user with the corresponding input files (see above). Initial surface areas as well as PSDs at all depths are assumed to be the same as those of parent rock specified by the user. Porosity similarly takes the initial value provided by the user at all depths. When the volume sum of all chosen solid species in the parent rock is less than the solid fraction implied by the initial/bottom porosity, then an imaginary 'bulk' species is additionally tracked to occupy the void space whose physical properties are assumed to be the same as those of 440 kaolinite but with no reactions allowed ( $R_{\theta} \equiv 0$ with $\theta=$ 'bulk'). When the volume sum of all chosen solid species exceeds the assigned value from the initial/bottom porosity, the parent rock concentrations of chosen solid species are rescaled to be consistent with the initial/bottom porosity. Volume conservation (Eq. (16)) is thus always satisfied by SCEPTER (cf. Archer et al., 2002; Munhoven, 2021; Kanzaki et al., 2021).

\section{Application examples}

445 To illustrate the features and capabilities of SCEPTER, we present a series of idealized example experiments. First, the basic features of SCEPTER are illustrated by simulating abiotic weathering (e.g., without SOM and mixing; Section 3.1.1), biotic weathering (with SOM and mixing; Section 3.1.2), and basalt application (with SOM, mixing, and additional mineral supplied at the soil surface; Section 3.1.3) scenarios with the default surface area calculation method. The same set of simulations is then repeated using the PSD-based surface area calculation (Section 3.1.4). Finally, we show a series of

450 SCEPTER runs driven by observational data from a subset of relatively pristine natural systems coupled with the USGS soil chemistry database (U.S. Geological Survey, 2016), and track time-dependent $\mathrm{CO}_{2}$ capture across a range of timescales. (Section 3.2). 
https://doi.org/10.5194/gmd-2022-8

Preprint. Discussion started: 10 February 2022

(C) Author(s) 2022. CC BY 4.0 License.

\subsection{Illustration of basic features of SCEPTER}

\subsubsection{Abiotic weathering}

The simplest configuration of SCEPTER explored here is the simulation of abiotic weathering of albite and pyrite, respectively (Fig. 1, 2; Table 7). Dominant controls on and locations of reaction fronts of albite and pyrite are consistent with simpler models (e.g., water flow for albite weathering, and water table depth on pyrite weathering; e.g., Kanzaki et al., 2020). SCEPTER allows tracking of time-dependent changes to gradients in solid and solute species, which in the simple abiotic cases evolve as expected - in the first case, with gradual conversion of albite to kaolinite and progressive release of $\mathrm{Si}$ and Na to soil pore fluids (Fig. 1), and in the second case a sharp reaction front along which pyrite is converted to goethite and $\mathrm{O}_{2}$ is drown down to negligible levels at the water table depth (Fig. 2). Overall depth-dependent changes to porosity and particle density are relatively small in both of these simplified abiotic cases (Figs. 1 and 2). Note that, in these examples input parent-rock concentrations of minerals (10 wt $\%$ albite and $0.56 \mathrm{wt} \%$ pyrite) are smaller than inferred from assumed initial/bottom porosity (0.1). Thus, an imaginary bulk species is simulated along with the above minerals (not shown in Figs. 1 and 2), ensuring that volume conservation is satisfied (Eq. (16)).

Results of a more complicated abiotic weathering simulation are shown in Figs. 3 and 4, in which SCEPTER is fed by the bulk mineralogy and climatological boundary conditions for a natural weathering site (Site 1 in Fig. 5 and Table 8) (see also Section 3.2). Here, we assume zero OM rain to the system and no mixing to exclude biotic aspects of weathering (cf. Section 3.1.2), and run an abiotic weathering simulation to reach a steady state. Because production of soil $\mathrm{CO}_{2}$ is minimized without a flux of $\mathrm{OM}$ to the soil surface, soil $\mathrm{CO}_{2}$ drops at depth as a result of cation release (and alkalinity production) from mineral dissolution. Primary silicates such as albite and diopside are largely dissolved. Initially, carbonate phases dissolve at the surface but precipitate at depth. However, as the system approaches steady state ( $10^{4}$ years) carbonate phases redissolve and secondary clays accumulate (Fig. 3). Solute profiles evolve in accord with mineral profiles, and once again overall changes to soil porosity and particle density are relatively small (Fig. 4). In this case, SCEPTER does not include the imaginary bulk species (Fig. 3; Tables 7 and 8), but volume conservation is nevertheless always satisfied.

\subsubsection{Biotic weathering: addition of organic matter flux to soil surface and soil mixing}

Following the expansion of vascular plant ecosystems across Earth's land surface, natural weathering generally occurs in the presence of SOM and soil respiration (cf. Volk, 1987; Berner, 1992; Kanzaki and Kump, 2017; Ibarra et al., 2019; Wen et al., 2021). Indeed, the recycling of SOM represents a critical component of soil acid-base chemistry and $\mathrm{CO}_{2}$ cycling, and is likely to change significantly across a range of ecosystems in the coming century (e.g., Brovkin et al., 2013; McGuire et al., 2018). The current version of SCEPTER can simulate up to three classes of SOM of varying lability. By default, the lability of each class of SOM progressively decreases, with turn-over times of 1,8 , and $10^{3}$ years, respectively. However, the intrinsic SOM labilities can be scaled arbitrarily for a range of applications (e.g., manure application, biochar amendment, etc.), provided reliable kinetic data are implemented. The OM flux to the soil surface can either be specified arbitrarily or can 
485 be scaled to above-ground net primary production; by default SCEPTER scales the OM flux to the soil surface as 1.5 times above ground primary production, following Beerling et al. (2020).

Figures 6 and 7 show results of a simple biotic weathering experiment in which Class 2 SOM (here taken to represent a generalized "natural" SOM; e.g., Chen et al., 2010) and soil bioturbation (here termed Fickian mixing) are added to the experimental conditions for the abiotic weathering experiment shown in Figs. 3 and 4. As a result of SOM respiration, soil $\mathrm{CO}_{2}$ builds up as high as $>0.01$ atm as weathering proceeds (Fig. 7). This buildup in $\mathrm{CO}_{2}$ significantly lowers soil $\mathrm{pH}$, which promotes dissolution of primary mineral phases and leads to an increase in porosity around the mid-depth of the soil mixed layer $(\sim 0.1 \mathrm{~m})$. A range of silicate mineral phases become unstable and dissolve with the presence of SOM respiration (e.g., compare Figs. 3 and 6). On a timescale of $\sim 10^{2}$ years, carbonate phases dissolve at the surface of the model domain and precipitate at the bottom of the soil column, but all carbonate phases ultimately dissolve at steady state.

At steady state soil $\mathrm{CO}_{2}$ is around $0.006 \mathrm{~atm}$, still more than 10 times higher than the ambient atmospheric level. SOM dominates amongst the solid phases near the soil surface, below which clays and Si oxide phases become more dominant (Fig. 6). Dissolved cations are concentrated only at the deepest depths of the model domain, consistent with the observed distributions of mineral phases (Fig. 7). Dissolved Al shows higher concentrations in the biotic weathering scenario relative to the abiotic weathering regime due to increased solubility at lower $\mathrm{pH}$ (e.g., compare Figs. 4 and 7). Average grains

500 (aggregates) of soil become less dense closer to the surface because they consist more of SOM whose particle density is relatively small $\left(1.5 \mathrm{~g} \mathrm{~cm}^{-3}\right)$ compared to those of other solid phases (Fig. 7). Note that volume conservation is again satisfied throughout the experiment even with a continuous flux of OM to the soil surface (Fig. 7i).

\subsubsection{Basalt powder application: Enhanced rock weathering (ERW)}

A hopefully useful user option for simulating enhanced rock weathering in SCEPTER is the ability to conduct a re-start 505 experiment from the previously conducted simulation. This feature allows the user to first run a spin-up experiment - for instance, to fit the model to current observations at a given location — and then examine the impacts of adding crushed rock feedstock in a transient experiment branched from the spin-up simulation. Here, we illustrate this procedure by conducting a re-start experiment including basalt powder application to the soil surface branched from the biotic weathering experiment for Site 1 (Table 8 and Fig. 5) presented in Section 3.1.2, which has been spun up to steady state by running the model for $510 \sim 10^{5}$ years.

We set the application rate of basalt powder at $40 \mathrm{tha}^{-1} \mathrm{yr}^{-1}$, whose mineral composition is assumed to be the same as that adopted for basalt by Beerling et al. (2020). Because basalt powder will generally contain significant amounts of reduced $\mathrm{Fe}$, we implement aqueous $\mathrm{Fe}(\mathrm{II})$ oxidation by $\mathrm{O}_{2}$ as an extra reaction in the re-start experiment (Table 7). Application of basalt powder adds a large amount of primary minerals to surface soils, where they have generally been 515 depleted during spin-up to steady state (Fig. 8). One outcome of this is that carbonate phases precipitate during basalt application (Fig. 8d) together with kaolinite and goethite, and later with smectite (Figs. 8c, n, and o). There is a drop in SOM near the soil surface (Fig. 8p), despite the OM rain flux remaining identical to that in the spin-up simulation (Section 3.1.2). 
Rained minerals with high solubility and reactivity result in similar depth profiles to that of SOM (e.g., Figs. 8h, k, 1 and p), while those with lower solubility/reactivity tend to accumulate at depth (e.g., Figs. $8 \mathrm{f}$ and g). Soil $\mathrm{CO}_{2}$ accumulates as high as $>0.075$ atm because surface porosity drops significantly following basalt application (Fig. 9g). Soil $\mathrm{O}_{2}$ becomes depleted over time, in part due to the porosity change but also because of the introduction of $\mathrm{Fe}$ (II) oxidation as an additional $\mathrm{O}_{2}$ sink that does not exist during the spin-up simulation. Once again, volume conservation is satisfied even with a significant external flux of mineral phases to the system (Fig. 9i).

\subsubsection{The impact of particle size tracking}

In order to illustrate the potential use of optional PSD tracking for calculating mineral surface area in SCEPTER, we repeated the same experiments presented above for Site 1 (Fig. 5 and Table 8; Sections 3.1.1-3.1.3) while implementing mineral surface area based on tracked PSDs for bulk soil minerals, including a dynamic roughness factor (see Section 2.2.6.2-2.2.6.4). For parent rock, we assume a log-normal size distribution centered at $10 \mu \mathrm{m}$ with a standard deviation of 1 $\log$ unit (i.e., $f_{\mathrm{PR}}(r) \propto \exp \left(-(\log r+5)^{2} / 2\right)$ where $f_{\mathrm{PR}}$ is defined as the PSD of parent rock and $r$ is the particle radius in meters). We assign the same distribution to the OM rain flux in the biotic weathering experiment, while basalt powder is assumed to have a PSD that mixes equally four log-normal distributions centered at 5, 20, 50 and $70 \mu \mathrm{m}$ with standard deviations of $0.2 \mathrm{log}$ units. Note that because our intention is to illustrate the basic behavior of the model the PSD parameterizations adopted here are not necessarily realistic for a given application (cf. Eberl et al., 1998; Sklar et al., 2017; Beerling et al., 2020), and should be modified within the code by the user when necessary.

Concentration profiles for solid, aqueous, and gas species are largely similar to those obtained with the default surface area scheme, particularly for the abiotic and biotic natural weathering experiments, because the resultant surface areas are fairly similar (Figs. 10b, c, e and f). In the abiotic weathering experiment, particles with small radii dissolve and disappear rapidly, particularly at shallower depths (Fig. 10a). In the biotic weathering experiment, the soil surface receives an OM rain flux whose particle distribution is assumed to be the same as that of parent rock, and thus the relative depletion of small particles in the PSD is most prominent near the bottom of mixed layer (dotted curves in Fig. 10d), where mineral dissolution is significant but the particle input from the OM rain flux is attenuated.

In contrast, mineral surface area in the basalt application case is significantly different between the default and PSDtracking schemes (Figs. 10h and i). This is because the crushed rock particles, whose size distributions are centered at 5-70 $\mu \mathrm{m}$ with relatively small standard deviations, become the dominant constituent of the surface mixed layer of soil (e.g., solid and dotted curves in Fig. 10g). The dominance of particles with relatively small radius results in large surface area per unit mass, leading to a large surface area difference between the PSD-based and default methods (Figs. 10h and i).

To further explore the impact of PSD tracking on mineral surface area, we conducted another set of experiments identical to those above but with PSD tracking for individual solid species (rather than the bulk solid phase). We present the results of a basalt application experiment in which PSD tracking has the most prominent effects on the surface area 
calculation (Figs. 11 and 12) and compare these with the default surface area parameterization and the calculation based on the PSD for bulk soil. Individually tracked PSDs are different between solid species (Fig. 11), and also differ from the PSD for bulk soil (Fig. 10g). For example, solid species that are introduced to the system only through basalt powder application show patterns similar to the PSD specified for basalt powder, with smaller particles being produced via dissolution as time proceeds (e.g., Fig. 11k), and those precipitated as a result of basalt powder application show significant particle growth

555 (Figs. 11c, d, $\mathrm{n}$ and o). Accordingly, surface area depth profiles vary between solid species, and are significantly different from those simulated with the default method and the PSD tracked only for bulk soil (Fig. 12). In the basalt application scenario, surface areas for individual solid species increase more significantly when tracking species-specific PSDs, relative to those calculated based on PSD for bulk soil (e.g., Fig. 12k). On the other hand, surface areas of solid species that are not supplied through basalt application are generally smaller when tracking species-specific PSDs than tracking only PSD for

560 bulk soil (e.g., Figs. $12 \mathrm{j}$ and m). Note that surface areas of secondary minerals (e.g., Fig. 12d) are not significantly reduced compared to those of dissolving primary minerals that are not supplied through basalt application (Fig. 12j) because surface roughness is accounted for. Overall, when conducting experiments involving addition of particles whose size distributions are significantly different from the PSD of parent rock, we recommend PSD tracking for individual solid species though computationally more demanding.

565 3.2 Example ERW application - time-dependent $\mathrm{CO}_{2}$ capture following basalt addition at contrasting pristine hinterland sites

As a final illustration of model capability, we estimate time-dependent $\mathrm{CO}_{2}$ capture during continuous and pulsed basalt application at two pristine hinterland watersheds in the U.S. The two watersheds are obtained by delineating all watersheds corresponding to the USGS river gauges (U.S. Geological Survey, 2016) using GRASS GIS (GRASS Development Team,

570 2017), followed by selecting watersheds that have experienced minimum human interferences (watersheds that have a population density less than 1 person per square kilometer; land proportion of cultivated vegetation less than 1\%; land proportion of urban land less than 1\%). The mineral compositions for these two pristine watersheds are derived from the USGS soil chemistry database (U.S. Geological Survey, 2016). We emphasize that the sites used for illustration are not optimized for $\mathrm{CO}_{2}$ capture, given they are characterized by relatively low runoff and temperature (Table 8). The only aim

575 here is to demonstrate the ability of SCEPTER to examine first-order controls on $\mathrm{CO}_{2}$ capture during enhanced rock weathering and these sites, given the lack of human intervention, have a more predictable history than sites that have been strongly directly influenced by human activity. Experimental conditions are the same as those adopted in Sections 3.1.3 and 3.1.4 except for the used sites (Sites 2 and 3; Table 8 and Fig. 5).

\subsubsection{Tuned spinup to observational data}

580 When detailed observational data are available for a specific individual site of potential enhanced rock weathering, one can perform site-specific tuning at spinup prior to crushed rock application. As an illustration, we tune SCEPTER to observed 
$\mathrm{OM}$ and $\mathrm{pH}$ profiles at two pristine hinterland sites (Sites 2 and 3 in Table 8; see Fig. 5 for their locations) assuming Fickian mixing (e.g., bioturbation) (Fig. 13). For Site 2, optimized OM and pH profiles can be obtained by introducing an additional class of SOM (e.g., Class 3 SOM introduced at 0.1016 times the Class 2 SOM rain flux), and assuming slightly different labilities for the two classes of SOM relative to the default values (5 and 85 years for turnover of SOM Classes 2 and 3 , respectively). In tuning to Site 3, no extra SOM class is added but the rain flux and turnover time are modified for Class 2 SOM to $0.64 \mathrm{~g} \mathrm{C} \mathrm{m}^{-2} \mathrm{yr}^{-1}$ and $1600 \mathrm{yr}$, respectively. The simulated soil thickness and mixed layer depth are extended to $2 \mathrm{~m}$ to fit to the observed $\mathrm{OM}$ and $\mathrm{pH}$ profiles and the total grid number is doubled (60). Surface area is calculated during spinup with the default method assuming 100 and $7 \mu \mathrm{m}$ of average particle radii for Sites 2 and 3, respectively. The remaining boundary conditions are defined in the same way as detailed in the biotic weathering experiment for Site 1 (Table 7; Section 3.1.2) but using the parameter values specified for Sites 2 and 3 in Table 8.

Observed soil OM and $\mathrm{pH}$ depth profiles are reproduced well by SCEPTER with minimal tuning (Fig. 13). Fickian mixing is effective only where solid concentrations are relatively high and is thus particularly intense close to the surface. Therefore, Fickian mixing introduces some difficulty in reproducing the SOM profile for Site 2 at depth ( 1 wt\%, Table 9). In contrast, because a relatively low SOM reactivity is assumed, Fickian mixing closely reproduces SOM concentrations throughout the soil column for Site 3, except for the low surface value. In any case, this exercise demonstrates that SCEPTER can be readily tuned using site-specific observations in order to optimize ERW capture for local boundary conditions, and that in general minimal effort should be required to perform robust site-specific tuning across a very wide range of soil pore fluid $\mathrm{pH}$ and organic matter content (Fig. 13).

\subsubsection{Time-dependent variation in $\mathrm{CO}_{2}$ capture}

We perform two sets of time-dependent $\mathrm{CO}_{2}$ capture experiments, applying crushed basalt at a rate of 40 ton ha-1 $\mathrm{yr}^{-1}$ to the tuned spinups discussed in Section 3.2.1. In the first set, basalt is applied continuously throughout the simulation and Fickian mixing is applied across all solid phases. In the second, we perform pulsed basalt addition in which crushed basalt is applied at the same overall annual application rate and homogeneously mixed into the soil but only during the initial part of each year (0.1 year), while mixing occurs in the Fickian regime throughout the remainder of the year. We perform all simulations across the range of PSD options in SCEPTER (see above), including the default setting, bulk PSD tracking, and full PSD tracking.

We find that the surface area scheme significantly impacts predicted $\mathrm{CO}_{2}$ capture (Fig. 14). In particular, significant differences between the default parameterization and PSD-based methods (Fig. 14) suggest that explicit differentiation of particle sizes between added powder and existent soil/rock is crucial for accurate predictive quantification of carbon capture during enhanced rock weathering. The results also suggest that species-specific PSD tracking is fundamental particularly for the prediction of short-term $\mathrm{CO}_{2}$ capture efficiency ( $<10 \mathrm{yr}$; Figs. 14a and d). It is also clear that $\mathrm{CO}_{2}$ capture rate depends strongly on chosen site and associated background boundary conditions (compare Figs. 14a-c with d-f; see also Tables 8 and 9), particularly over longer time horizons. 
Pulsed basalt addition leads to a significant short-term enhancement in $\mathrm{CO}_{2}$ capture, but on century timescales overall captures rates for both sites are comparable regardless of whether feedstock amendment is continuous or pulsed (Figs. 14 and 15). The long-term $\mathrm{CO}_{2}$ capture rates estimated here are broadly comparable to previous estimates (e.g., Beerling et al., 2020), but our model predicts significant induction time before achieving maximum $\mathrm{CO}_{2}$ capture at a given feedstock application rate (e.g., 0.16 capture efficiency ( $\equiv$ mass ratio of captured $\mathrm{CO}_{2}$ against deployed basalt) in 100 years at Site 2 vs. 0.15- 0.25 capture efficiency in 10 years by Beerling et al., 2020). However, we emphasize that these simulations are only meant to be illustrative of the capabilities of the model, and that the sites and ERW deployment procedure have not been optimized for maximizing $\mathrm{CO}_{2}$ capture rates. As a result, these results should not in any way be interpreted as conclusive or generalizable with respect to $\mathrm{CO}_{2}$ capture rate, efficiency, and induction time.

\section{Conclusions}

625 SCEPTER is a traceable, open-access code with the capability to comprehensively realize phenomena occurring within soil weathering systems, including abiotic/biotic weathering of minerals, mixing of soil particles, and addition of OM/minerals under natural or managed conditions. The model is equipped with options to calculate surface areas of soil particles by tracking particle size distributions through time and space. This specific feature may be of particular importance for calculating the cost performance of terrestrial enhanced rock weathering, as a significant component of both economic cost and secondary $\mathrm{CO}_{2}$ emissions is the grinding and transport of rock feedstocks (e.g., Renforth, 2012). Application of the model to U.S. soil data indicates that it is well-suited to capturing the major mineral transformations and solute fluxes attendant to natural weathering.

The current version of the model can serve several purposes relevant for natural weathering, carbon cycle dynamics, and managed soil chemistry. Ongoing model developments include a full mechanistic implementation and validation of nutrient $(\mathrm{P}$ and $\mathrm{N}$ ) cycles and nutrient uptake by plants; inclusion of size-dependent changes of particle solubility and nucleation kinetic barrier when tracking species-specific PSDs (e.g., Hochella, 2003; Perez et al., 2008; Emmanuel and Ague, 2011); implementation of a wider range of potential management practices; and coupling to Earth system model frameworks in order to more fully explore the dynamics of CDR (e.g., Ridgwell et al., 2007; Holden et al., 2016; Taylor et al., 2016). We suggest that SCEPTER can be a powerful tool for predicting and diagnosing the effects of enhanced rock weathering on existing soil systems, particularly following robust site-specific tuning against background observations. 


\section{Code availability}

The source codes of the model are available at GitHub (https://github.com/lithos-erw/SCEPTER) under the MIT License. The specific version of the model used in this paper is tagged as "v0.9" and has been assigned a doi (https://doi.org/10.5281/zenodo.5835413). A readme file on the web provides the instructions for executing the simulations.

\section{Author contributions}

YK designed and implemented the model with significant contributions from the other authors. SZ compiled and filtered observational data. All authors contributed to the experimental design and YK conducted the experiments and analyzed the results. All authors contributed to the writing of the paper.

\section{Competing interests}

The authors declare no competing interests.

\section{References}

Aachib, M., Mbonimpa, M. and Aubertin, M.: Measurement and prediction of the oxygen diffusion coefficient in unsaturated media, with applications to soil covers, Water Air Soil Pollut., 156, 163-193, https://doi.org/10.1023/B:WATE.0000036803.84061.e5, 2004.

Archer, D. E., Morford, J. L., and Emerson, S. R.: A model of suboxic sedimentary diagenesis suitable for automatic tuning and gridded global domains, Global Biogeochem. Cycles, 16, 1017, https://doi.org/10.1029/2000GB001288, 2002.

Astete, C. E., Thibodeaux, L. J., and Constant, W. D.: Semi-volatile organic compounds as chemical tracers for estimating soil particle biodiffusion coefficients: application of polychlorinated biphenyls in earthworm bioturbation at a grassland site, Soil Sci., 181, 457-464, https://doi.org/10.1097/SS.0000000000000178, 2014.

Beerling, D. J., Kantzas, E. P., Lomas, M. R., Wade, P., Eufrasio, R. M., Renforth, P., Sarkar, B., Andrews, M. G., James, R. H., Pearce, C. R., Mercure, J.-F., Pollitt, H., Holden, P. B., Edwards, N. R., Khanna, M., Koh, L., Quegan, S., Pidgeon, N. F., Janssens, I. A., Hansen, J., and Banwart, S. A.: Potential for large-scale $\mathrm{CO}_{2}$ removal via enhanced rock weathering with croplands, Nature, 583, 242-248, https://doi.org/10.1038/s41586-020-2448-9, 2020.

665 Berner, R. A.: Weathering, plants, and the long-term carbon cycle, Geochim. Cosmochim. Acta, 56, 3225-3231, https://doi.org/10.1016/0016-7037(92)90300-8, 1992.

Bibi, I., Singh, B., and Silvester, E.: Dissolution of illite in saline-acidic solutions at $25{ }^{\circ} \mathrm{C}$, Geochim. Cosmochim. Acta, 75 , 3237-3249, https://doi.org/10.1016/j.gca.2011.03.022, 2011. 
Bolton, E. W., Berner, R. A., and Petsch, S. T.: The weathering of sedimentary organic matter as a control on atmospheric $\mathrm{O}_{2}$ : II. Theoretical modeling, Am. J. Sci., 306, 575-615, https://doi.org/10.2475/08.2006.01, 2006.

Boudreau. B. P.: Diagenetic Models and Their Implication, Springer, 1997.

Boudreau, B. P., Choi, J., Meysman, F. and François-Carcaillet, F.: Diffusion in a lattice-automaton model of bioturbation by small deposit feeders, J. Mar. Res., 59, 749-768, https://doi.org/10.1357/002224001762674926, 2001.

Brantley, S. L. and Lebedeva, M.: Learning to read the chemistry of regolith to understand the Critical Zone, Annu. Rev. Earth Planet. Sci., 39, 387-416, https://doi.org/10.1146/annurev-earth-040809-152321, 2011.

Brantley, S. L. and Mellott, N. P.: Surface area and porosity of primary silicate minerals, Am. Mineral., 85, 1767-1783, https://doi.org/10.2138/am-2000-11-1220, 2000.

Brantley, S. L., Kubicki, J. D., and White, A. F.: Kinetics of Water-Rock Interaction, Springer, 2008.

Brovkin, V., Boysen, L., Arora, V. K., Boisier, J. P., Cadule, P., Chini, L., Claussen, M., Friedlingstein, P., Gayler, V., van den Hurk, B. J. J. M., Hurtt, G. C., Jones, C. D., Kato, E., de Noblet-Ducoudré, N., Pacifico, F., Pongratz, J., and Weiss, M.: Effect of anthropogenic land-use and land-cover changes on climate and land carbon storage in CMIP5 projections for the twenty-first century, J. Clim., 26, 6859-6881, https://doi.org/10.1175/JCLI-D-12-00623.1, 2013.

Chen, S., Huang, Y., Zou, J., Shen, Q., Hu, Z., Qin, Y., Chen, H., and Pan, G.: Modeling interannual variability of global soil respiration from climate and soil properties, Agric. For. Meteorol., 150, 590-605, https://doi.org/10.1016/j.agrformet.2010.02.004, 2010.

Chen, Z., Guo, M., and Wang, W.: Variations in soil erosion resistance of gully head along a 25-year revegetation age on the Loess Plateau, Water, 12, 3301, https://doi.org/10.3390/w12123301, 2020.

Choi, J., Francois-Carcaillet, F., and Boudreau, B. P.: Lattice-automaton bioturbation simulator (LABS): implementation for small deposit feeders, Comput. Geosci., 28, 213-222, https://doi.org/10.1016/S0098-3004(01)00064-4, 2002.

Clennell, M. B.: Tortuosity: a guide through the maze, In: Developments in Petrophysics, edited by: M. A. Lovell and P. K. Harvey, Geological Society Special Publication No. 122, 299-344, 1997.

Delany, J. M. and Lundeen, S. R.: The LLNL thermochemical database, Lawrence Livermore National Laboratory Report UCRL-21658, Lawrence Livermore National Laboratory, 1990.

Eberl, D. D., Drits, V. A., and Środoń, J.: Deducing growth mechanisms for minerals from the shapes of crystal size distributions, Am. J. Sci., 298, 499-533, https://doi.org/10.2475/ajs.298.6.499, 1998.

Elberling, B. and Nicholson, R. V.: Field determination of sulphide oxidation rates in mine tailings, Water Resour. Res., 32, 1773-1784, https://doi.org/10.1029/96WR00487, 1996.

Emmanuel, S. and Ague, J. J.: Impact of nano-size weathering products on the dissolution rates of primary minerals, Chem. Geol., 282, 11-18, https://doi.org/10.1016/j.chemgeo.2011.01.002, 2011.

700 Emmanuel, S. and Berkowitz, B.: Mixing-induced precipitation and porosity evolution in porous media, Adv. Water Resour., 28, 337-344, https://doi.org/10.1016/j.advwatres.2004.11.010, 2005.

Fanchi, J. R.: Principles of Applied Reservoir Simulation, $4^{\text {th }}$ ed., Elsevier, 2018. 
Fekete, B. M., Vörösmarty, C. J., and Grabs, W.: High-resolution fields of global runoff combining observed river discharge and simulated water balances, Global Biogeochem. Cycles, 16, 15-1-15-10, https://doi.org/10.1029/1999GB001254, 2002.

Fick, S. E. and Hijmans, R. J.: WorldClim 2: new 1-km spatial resolution climate surfaces for global land areas. Int. J. Climatol., 37, 4302-4315, https://doi.org/10.1002/joc.5086, 2017.

Fuss, S., Ganadell, J. G., Peters, G. P., Tavoni, M., Andrew, R. M., Ciais, P., Jackson, R. B., Jones, C. D., Kraxner, F., Nakicenovic, N., Le Quéré, C., Raupach, M. R., Sharifi, A., Smith, P., and Yamagata, Y.: Betting on negative emissions, Nat. Clim. Change, 4, 850-853, https://doi.org/10.1038/nclimate2392, 2014.

Gasser, T., Cuivarch, C., Tachiiri, K., Jones, C. D., and Ciais, P.: Negative emissions physically needed to keep global warming below $2{ }^{\circ} \mathrm{C}$, Nat. Commun., 6, 7958, https://doi.org/10.1038/ncomms8958, 2015.

Goldberg, E. D. and Koide, M.: Geochronological studies of deep sea sediments by the ionium/thorium method, Geochim. Cosmochim. Acta, 26, 417-450, https://doi.org/10.1016/0016-7037(62)90112-6, 1962.

715 Goll, D. S., Ciais, P., Amann, T., Buermann, W., Chang, J., Eker, S., Hartmann, J., Janssens, I., Li, W., Obersteiner, M., Penuelas, J., Tanaka, K., and Vicca, S: Potential $\mathrm{CO}_{2}$ removal from enhanced weathering by ecosystem responses to powdered rock, Nat. Geosci, 14, 545-549, https://doi.org/10.1038/s41561-021-00798-x, 2021.

GRASS Development Team.: Geographic Resources Analysis Support System (GRASS GIS) Software, Version 7.2, Open Source Geospatial Foundation, http://grass.osgeo.org, 2017.

Gíslason, S. R. and Arnósson, S.: Dissolution of primary basaltic minerals in natural waters: saturation state and kinetics, Chem. Geol., 105, 117-135, https://doi.org/10.1016/0009-2541(93)90122-Y, 1993.

Hartmann, J., West, A. J., Renforth, P., Köhler, P., De La Rocha, C. L., Wolf-Gladrow, D. A., Dürr, H. H., and Scheffran, J.: Enhanced chemical weathering as a geoengineering strategy to reduce atmospheric carbon dioxide, supply nutrients, and mitigate ocean acidification, Rev. Geophys., 51, 113-149, https://doi.org/10.1002/rog.20004, 2013.

Hengl, T., Mendes de Jesus, J., Heuvelink, G. B. M., Gonzalez, M. R., Kilibarda, M., Blagotić, A., Shangguan, W., Wright, M. N., Geng, X., Bauer-Marschallinger, B., Guevara, M. A., Vargas, R., MacMillan, R. A., Batjes, N. H., Leenaars, J. G. B., Ribeiro, E., Wheeler, I., Mantel, S., and Kempen, B.: SoilGrids250m: Global gridded soil information based on machine learning, PloS One 12, e0169748, https://doi.org/10.1371/journal.pone.0169748, 2017.

Hochella, Jr., M. F.: Nanoscience and technology: the next revolution in the Earth sciences, Earth Planet. Sci. Lett., 203, 593-605, https://doi.org/10.1016/S0012-821X(02)00818-X, 2003.

Holden, P. B., Edwards, N. R., Fraedrich, K., Kirk, E., Lunkeit, F., and Zhu, X.: PLASIM-GENIE v1.0: a new intermediate complexity AOGCM, Geosci. Model Dev., 9, 3347-3361, https://doi.org/10.5194/gmd-9-3347-2016, 2016.

Ibarra, D. E., Caves Rugenstein, J. K., Bachan, A., Baresch, A., Lau, K. V., Thomas, D. L., Lee, J.-E., Boyce, C. K., and Chamberlain, C. P.: Modeling the consequences of land plant evolution on silicate weathering, Am. J. Sci., 319, 1-43, https://doi.org/10.2475/01.2019.01, 2019. 
https://doi.org/10.5194/gmd-2022-8

Preprint. Discussion started: 10 February 2022

(c) Author(s) 2022. CC BY 4.0 License.

\section{(c) (i)}

Iggland, M. and Mazzotti, M.: Population balance modeling with size-dependent solubility: Ostwald ripening, Cryst. Growth Des., 12, 1489-1500, https://doi.org/10.1021/cg201571n, 2012.

IPCC: 2006 IPCC Guidelines for National Greenhouse Gas Inventories, IPCC, 2006.

IPCC: Global Warming of $1.5^{\circ} \mathrm{C}$, IPCC, 2018.

Jarvis, N. J., Taylor, A., Larsbo, M., Etana, A., and Rosén, K.: Modelling the effects of bioturbation on the re-distribution of ${ }^{137} \mathrm{Cs}$ in an undisturbed grassland soil, Eur. J. Soil Sci., 61, 24-34, https://doi.org/10.1111/j.1365-2389.2009.01209.x, 2010.

Jia, M., Jacques, D., Gérard, F., Su, D., Mayer, K. U., and Šimůnek, J.: A benchmark for soil organic matter degradation under variably saturated flow conditions, Comput. Geosci., 25, 1359-1377, https://doi.org/10.1007/s10596-019-09862-3, 2021.

Kanzaki, Y. and Kump, L. R.: Biotic effects on oxygen consumption during weathering: Implications for the second rise of oxygen, Geology, 45, 611-614, https://doi.org/10.1130/G38869.1, 2017.

Kanzaki, Y. and Murakami, T.: Estimates of atmospheric $\mathrm{CO}_{2}$ in the Neoarchean-Paleoproterozoic from paleosols, Geochim. Cosmochim. Acta, 159, 190-219, https://doi.org/10.1016/j.gca.2015.03.011, 2015.

Kanzaki, Y. and Murakami, T.: Estimates of atmospheric $\mathrm{O}_{2}$ in the Paleoproterozoic from paleosols, Geochim. Cosmochim. Acta, 174, 263-290, https://doi.org/10.1016/j.gca.2015.11.022, 2016.

Kanzaki, Y. and Murakami, T.: Effects of atmospheric composition on apparent activation energy of silicate weathering: I. Model formulation, Geochim. Cosmochim. Acta, 223, 159-186, https://doi.org/10.1016/j.gca.2017.10.008, 2018.

Kanzaki, Y., Boudreau, B. P., Kirtland Turner, S., and Ridgwell, A.: A lattice-automaton bioturbation simulator with coupled physics, chemistry, and biology in marine sediments (eLABS v0.2), Geosci. Model Dev., 12, 4469-4496, https://doi.org/10.5194/gmd-12-4469-2019, 2019.

Kanzaki, Y., Brantley, S. L., and Kump, L. R.: A numerical examination of the effect of sulfide dissolution on silicate weathering, Earth Planet. Sci. Lett., 539, 116239, https://doi.org/10.1016/j.eps1.2020.116239, 2020.

Kanzaki, Y., Hülse, D., Kirtland Turner, S., and Ridgwell, A.: A model for marine sedimentary carbonate diagenesis and paleoclimate proxy signal tracking: IMP v1.0, Geosci. Model Dev., 14, 5999-6023, https://doi.org/10.5194/gmd-145999-2021, 2021.

Köhler, P., Hartmann, J., and Wolf-Gladrow, D. A.: Geoengineering potential of artificially enhanced silicate weathering of olivine, Proc. Natl. Acad. Sci. U. S. A., 107, 20228-20233, https://doi.org/10.1073/pnas.1000545107, 2010.

Larsen, I. J., Montgomery, D. R., and Greenberg, H. M.: The contribution of mountains to global denudation, Geology, 42, 527-530, https://doi.org/10.1130/G35136.1, 2014.

LeBlanc, S. E. and Fogler, H. S.: Population balance modeling of the dissolution of polydisperse solids: rate limiting regimes, AIChE J., 33, 54-63, https://doi.org/10.1002/aic.690330108, 1987.

Le Quéré, C, Andrew, R. M., Friedlingstein, P., Sitch, S., Hauck, J., Pongratz, J., Pickers, P. A., Korsbakken, J. I., Peters, G. P., Canadell, J. G., Arneth, A., Arora, V. K., Barbero, L., Bastos, A., Bopp, L., Chevallier, F., Chini, L. P., Ciais, P., 
Doney, S. C., Gkritzalis, T, Goll, D. S., Harris, I., Haverd, V., Hoffman, F. M., Hoppema, M., Houghton, R. A., Hurtt, G., Ilyina, T., Jain, A. K., Johannessen, T., Jones, C. D., Kato, E., Keeling, R. F., Goldewijk, K. K., Landschützer, P., Lefèvre, N., Lienert, S., Liu Z., Lombardozzi, D., Metzl, N., Munro, D. R., Nabel, J. E. M. S., Nakaoka, S., Neill, C., Olsen, A., Ono, T., Patra, P., Peregon, A., Peters, W., Peylin, P., Pfeil, B., Pierrot, D., Poulter, B., Rehder, G., Resplandy, L., Robertson, E., Rocher, M., Rödenbeck, C., Schuster, U., Schwinger, J., Séférian, R., Skjelvan, I., Steinhoff, T., Sutton, A., Tans, P. P., Tian, H., Tilbrook, B., Tubiello, F. N., van der Laan-Luijkx, I. T., van der Werf, G. R., Viovy, N., Walker, A. P., Wiltshire, A. J., Wright, R., Zaehle, S., and Zheng, B.: Global carbon budget 2018, Earth Syst. Sci. Data, 10, 2141-2194, https://doi.org/10.5194/essd-10-2141-2018, 2018.

Li, D. D., Jacobson, A. D., and McInerney, D. J.: A reactive-transport model for examining tectonic and climatic controls on chemical weathering and atmospheric $\mathrm{CO}_{2}$ consumption in granitic regolith, Chem. Geol., 365, 30-42, https://doi.org/10.1016/j.chemgeo.2013.11.028, 2014.

Li, Y.- H. and Gregory, S.: Diffusion of ions in sea water and in deep-sea sediments, Geochim. Cosmochim. Acta, 38, 703714, https://doi.org/10.1016/0016-7037(74)90145-8, 1974.

Liddicoat, S. K., Wiltshire, A. J., Jones, C. D., Arora, V. K., Brovkin, V., Cadule, P., Hajima, T., Lawrence, D. M., Pongratz, J., Schwinger, J., Séférian, R., Tjiputra, J. F., and Ziehn, T.: Compatible fossil fuel $\mathrm{CO}_{2}$ emissions in the CMIP6 Earth system models' historical and Shared Socioeconomic Pathway experiments of the twenty-first century, J. Clim., 34, 2853-2875, https://doi.org/10.1175/JCLI-D-19-0991.1, 2021.

Maggi, F., Gu, C., Riley, W. J., Hornberger, G. M., Venterea, R. T., Xu, T., Spycher, N., Steefel, C., Miller, N. L., and Oldenburg, C. M.: A mechanistic treatment of the dominant soil nitrogen cycling processes: Model development, testing, and application, J. Geophys. Res., 113, G02016, https://doi.org/10.1029/2007JG000578, 2008.

Massmann, W. J.: A review of the molecular diffusivities of $\mathrm{H}_{2} \mathrm{O}, \mathrm{CO}_{2}, \mathrm{CH}_{4}, \mathrm{CO}, \mathrm{O}_{3}, \mathrm{SO}_{2}, \mathrm{NH}_{3}, \mathrm{~N}_{2} \mathrm{O}, \mathrm{NO}$, and $\mathrm{NO}_{2}$ in air, $\mathrm{O}_{2}$ and $\mathrm{N}_{2}$ near STP, Atmos. Environ., 32, 1111-1127, https://doi.org/10.1016/S1352-2310(97)00391-9, 1998.

Mayer, L. M., Schick, L. L., Hardy, K. R., Wagai, R., and McCarthy, J.: Organic matter in small mesopores in sediments and soils, Geochim. Cosmochim. Acta, 68, 3863-3872, https://doi.org/10.1016/j.gca.2004.03.019, 2004.

McGuire, A. D., Lawrence, D. M., Koven, C., Clein, J. S., Burke, E., Chen, G., Jafarov, E., MacDougall, A. H., Marchenko, S., Nicolsky, D., Peng, S., Rinke, A., Ciais, P., Gouttevin, I., Hayes, D. J., Ji, D., Krinner, G., Moore, J. C., Romanovsky, V., Schädel, C., Schaefer, K., Schuur, E. A. G., and Zhuang, Q.: Dependence of the evolution of carbon dynamics in the northern permafrost region on the trajectory of climate change, Proc. Natl. Acad. Sci. U. S. A., 115, 3882-3887, https://doi.org/10.1073/pnas.1719903115, 2018.

McKibben, M. A. and Barnes, H. L.: Oxidation of pyrite in low temperature acidic solutions: Rate laws and surface textures, Geochim. Cosmochim. Acta, 50, 1509-1520, https://doi.org/10.1016/0016-7037(86)90325-X, 1986.

Minx, J. C., Lamb, W. F., Callaghan, M. W., Fuss, S., Hilaire, J., Creutzig, F., Amann, T., Beringer, T., de Oliveria Garcia, W., Hartmann, J., Khanna, T., Lenzi, D., Luderer, G., Nemet, G. F., Rogelj, J., Smith, P., Luis Vincente Vincente, J., 
Wilcox, J., and del Mar Zamora Dominguez, M.: Negative emissions-Part 1: Research landscape and synthesis, Environ. Res. Lett., 13, 063001, https://doi.org/10.1088/1748-9326/aabf9b, 2018.

Munhoven, G.: Model of Early Diagenesis in the Upper Sediment with Adaptable complexity - MEDUSA (v. 2): a timedependent biogeochemical sediment module for Earth System Models, process analysis and teaching, Geosci. Model Dev., 14, 3603-3631, 2021.

Navarre-Sitchler, A. and Brantley, S.: Basalt weathering across scales, Earth Planet. Sci. Lett., 261, 321-334, https://doi.org/10.1016/j.eps1.2007.07.010, 2007.

Nicholson, R. V., Gillham, R. W., and Reardon, E. J.: Pyrite oxidation in carbonate-buffered solution: 2. Rate control by oxide coatings, Geochim. Cosmochim. Acta, 54, 395-402, https://doi.org/10.1016/0016-7037(90)90328-I, 1990.

Palandri, J. L. and Kharaka, Y. K.: A Compilation of Rate Parameters of Water-Mineral Interaction Kinetics for Application to Geochemical Modeling, Geological Survey, Menlo Park CA, 2004.

Parkhurst, D. L. and Appelo, C. A. J.: Description of input and examples for PHREEQC version 3: a computer program for speciation, batch-reaction, one-dimensional transport, and inverse geochemical calculations, U. S. Geological Survey, https://doi.org/10.3133/tm6A43, 2013.

Perez, M., Dumont, M., and Acevedo-Reyes, D.: Implementation of classical nucleation and growth theories for precipitation, Acta Mater., 56, 2119-2132, https://doi.org/10.1016/j.actamat.2007.12.050, 2008.

Pritchard, D. T. and Currie, J. A.: Diffusion of coefficients of carbon dioxide, nitrous oxide, ethylene and ethane in air and their measurement, J. Soil Sci., 33, 175-184, https://doi.org/10.1111/j.1365-2389.1982.tb01757.x, 1982.

Ragnarsdóttir, K. V.: Dissolution kinetics of heulandite at pH 2-12 and $25^{\circ} \mathrm{C}$, Geochim. Cosmochim. Acta, 57, 2439-2449, https://doi.org/10.1016/0016-7037(93)90408-O, 1993.

Rau, G. H., Knauss, K. G., Langer, W. H., and Caldeira, K.: Reducing energy-related $\mathrm{CO}_{2}$ emissions using accelerated weathering of limestone, Energy, 32, 1471-1477, https://doi.org/10.1016/j.energy.2006.10.011, 2007.

Rebreanu, L., Vanderborght, J. P., and Chou, L.: The diffusion coefficient of dissolved silica revisited, Mar. Chem., 112, 230-233, https://doi.org/10.1016/j.marchem.2008.08.004, 2008.

Renforth, P.: The potential of enhanced weathering in the UK, Int. J. Greenh. Gas Control., 10, 229-243, https://doi.org/10.1016/j.ijggc.2012.06.011, 2012.

Renforth, P. and Henderson, G.: Assessing ocean alkalinity for carbon sequestration, Rev. Geophys., 55, 636-674, https://doi.org/10.1002/2016RG000533, 2017.

Renforth, P., Pogge von Strandmann, P. A. E, and Henderson, G. M.: The dissolution of olivine added to soil: Implications for enhanced weathering, Appl. Geochem., 61, 109-118, https://doi.org/10.1016/j.apgeochem.2015.05.016, 2015.

Ridgwell, A., Hargreaves, J. C., Edwards, N. R., Annan, J. D., Lenton, T. M., Marsh, R., Yool, A., and Watson, A.: Marine geochemical data assimilation in an efficient Earth System Model of global biogeochemical cycling, Biogeosciences, 4, 87-104, https://doi.org/10.5194/bg-4-87-2007, 2007. 
Robie, R. A. Hemingway, B. S., and Fisher, J. R.: Thermodynamic properties of minerals and related substances at 298.15 K and 1 bar ( $10^{5}$ pascals) pressure and at higher temperatures, U. S. Geological Survey, 1978.

Rogelj, J., Shindell, D., Jiang, K., Fifita, S., Forster, P., Ginzburg, V., Handa, C., Kobayashi, S., Kriegler, E., Mundaca, L., Séférian, R., Vilariño, M. V., Calvin, K., Emmerling, J., Fuss, S., Gillett, N., He, C., Hertwich, E., Höglund-Isaksson, L., Huppmann, D., Luderer, G., McCollum, D.L., Meinshausen, M., Millar, R., Popp, A., Purohit, P., Riahi, K., Ribes, A., Saunders, H., Schädel, C., Smith, P., Trutnevyte, E., Xiu, Y., Zhou, W., Zickfeld, K., Flato, G., Fuglestvedt, J., Mrabet, R., and Schaeffer, R.: Mitigation pathways compatible with $1.5^{\circ} \mathrm{C}$ in the context of sustainable development, IPCC, 2018.

Safari, V., Arzpeyma, G., Raschchi, F., and Mostoufi, N.: A shrinking particle—shrinking core model for leaching of a zinc ore containing silica, Int. J. Miner. Process., 93, 79-83, https://doi.org/10.1016/j.minpro.2009.06.003, 2009.

Schulz, H. D. and Zabel, M.: Marine Geochemistry, Springer, 2006.

Shull, D. H.: Transition-matrix model of bioturbation and radionuclide diagenesis, Limnol. Oceanogr., 46, 905-916, https://doi.org/10.4319/lo.2001.46.4.0905, 2001.

Singer, P. C. and Stumm, W.: Acidic mine drainage: the rate-determining step, Science, 167, 1121-1123, https://doi.org/10.1126/science.167.3921.1121, 1970.

Sklar, L. S., Riebe, C. S., Marshall, J. A., Genetti, J., Leclere, S., Lukens, C. L., and Merces, V.: The problem of predicting the size distribution of sediment supplied by hillslopes to rivers, Geomorphology, 277, 31-49, https://doi.org/10.1016/j.geomorph.2016.05.005, 2017.

Steefel, C. I.: CrunchFlow Software for Modeling Multicomponent Reactive Flow and Transport USER'S MANUAL, 2009.

Steefel, C. I. and Lasaga, A. C.: A coupled model for transport of multiple chemical species and kinetic precipitation/dissolution reactions with application to reactive flow in single phase hydrothermal systems, Am. J. Sci., 294, 529-592, https://doi.org/10.2475/ajs.294.5.529, 1994.

Steefel, S. I., Appelo, C. A. J., Arora, B., Jacques, D., Kalbacher, T., Kolditz, O., Lagneau, V., Lichtner, P. C., Mayer, K. U., Meeussen, J. C.L., Molins, S., Moulton, D., Shao, H., Šimůnek, J., Spycher, N., Yabusaki, S. B., and Yeh, G. T.: Reactive transport codes for subsurface environmental simulation, Comput. Geosci., 19, 445-478, https://doi.org/10.1007/s10596-014-9443-x, 2015.

Stonestrom, D. A., White, A. F., and Akstin, K. C.: Determining rates of chemical weathering in soils—solute transport versus profile evolution, J. Hydrol., 209, 331-345, https://doi.org/10.1016/S0022-1694(98)00158-9, 1998.

Strefler, J., Amann, T., Bauer, N., Kriegler, E., and Hartmann, J.: Potential and costs of carbon dioxide removal by enhanced weathering of rocks, Environ. Res. Lett., 13, 034010, https://doi.org/10.1088/1748-9326/aaa9c4, 2018.

Sugimori, H., Kanzaki, Y., and Murakami, T.: Relationships between Fe redistribution and $P_{\mathrm{O}_{2}}$ during mineral dissolution under low $\mathrm{O}_{2}$ conditions, Geochim. Cosmochim. Acta, 84, 29-46, https://doi.org/10.1016/j.gca.2012.01.001, 2012.

Trauth, M. H.: TURBO: A dynamic-probabilistic simulation to study the effects of bioturbation on paleoceanographic time series, Comput. Geosci., 24, 433-441, https://doi.org/10.1016/S0098-3004(98)00019-3,1998. 
Taylor, L. L., Quirk, J., Thorley, R. M. S., Kharecha, P. A., Hansen, J., Ridgwell, A., Lomas, M. R., Banwart, S. A., and Beerling, D. J.: Enhanced weathering strategies for stabilizing climate and averting ocean acidification, Nat. Clim. Change, 6, 402-406, https://doi.org/10.1038/NCLIMATE2882, 2016.

U.S. Geological Survey: National Geochemical Database: Soil, U.S. Geological Survey, https://mrdata.usgs.gov/ngdb/soil/, 2016.

Volk, T.: Feedbacks between weathering and atmospheric $\mathrm{CO}_{2}$ over the last 100 million years, Am. J. Sci., 287, 763-779, https://doi.org/10.2475/ajs.287.8.763, 1987.

Wang, B., Zhang, G.-H., Shi, Y.-Y., and Zhang, X. C.: Soil detachment by overland flow under different vegetation restoration models in the Loess Plateau of China, Catena, 116, 51-59, https://doi.org/10.1016/j.catena.2013.12.010, 2014.

Weiss, R. F. and Price, B. A.: Nitrous oxide solubility in water and seawater, Mar. Chem., 8, 347-357, https://doi.org/10.1016/0304-4203(80)90024-9, 1980.

Wen, H., Sullivan, P. L., Macpherson, G. L., Billings, S. A., and Li, L.: Deepening roots can enhance carbonate weathering by amplifying $\mathrm{CO}_{2}$-rich recharge, Biogeosciences, 18, 55-75, https://doi.org/10.5194/bg-18-55-2021, 2021.

White, A. F. and Peterson, M. L.: Role of reactive-surface-area characterization in geochemical kinetic models, In: Chemical Modeling of Aqueous Systems II, ACS Symposium Series, 416, 461-475, https://doi.org/10.1021/bk-1990-0416.ch035, 1990.

Williamson, M. A. and Rimstidt, J. D.: The kinetics and electrochemical rate-determining step of aqueous pyrite oxidation, Geochim. Cosmochim. Acta, 58, 5443-5454, https://doi.org/10.1016/0016-7037(94)90241-0, 1994.

Wilkin, R. T. and Barnes, H. L.: Solubility and stability of zeolites in aqueous solution; I, Analcime, Na-, and Kclinoptilolite, Am. Mineral., 83, 746-761, https://doi.org/10.2138/am-1998-7-807, 1998.

Wolery, T. J. and Jove-Colon, C. F.: Qualification of thermodynamic data for geochemical modeling of mineral-water interactions in dilute systems, No. ANL-WIS-GS-000003 REV 00. YMP (Yucca Mountain Project, Las Vegas, Nevada), 2004.

Figure 1: Simulation of abiotic weathering of albite. Soil concentrations, saturation states and dissolution/precipitation rates of solid species are plotted in a-c, respectively; porewater concentrations of aqueous species and pH in $\mathrm{d}$ and e, respectively; soil porosity and particle density in $f$ and $g$, respectively; and ratio of total volume of solid species against solid space specified with porosity in $h$. See Table 7 for the details on the boundary conditions of the simulation.

Figure 2: Simulation of abiotic weathering of pyrite. Soil concentrations and saturation states of solid species are plotted in a and b, respectively; rate profile of reactions within soil in c; porewater concentrations of aqueous species and pH in $\mathrm{d}$ and e, respectively; concentrations of soil gases in $f$; soil porosity and particle density in $g$ and $h$, respectively; and ratio of total volume of solid species against solid space specified with porosity in i. See Table 7 for the details on the boundary conditions of the simulation.

Figure 3: Soil concentrations of solid species in simulation of abiotic weathering at Site 1 in Table 8 . See Table 7 for the details on the boundary conditions of the simulation. 
https://doi.org/10.5194/gmd-2022-8

Preprint. Discussion started: 10 February 2022

(C) Author(s) 2022. CC BY 4.0 License.

(c) (i)

Figure 4: Simulation of abiotic weathering at Site 1 in Table 8. Porewater concentrations of aqueous species and pH are plotted in a-d and e, respectively; concentrations of soil gases in $\mathrm{f}$; soil porosity and particle density in $\mathrm{f}$ and g, respectively; and ratio of total volume of solid species against solid space specified with porosity in $h$. See Table 7 for the details on the boundary conditions of the simulation.

Figure 5: Locations of natural weathering sites whose boundary conditions are tabulated in Table 8 and utilized for example simulations in Section 3.

Figure 6: Simulation of biotic weathering at Site 1 in Table 8. Shown are concentrations of simulated solid species. Note that the model configuration is the same as that for Fig. 3 except that soil respiration and bio-mixing are included.

Figure 7: Simulation of biotic weathering at Site 1 in Table 8. Panels show the depth profiles of aqueous and gas species and soil physical properties as in Fig. 4 except that simulation includes soil respiration and bio-mixing.

915 Figure 8: Basalt powder application at Site 1 in Table 8. Panels show the depth profiles of simulated solid species as in Fig. 6 except that basalt powder is continuously added at a rate of $40 \mathrm{t} \mathrm{ha}^{-1} \mathrm{yr}^{-1}$ and plots are focused on soil mixed layer (0-25 cm).

Figure 9: Basalt powder application at Site 1 in Table 8. Panels show the depth profiles of aqueous and gas species and soil physical properties as in Fig. 4 except that basalt powder is continuously added at a rate of $40 \mathrm{t} \mathrm{ha}^{-1} \mathrm{yr}^{-1}$.

Figure 10: Simulations of abiotic weathering (a-c), biotic weathering (d-f) and basalt powder application (g-i) at Site 1 in Table 8 with surface area calculated based on tracked particle size distribution (PSD) for bulk soil. PSDs at surface and bottom of soil mixed layer are shown in a, $d$ and g. Pore surface area per unit pore volume is plotted against depth (b, e and $h$ ) or porosity (c, $f$ and i) and compared to the calculation with the default surface area parameterization. See Section 3.1.4 and Table 7 for the details on the boundary conditions of the simulations.

Figure 11: Particle size distributions (PSDs) at surface and bottom of soil mixed layer for individual solid species in simulation of basalt powder application at Site 1 in Table 8 with the surface area calculated based on tracked PSDs for individual solid species. See Section 3.1.4 and Table 7 for the details on the boundary conditions of the simulation.

Figure 12: Surface area of individual solid species per unit pore volume plotted against depth (focused on mixed layer; 0-25 $\mathrm{cm}$ ) in simulation of basalt powder application at Site 1 in Table 8 with the surface area calculated based on tracked PSDs for individual solid species ('Full PSD'). The pore surface areas per unit pore volume calculated with the default parameterization ('Def.') and based on PSD for bulk soil ('Bulk PSD') are also plotted for comparison. See Section 3.1.4 and Table 7 for the details on the boundary conditions of the simulation.

Figure 13: Model fit to observed depth profiles of soil OM and pH for Sites 2 and 3 in Table 8. See Section 3.2.1 for the details.

Figure 14: $\mathrm{CO}_{2}$ capture predicted in simulations of continuous basalt powder application at Sites 2 and 3 in Table 8 with the surface area calculation based on assumed hydraulic radius ('Def.'), tracked PSD for bulk soil ('Bulk PSD') and tracked PSDs for individual solid species ('Full PSD'). See Section 3.2.2 for the details.

Figure 15: $\mathrm{CO}_{2}$ capture predicted in simulations of pulsative basalt application at Sites 2 and 3 in Table 8 . Milled basalt (dominated by 5, 20, 50 and $70 \mu \mathrm{m}$ particles) is applied non-continuously and homogeneously mixed at the soil surface. See Section 3.2.2 for the details. 
https://doi.org/10.5194/gmd-2022-8

Preprint. Discussion started: 10 February 2022

(c) Author(s) 2022. CC BY 4.0 License.

Table 1. Thermodynamic data of solid species ${ }^{\text {a }}$.

\begin{tabular}{|c|c|c|c|c|c|c|c|c|}
\hline ID & Name & Composition & $\begin{array}{l}T_{\mathrm{C}}^{\text {ref }} \\
{\left[{ }^{\circ} \mathrm{C}\right]}\end{array}$ & $\begin{array}{l}\log K_{\theta}^{\mathrm{ref}} \\
{\left[\left(\mathrm{mol} \mathrm{L}^{-1}\right)^{y}\right]^{\mathrm{b}}}\end{array}$ & $\begin{array}{l}\Delta H_{\theta} \\
{\left[\mathrm{kJ} \mathrm{mol}^{-1}\right]}\end{array}$ & $\begin{array}{l}M_{\theta} \\
{\left[\mathrm{g} \mathrm{mol}^{-1}\right]^{\mathrm{c}}}\end{array}$ & $\begin{array}{l}V_{\theta} \times 10^{-6} \\
{\left[\mathrm{~m}^{3} \mathrm{~mol}^{-1}\right]^{\mathrm{d}}}\end{array}$ & $\begin{array}{l}\text { Ref. } \\
\text { /note }^{\mathrm{e}}\end{array}$ \\
\hline amsi & Amorphous Si & $\mathrm{SiO}_{2}$ & 25 & -2.71 & 13.97 & 60.085 & 25.739 & 1 \\
\hline qtz & Quartz & $\mathrm{SiO}_{2}$ & 25 & -4.00 & 22.36 & 60.085 & 22.688 & 2 \\
\hline $\mathrm{gb}$ & Gibbsite & $\mathrm{Al}(\mathrm{OH})_{3}$ & 25 & 8.11 & -95.40 & 78.004 & 31.956 & 1 \\
\hline gt & Goethite & $\mathrm{FeO}(\mathrm{OH})$ & 25 & 0.53 & -61.54 & 88.854 & 20.82 & 3 \\
\hline $\mathrm{hm}$ & Hematite & $\mathrm{Fe}_{2} \mathrm{O}_{3}$ & 25 & -1.42 & -128.99 & 159.692 & 30.274 & 2 \\
\hline gps & Gypsum & $\mathrm{CaSO}_{4} \cdot 2 \mathrm{H}_{2} \mathrm{O}$ & 25 & -4.61 & 1.00 & 172.168 & 74.69 & 2 \\
\hline $\arg$ & Aragonite & $\mathrm{CaCO}_{3}$ & 25 & -8.30 & -12.00 & 100.089 & 34.15 & 2 \\
\hline $\mathrm{cc}$ & Calcite & $\mathrm{CaCO}_{3}$ & 15 & -8.43 & -8.03 & 100.089 & 36.934 & 4 \\
\hline $\mathrm{dlm}$ & Dolomite & $\mathrm{CaMg}\left(\mathrm{CO}_{3}\right)_{2}$ & 25 & -16.54 & -46.40 & 184.403 & 64.34 & 5 \\
\hline $\mathrm{ab}$ & Albite & $\mathrm{NaAlSi}_{3} \mathrm{O}_{8}$ & 15 & 3.41 & -54.15 & 262.225 & 100.07 & 4 \\
\hline $\mathrm{kfs}$ & K-feldspar & $\mathrm{KAlSi}_{3} \mathrm{O}_{8}$ & 15 & 0.23 & -26.31 & 278.33 & 108.72 & 4 \\
\hline an & Anorthite & $\mathrm{CaAl}_{2} \mathrm{Si}_{2} \mathrm{O}_{8}$ & 15 & 28.86 & -292.88 & 278.311 & 100.79 & 4 \\
\hline fo & Foresterite & $\mathrm{Mg}_{2} \mathrm{SiO}_{4}$ & 15 & 29.41 & -208.59 & 140.694 & 43.79 & 4 \\
\hline $\mathrm{fa}$ & Fayarite & $\mathrm{Fe}_{2} \mathrm{SiO}_{4}$ & 15 & 19.99 & -153.77 & 203.778 & 46.39 & 4 \\
\hline en & Enstatite & $\mathrm{MgSiO}_{3}$ & 15 & 11.99 & -85.82 & 100.389 & 31.31 & 4 \\
\hline fer & Ferrosilite & $\mathrm{FeSiO}_{3}$ & 15 & 7.78 & -60.09 & 131.931 & 33.00 & 4 \\
\hline $\mathrm{dp}$ & Diopside & $\mathrm{MgCaSi}_{2} \mathrm{O}_{6}$ & 15 & 21.80 & -138.60 & 216.553 & 66.09 & 4 \\
\hline $\mathrm{hb}$ & Hedenbergite & $\mathrm{FeCaSi}_{2} \mathrm{O}_{6}$ & 15 & 20.21 & -128.50 & 248.09 & 69.88 & 4 \\
\hline $\mathrm{tm}$ & Tremolite & $\mathrm{Ca}_{2} \mathrm{Mg}_{5}\left(\mathrm{Si}_{8} \mathrm{O}_{22}\right)(\mathrm{OH})_{2}$ & 15 & 61.67 & -429.00 & 812.374 & 272.92 & 4 \\
\hline antp & Anthophyllite & $\mathrm{Mg}_{7} \mathrm{Si}_{8} \mathrm{O}_{22}(\mathrm{OH})_{2}$ & 15 & 70.84 & -508.66 & 780.976 & 274.00 & 4 \\
\hline $\mathrm{mscv}$ & Muscovite & $\mathrm{KAl}_{2}\left(\mathrm{AlSi}_{3} \mathrm{O}_{10}\right)(\mathrm{OH})_{2}$ & 15 & 15.98 & -230.78 & 398.311 & 140.71 & 4 \\
\hline plgp & Phlogopite & $\mathrm{KMg}_{3}\left(\mathrm{AlSi}_{3} \mathrm{O}_{10}\right)(\mathrm{OH})_{2}$ & 15 & 40.12 & -312.78 & 417.262 & 149.91 & 4 \\
\hline $\mathrm{ct}$ & Crysotile & $\mathrm{Mg}_{3} \mathrm{Si}_{2} \mathrm{O}_{5}(\mathrm{OH})_{4}$ & 25 & 32.20 & -195.81 & 277.113 & 108.5 & 1 \\
\hline $\mathrm{ka}$ & Kaolinite & $\mathrm{Al}_{2} \mathrm{Si}_{2} \mathrm{O}_{5}(\mathrm{OH})_{4}$ & 25 & 7.44 & -147.70 & 258.162 & 99.52 & 1 \\
\hline anl & Analcime & $\mathrm{NaAlSi}_{2} \mathrm{O}_{6} \cdot \mathrm{H}_{2} \mathrm{O}$ & 25 & -16.06 & 101.00 & 220.155 & 97.49 & 6 \\
\hline nph & Nepheline & $\mathrm{NaAlSiO}_{4}$ & 15 & 14.94 & -130.82 & 142.055 & 54.16 & 4 \\
\hline nabd & Na-beidellite & $\mathrm{Na}_{1 / 3} \mathrm{Al}_{7 / 3} \mathrm{Si}_{11 / 3} \mathrm{O}_{10}(\mathrm{OH})_{2}$ & 15 & 7.29 & -150.73 & 367.609 & 130.73 & 4 \\
\hline kbd & K-beidellite & $\mathrm{K}_{1 / 3} \mathrm{Al}_{7 / 3} \mathrm{Si}_{11 / 3} \mathrm{O}_{10}(\mathrm{OH})_{2}$ & 15 & 6.93 & -145.68 & 372.978 & 134.15 & 4 \\
\hline cabd & Ca-beidellite & $\mathrm{Ca}_{1 / 6} \mathrm{Al}_{7 / 3} \mathrm{Si}_{11 / 3} \mathrm{O}_{10}(\mathrm{OH})_{2}$ & 15 & 7.27 & -157.02 & 366.625 & 129.77 & 4 \\
\hline mgbd & Mg-beidellite & $\mathrm{Mg}_{1 / 6} \mathrm{Al}_{7 / 3} \mathrm{Si}_{11 / 3} \mathrm{O}_{10}(\mathrm{OH})_{2}$ & 15 & 7.27 & -160.19 & 363.996 & 128.73 & 4 \\
\hline ill & Illite & $\mathrm{K}_{0.6} \mathrm{Mg}_{0.25} \mathrm{Al}_{2.3} \mathrm{Si}_{3.5} \mathrm{O}_{10}(\mathrm{OH})_{2}$ & 15 & 10.81 & -166.40 & 383.90 & 139.35 & 4 \\
\hline olg & Oligoclase & an: $(a b+a n)=0.1-0.3$ & & & & & & 7 \\
\hline and & Andesine & an: $(a b+a n)=0.3-0.5$ & & & & & & 7 \\
\hline la & Laboratorite & $a n:(a b+a n)=0.5-0.7$ & & & & & & 7 \\
\hline by & Bytownite & an: $(a b+a n)=0.7-0.9$ & & & & & & 7 \\
\hline cpx & Clinopyroxene & $h b:(h b+d p)=0-1$ & & & & & & 7 \\
\hline
\end{tabular}


https://doi.org/10.5194/gmd-2022-8

Preprint. Discussion started: 10 February 2022

(c) Author(s) 2022. CC BY 4.0 License.

(c) (i)

\begin{tabular}{|c|c|c|c|c|}
\hline opx & Orthopyroxene & fer:(fer+en $)=0-1$ & & \\
\hline & & fer:(fer+en $)=0-1$, & & \\
\hline agt & Augite & $\operatorname{cpx}:(\mathrm{cpx}+\mathrm{opx})=0-1$ & & \\
\hline py & Pyrite & $\mathrm{FeS}_{2}$ & 119.967 & 23.94 \\
\hline $\mathrm{g} 1$ & SOM Class 1 & $\mathrm{CH}_{2} \mathrm{O}$ & 30 & 20 \\
\hline g2 & SOM Class 2 & $\mathrm{CH}_{2} \mathrm{O}$ & 30 & 20 \\
\hline g3 & SOM Class 3 & $\mathrm{CH}_{2} \mathrm{O}$ & 30 & 20 \\
\hline
\end{tabular}

${ }^{\text {a }}$ Thermodynamic constant for species $\theta\left(K_{\theta}\right)$ is calculated as $K_{\theta}=K_{\theta}^{\text {ref }} \exp \left[-\Delta H_{\theta}\left\{1 /\left(T_{\mathrm{C}}+273.15\right)-1 /\left(T_{\mathrm{C}}^{\text {ref }}+273.15\right)\right\} / \Re\right]$ where $T_{\mathrm{C}}$ is temperature in ${ }^{\circ} \mathrm{C}$ and $\Re$ is the gas constant in units of $\mathrm{kJ} \mathrm{mol}^{-1} \mathrm{~K}^{-1}\left(\Re=8.314 \times 10^{-3} \mathrm{~kJ} \mathrm{~mol}^{-1} \mathrm{~K}^{-1}\right)$. Thermodynamic constants for SOMs and pyrite are not defined here as the saturation states for these species are kinetically defined (see Section 2.2.2 for more details): $\Omega_{\mathrm{py}}=1-p_{\mathrm{O}_{2}}^{0.5}$ (pyrite) and $\Omega_{\mathrm{g}}=1-p_{\mathrm{O}_{2}} /\left(p_{\mathrm{O}_{2}}+K_{\mathrm{g}, \mathrm{O}_{2}}\right)(\mathrm{SOM}$ Class 1 to 3 ) where $p_{\mathrm{O}_{2}}$ is the partial pressure of soil $\mathrm{O}_{2}(\mathrm{~atm})$ and $K_{\mathrm{g}, \mathrm{O}_{2}}$ is the Michaelis constant for aerobic respiration (=0.121 atm; see Kanzaki and Kump (2017) and references therein).

${ }^{\mathrm{b}}$ Units change with $y$ depending on minerals.

${ }^{\mathrm{c}}$ From Robie et al. (1978) except for illite and beidellites (Wolery and Jove-Colon, 2004), hedenbergite (calculated from the molar weight and density in https://www.mindat.org) and SOMs (Mayer et al., 2004). Solid solutions are calculated from molar volumes of endmember minerals.

${ }^{\mathrm{d}}$ From Robie et al. (1978). When not available in Robie et al. (1978), calculated from chemical composition.

e [1] From phreeqc.dat available in PHREEQC v.3 (Parkhurst and Appelo, 2013). [2] From minteq.v4.dat available in PHREEQC v.3 (Parkhurst and Appelo, 2013). [3] Data by Sugimori et al. (2012) from Lawrence Livermore National Laboratory thermodynamic dataset, thermo.com.v8r6+.dat (Delany and Lundeen, 1990). [4] Summarized data by Kanzaki and Murakami (2018) from thermo.com.v8r6+.dat (Delany and Lundeen, 1990). [5] Data for disordered dolomite from minteq.v4.dat available in PHREEQC v.3 (Parkhurst and Appelo, 2013). [6] Wilkin and Barnes (1998). [7] Calculated assuming ideal solid solution after Gislason and Arnorsson (1993). [8] Not defined (see caption a and Section 2.2.2). 
https://doi.org/10.5194/gmd-2022-8

Preprint. Discussion started: 10 February 2022

(c) Author(s) 2022. CC BY 4.0 License.

Table 2. Dissolution/precipitation kinetic data of solid species a

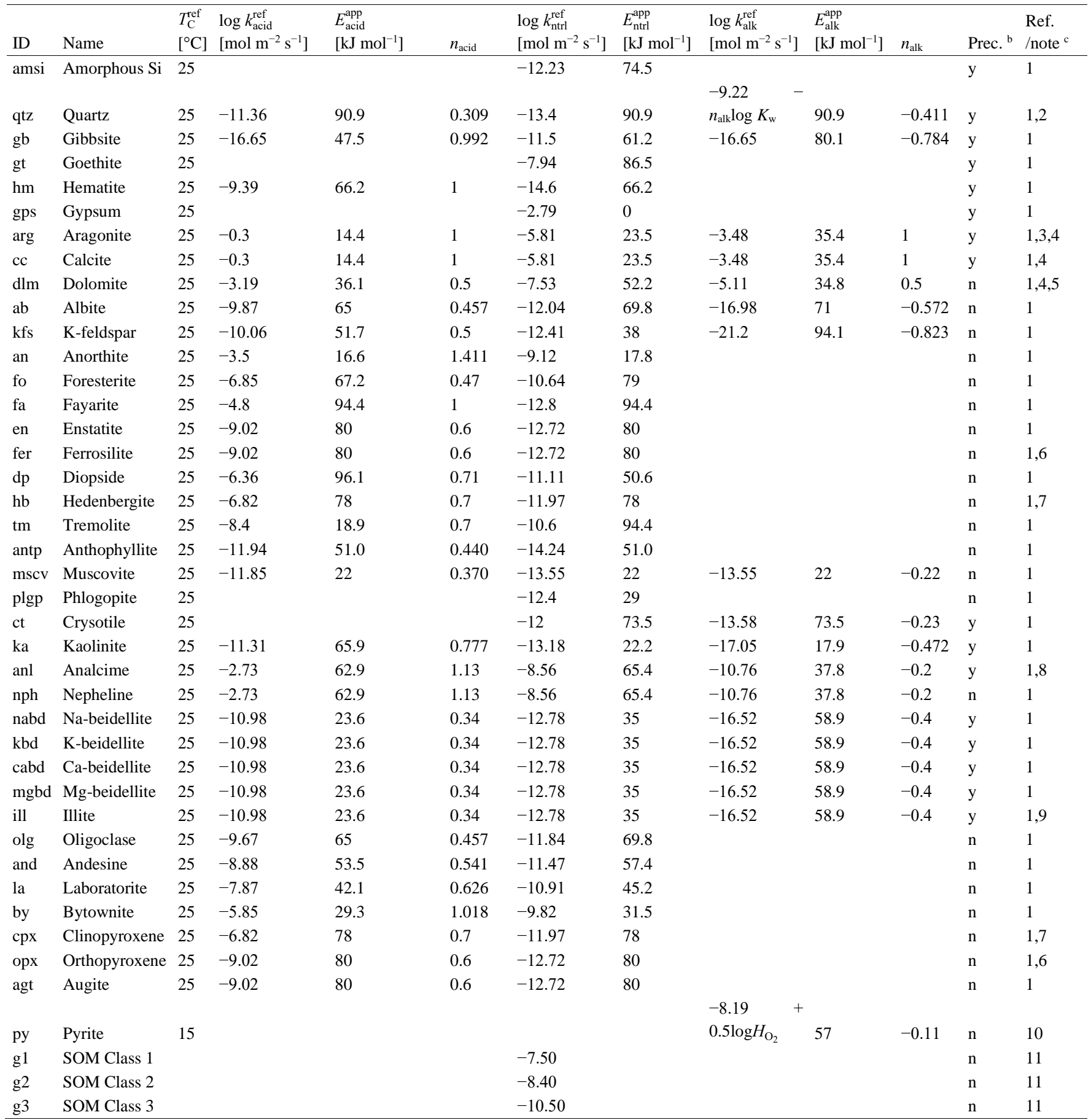


${ }^{a}$ Rate constant for species $\theta\left(\mathrm{mol} \mathrm{m}{ }^{-2} \mathrm{~s}^{-1}\right)$ is calculated as $k_{\theta}=\left[\mathrm{H}^{+}\right]^{n_{\text {acid }}} k_{\text {acid }}^{\text {ref }} \exp \left[-E_{\text {acid }}^{\text {app }}\left\{1 /\left(T_{\mathrm{C}}+273.15\right)-1 /\left(T_{\mathrm{C}}^{\mathrm{ref}}+273.15\right)\right\} / \Re\right]+k_{\mathrm{ntrl}}^{\mathrm{ref}} \exp \left[-E_{\mathrm{ntrl}}^{\mathrm{app}}\left\{1 /\left(T_{\mathrm{C}}+\right.\right.\right.$ $\left.\left.273.15)-1 /\left(T_{\mathrm{C}}^{\mathrm{ref}}+273.15\right)\right\} / \Re\right]+\left[\mathrm{H}^{+}\right]^{n_{\mathrm{allk}}} k_{\mathrm{alk}}^{\mathrm{ref}} \exp \left[-E_{\mathrm{alk}}^{\mathrm{app}}\left\{1 /\left(T_{\mathrm{C}}+273.15\right)-1 /\left(T_{\mathrm{C}}^{\mathrm{ref}}+273.15\right)\right\} / \Re\right]$ where $T_{\mathrm{C}}$ is temperature in ${ }^{\circ} \mathrm{C}$ and $\Re$ is the gas constant in units of $\mathrm{kJ} \mathrm{mol}^{-1} \mathrm{~K}^{-1}\left(\Re=8.314 \times 10^{-3} \mathrm{~kJ} \mathrm{~mol}^{-1} \mathrm{~K}^{-1}\right)$, except for carbonates and SOMs. For carbonates, [H+ $\left.\mathrm{H}^{+}\right]$in the last term of the above equation ('base' mechanism) needs to be replaced by $p_{\mathrm{CO}_{2}}$ (atm), the partial pressure of soil $\mathrm{CO}_{2}$ ('carbonate' mechanism) according to Palandri and Kharaka (2004); and for SOMs, rate constants are assumed to be independent of $\mathrm{pH}$ and temperature.

${ }^{\mathrm{b}}$ Solid species that are unlikely to precipitate are not allowed to precipitate even when porewater is supersaturated with respect to them in the model, denoted with ' $n$ ' in this column. Those can precipitate are denoted with ' $y$ '.

' [1] Palandri and Kharaka (2004). [2] 'Acid' and 'base' mechanisms from Brantley et al. (2008) ( $K_{\mathrm{w}}$ is the water dissociation constant) and 'neutral' mechanism from Palandri and Kharaka (2004). Activation energy for 'neutral mechanism' is assumed to be applicable to other mechanisms. [3] Data for calcite is assumed. [4] 'Base' mechanism is replaced by 'carbonate' mechanism (see caption a for the detail). [5] Data for disordered dolomite is assumed. [6] Data for enstatite is assumed. [7] Data for augite is assumed. [8] Data for nepherine is assumed (cf. Ragnarsdóttir, 1993). [9] Data for smectite is assumed (cf. Bibi et al., 2011). [10] $H_{\mathrm{O}_{2}}$ is the solubility of $\mathrm{O}_{2}\left(\mathrm{~mol} \mathrm{~L}^{-1} \mathrm{~atm}^{-1}\right)$. Dependences on $\mathrm{pH}$ and $\mathrm{O}_{2}$ are from Williamson and Rimstidt (1994) and apparent activation energy from McKibben and Barnes (1986). [11] See caption a. Corresponding to turnover time of 1, 8 and $1000 \mathrm{yr}$ for decomposition of SOM Classes 1, 2 and 3, respectively (cf. Chen et al., 2010). 
https://doi.org/10.5194/gmd-2022-8

Preprint. Discussion started: 10 February 2022

(c) Author(s) 2022. CC BY 4.0 License.

Table 3. Thermodynamic data for aqueous species ${ }^{\mathrm{a}}$.

\begin{tabular}{|c|c|c|c|c|}
\hline Reaction & $\begin{array}{l}T_{\mathrm{C}}^{\mathrm{ref}} \\
{\left[{ }^{\circ} \mathrm{C}\right]}\end{array}$ & $\begin{array}{l}\log K_{\mathrm{aq}}^{\text {ref }} \\
{\left[\left(\mathrm{mol} \mathrm{L}^{-1}\right)^{y}\right]^{\mathrm{a}}}\end{array}$ & $\begin{array}{l}\Delta H_{\mathrm{aq}} \\
{\left[\mathrm{kJ} \mathrm{mol}^{-1}\right]}\end{array}$ & Ref./note ${ }^{b}$ \\
\hline $\mathrm{SO}_{4}^{2-}+\mathrm{H}^{+}=\mathrm{HSO}_{4}^{-}$ & 25 & 1.988 & 16.11 & 1 \\
\hline $\mathrm{H}^{+}+\mathrm{NO}_{3}^{-}=\mathrm{HNO}_{3}$ & 25 & -1.3 & 0.00 & 2 \\
\hline $\mathrm{Al}^{3+}+\mathrm{H}_{2} \mathrm{O}=\mathrm{Al}(\mathrm{OH})^{2+}+\mathrm{H}^{+}$ & 25 & -5 & 48.07 & 1 \\
\hline $\mathrm{Al}^{3+}+2 \mathrm{H}_{2} \mathrm{O}=\mathrm{Al}(\mathrm{OH})_{2}^{+}+2 \mathrm{H}^{+}$ & 25 & -10.1 & 112.55 & 1 \\
\hline $\mathrm{Al}^{3+}+3 \mathrm{H}_{2} \mathrm{O}=\mathrm{Al}(\mathrm{OH})_{3}+3 \mathrm{H}^{+}$ & 25 & -16.9 & 166.90 & 1 \\
\hline $\mathrm{Al}^{3+}+4 \mathrm{H}_{2} \mathrm{O}=\mathrm{Al}(\mathrm{OH})_{4}^{-}+4 \mathrm{H}+$ & 25 & -22.7 & 176.98 & 1 \\
\hline $\mathrm{Al}^{3+}+\mathrm{SO}_{4}^{2-}=\mathrm{AlSO}_{4}^{+}$ & 25 & 3.5 & 9.58 & 1 \\
\hline $\mathrm{H}_{4} \mathrm{SiO}_{4}=\mathrm{H}_{3} \mathrm{SiO}_{4}^{-}+\mathrm{H}^{+}$ & 25 & -9.83 & 25.61 & 1 \\
\hline $\mathrm{H}_{4} \mathrm{SiO}_{4}=\mathrm{H}_{2} \mathrm{SiO}_{4}^{2-}+2 \mathrm{H}^{+}$ & 25 & -23 & 73.64 & 1 \\
\hline $\mathrm{Mg}^{2+}+\mathrm{H}_{2} \mathrm{O}=\mathrm{Mg}(\mathrm{OH})^{+}+\mathrm{H}^{+}$ & 25 & -11.44 & 66.74 & 1 \\
\hline $\mathrm{Mg}^{2+}+\mathrm{CO}_{3}^{2-}=\mathrm{MgCO}_{3}$ & 25 & 2.98 & 11.35 & 1 \\
\hline $\mathrm{Mg}^{2+}+\mathrm{H}^{+}+\mathrm{CO}_{3}^{2-}=\mathrm{MgHCO}_{3}^{+}$ & 25 & 11.399 & -11.59 & 1 \\
\hline $\mathrm{Mg}^{2+}+\mathrm{SO}_{4}^{2-}=\mathrm{MgSO}_{4}$ & 25 & 2.37 & 19.04 & 1 \\
\hline $\mathrm{Ca}^{2+}+\mathrm{H}_{2} \mathrm{O}=\mathrm{Ca}(\mathrm{OH})^{+}+\mathrm{H}^{+}$ & 25 & -12.78 & 66.74 & 1 \\
\hline $\mathrm{Ca}^{2+}+\mathrm{CO}_{3}^{2-}=\mathrm{CaCO}_{3}$ & 25 & 3.224 & 14.83 & 1 \\
\hline $\mathrm{Ca}^{2+}+\mathrm{H}^{+}+\mathrm{CO}_{3}^{2-}=\mathrm{CaHCO}_{3}^{+}$ & 25 & 11.435 & -3.64 & 1 \\
\hline $\mathrm{Ca}^{2+}+\mathrm{SO}_{4}^{2-}=\mathrm{CaSO}_{4}$ & 25 & 2.25 & 5.54 & 1 \\
\hline $\mathrm{Fe}^{2+}+\mathrm{H}_{2} \mathrm{O}=\mathrm{Fe}(\mathrm{OH})^{+}+\mathrm{H}^{+}$ & 25 & -9.51 & 40.30 & 3 \\
\hline $\mathrm{Fe}^{2+}+\mathrm{CO}_{3}^{2-}=\mathrm{FeCO}_{3}$ & 25 & 5.69 & -45.60 & 3 \\
\hline $\mathrm{Fe}^{2+}+\mathrm{H}^{+}+\mathrm{CO}_{3}^{2-}=\mathrm{FeHCO}_{3}^{+}$ & 25 & 1.47 & -18.00 & 4 \\
\hline $\mathrm{Fe}^{2+}+\mathrm{SO}_{4}^{2-}=\mathrm{FeSO}_{4}$ & 25 & 2.25 & 13.51 & 1 \\
\hline $\mathrm{Fe}^{3+}+\mathrm{H}_{2} \mathrm{O}=\mathrm{Fe}(\mathrm{OH})^{2+}+\mathrm{H}^{+}$ & 25 & -2.19 & 43.51 & 1 \\
\hline $\mathrm{Fe}^{3+}+2 \mathrm{H}_{2} \mathrm{O}=\mathrm{Fe}(\mathrm{OH})_{2}^{+}+2 \mathrm{H}^{+}$ & 25 & -5.67 & 71.55 & 1 \\
\hline $\mathrm{Fe}^{3+}+3 \mathrm{H}_{2} \mathrm{O}=\mathrm{Fe}(\mathrm{OH})_{3}+3 \mathrm{H}^{+}$ & 25 & -12.56 & 103.76 & 1 \\
\hline $\mathrm{Fe}^{3+}+4 \mathrm{H}_{2} \mathrm{O}=\mathrm{Fe}(\mathrm{OH})_{4}^{-}+4 \mathrm{H}^{+}$ & 25 & -21.6 & 133.47 & 1 \\
\hline $\mathrm{Fe}^{3+}+\mathrm{SO}_{4}^{2-}=\mathrm{FeSO}_{4}^{+}$ & 25 & 4.04 & 16.36 & 1 \\
\hline $\mathrm{Na}^{+}+\mathrm{CO}_{3}^{2-}=\mathrm{NaCO}_{3}^{-}$ & 25 & 1.27 & 37.28 & 1 \\
\hline $\mathrm{Na}^{+}+\mathrm{H}^{+}+\mathrm{CO}_{3}^{2-}=\mathrm{NaHCO}_{3}$ & 25 & -0.25 & -4.18 & 5 \\
\hline $\mathrm{Na}^{+}+\mathrm{SO}_{4}^{2-}=\mathrm{NaSO}_{4}^{-}$ & 25 & 0.7 & 4.69 & 1 \\
\hline $\mathrm{K}^{+}+\mathrm{SO}_{4}^{2-}=\mathrm{KSO}_{4}^{-}$ & 25 & 0.85 & 9.41 & 1 \\
\hline $\mathrm{H}_{2} \mathrm{O}=\mathrm{H}^{+}+\mathrm{OH}^{-}$ & 15 & -14.35 & 58.74 & 6 \\
\hline
\end{tabular}

${ }^{\mathrm{a}}$ Thermodynamic constant $\left(K_{\mathrm{aq}}\right)$ is calculated as $K_{\mathrm{aq}}=K_{\mathrm{aq}}^{\mathrm{ref}} \exp \left[-\Delta H_{\mathrm{aq}}\left\{1 /\left(T_{\mathrm{C}}+273.15\right)-1 /\left(T_{\mathrm{C}}^{\mathrm{ref}}+273.15\right)\right\} / \Re\right]$ where $T_{\mathrm{C}}$ is temperature in ${ }^{\circ} \mathrm{C}$ and $\mathfrak{R}$ is the gas constant in units of $\mathrm{kJ} \mathrm{mol}^{-1} \mathrm{~K}^{-1}\left(\Re=8.314 \times 10^{-3} \mathrm{~kJ} \mathrm{~mol}^{-1} \mathrm{~K}^{-1}\right)$. 
https://doi.org/10.5194/gmd-2022-8

Preprint. Discussion started: 10 February 2022

(c) Author(s) 2022. CC BY 4.0 License.

(c) (i)

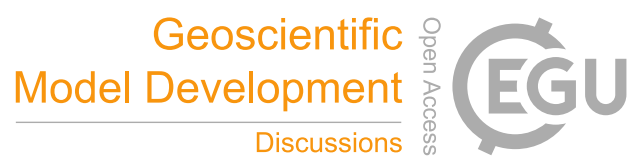

${ }^{\mathrm{b}}$ [1] From phreeqc.dat available in PHREEQC v.3 (Parkhurst and Appelo, 2013). [2] Maggi et al. (2008). Temperature dependence is assumed to be 0. [3] Kanzaki and Murakami (2016). [4] Thermodynamic constant for $\mathrm{Fe}^{2+}+\mathrm{HCO}_{3}^{-}=\mathrm{FeHCO}_{3}^{+}$from Kanzaki and Murakami (2016) divided by that for $\mathrm{HCO}_{3}^{-}=$ $\mathrm{H}^{+}+\mathrm{CO}_{3}^{2-}$ (Table 4). [5] Thermodynamic constant for $\mathrm{Na}^{+}+\mathrm{HCO}_{3}^{-}=\mathrm{NaHCO}_{3}$ from phreeqc.dat available in PHREEQC v.3 (Parkhurst and Appelo, 2013 ) divided by that for $\mathrm{HCO}_{3}^{-}=\mathrm{H}^{+}+\mathrm{CO}_{3}^{2-}$ (Table 4). [6] Kanzaki and Murakami (2015). 
https://doi.org/10.5194/gmd-2022-8

Preprint. Discussion started: 10 February 2022

(c) Author(s) 2022. CC BY 4.0 License.

(c) (i)

Table 4. Thermodynamic data for gaseous species ${ }^{\mathrm{a}}$.

\begin{tabular}{|c|c|c|c|c|}
\hline Reaction & $\begin{array}{l}T_{\mathrm{C}}^{\mathrm{ref}} \\
{\left[{ }^{\circ} \mathrm{C}\right]}\end{array}$ & $\begin{array}{l}\log K_{\text {gas }}^{\text {ref }} \\
{\left[\left(\mathrm{mol} \mathrm{L}^{-1}\right)^{y}\right]^{\text {a }}}\end{array}$ & $\begin{array}{l}\Delta H_{\mathrm{gas}} \\
{\left[\mathrm{kJ} \mathrm{mol}^{-1}\right]}\end{array}$ & Ref./note ${ }^{b}$ \\
\hline $\mathrm{O}_{2}(\mathrm{~g})=\mathrm{O}_{2}(\mathrm{aq})$ & 25 & -2.89 & -13.20 & 1 \\
\hline $\mathrm{CO}_{2}(\mathrm{~g})=\mathrm{CO}_{2}(\mathrm{aq})$ & 15 & -1.34 & -21.33 & 2 \\
\hline $\mathrm{NH}_{3}(\mathrm{~g})=\mathrm{NH}_{3}(\mathrm{aq})$ & 25 & 1.77 & -34.18 & 3 \\
\hline $\mathrm{N}_{2} \mathrm{O}(\mathrm{g})=\mathrm{N}_{2} \mathrm{O}(\mathrm{aq})$ & 15 & 0.03 & -22.22 & 4 \\
\hline \multicolumn{5}{|l|}{$\underline{\text { Dissociations }}$} \\
\hline $\mathrm{CO}_{2}(\mathrm{aq})+\mathrm{H}_{2} \mathrm{O}=\mathrm{HCO}_{3}^{-}+\mathrm{H}^{+}$ & 15 & -6.42 & 11.94 & 2 \\
\hline $\mathrm{HCO}_{3}^{-}=\mathrm{CO}_{3}^{2-}+\mathrm{H}^{+}$ & 15 & -10.43 & 17.00 & 2 \\
\hline $\mathrm{NH}_{4}^{+}=\mathrm{NH}_{3}(\mathrm{aq})+\mathrm{H}^{+}$ & 25 & -9.25 & 52.22 & 3 \\
\hline
\end{tabular}

${ }^{a}$ Thermodynamic constant $\left(K_{\text {gas }}\right)$ is calculated as $K_{\text {gas }}=K_{\text {gas }}^{\text {ref }} \exp \left[-\Delta H_{\text {gas }}\left\{1 /\left(T_{\mathrm{C}}+273.15\right)-1 /\left(T_{\mathrm{C}}^{\text {ref }}+273.15\right)\right\} / \Re\right]$ where $T_{\mathrm{C}}$ is temperature in ${ }^{\circ} \mathrm{C}$ and $\Re$ is the gas constant in units of $\mathrm{kJ} \mathrm{mol}^{-1} \mathrm{~K}^{-1}\left(\Re=8.314 \times 10^{-3} \mathrm{~kJ} \mathrm{~mol}^{-1} \mathrm{~K}^{-1}\right)$.

${ }^{\mathrm{b}}$ [1] Kanzaki and Murakami (2016). [2] Kanzaki and Murakami (2015). [3] From wateq4f.dat available in PHREEQC v.3 (Parkhurst and Appelo, 2013). [4] Weiss and Price (1980). 
https://doi.org/10.5194/gmd-2022-8

Preprint. Discussion started: 10 February 2022

(c) Author(s) 2022. CC BY 4.0 License.

(c) (i)

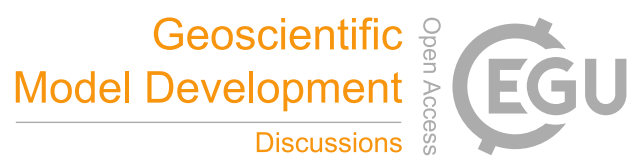

Table 5. Diffusion coefficient for aqueous and gaseous species ${ }^{\text {a }}$.

\begin{tabular}{|c|c|c|c|c|}
\hline Aq./gas. species & $T_{\mathrm{C}}^{\mathrm{ref}}\left[{ }^{\circ} \mathrm{C}\right]$ & $D^{\mathrm{ref}}\left[\mathrm{m}^{2} \mathrm{yr}^{-1}\right]$ & $E_{\mathrm{diff}}^{\mathrm{app}}\left[\mathrm{kJ} \mathrm{mol}{ }^{-1}\right]$ & Ref./note ${ }^{b}$ \\
\hline \multicolumn{5}{|l|}{ Aqueous species } \\
\hline $\mathrm{Fe}(\mathrm{II})$ & 15 & 0.0170 & 19.62 & 1 \\
\hline $\mathrm{Fe}(\mathrm{III})$ & 15 & 0.0157 & 14.34 & 1 \\
\hline $\mathrm{SO}_{4}$ & 15 & 0.0254 & 20.67 & 1 \\
\hline $\mathrm{NO}_{3}$ & 15 & 0.0468 & 18.01 & 1 \\
\hline $\mathrm{Na}$ & 15 & 0.0319 & 20.59 & 1 \\
\hline K & 15 & 0.0480 & 18.72 & 1 \\
\hline $\mathrm{Mg}$ & 15 & 0.0172 & 18.52 & 1 \\
\hline $\mathrm{Si}$ & 15 & 0.0268 & 22.71 & 2 \\
\hline $\mathrm{Ca}$ & 15 & 0.0190 & 20.22 & 1 \\
\hline $\mathrm{Al}$ & 15 & 0.0117 & 21.28 & 1 \\
\hline \multicolumn{5}{|l|}{ Gaseous species } \\
\hline $\mathrm{O}_{2}(\mathrm{~g})$ & 15 & 609.00 & 4.18 & 3 \\
\hline $\mathrm{CO}_{2}(\mathrm{~g})$ & 15 & 441.50 & 4.18 & 4 \\
\hline $\mathrm{NH}_{3}(\mathrm{~g})$ & & & & 5 \\
\hline $\mathrm{N}_{2} \mathrm{O}(\mathrm{g})$ & 15 & 441.50 & 4.18 & 6 \\
\hline \multicolumn{5}{|l|}{ Dissolved forms } \\
\hline $\mathrm{O}_{2}(\mathrm{aq})$ & 15 & 0.0549 & 20.07 & 3 \\
\hline $\mathrm{CO}_{2}(\mathrm{aq})$ & 15 & 0.0225 & 21.01 & 1,7 \\
\hline $\mathrm{NH}_{3}(\mathrm{aq})$ & 15 & 0.0464 & 19.15 & 8 \\
\hline $\mathrm{N}_{2} \mathrm{O}(\mathrm{aq})$ & 15 & 0.0489 & 20.33 & 9 \\
\hline
\end{tabular}

${ }^{\text {a }}$ Diffusion coefficient is calculated as $D=D^{\text {ref }} \exp \left[-E_{\text {diff }}^{\text {app }}\left\{1 /\left(T_{\mathrm{C}}+273.15\right)-1 /\left(T_{\mathrm{C}}^{\text {ref }}+273.15\right)\right\} / \Re\right]$ where $T_{\mathrm{C}}$ is temperature in ${ }^{\circ} \mathrm{C}$ and $\Re$ is the gas constant in units of $\mathrm{kJ} \mathrm{mol}^{-1} \mathrm{~K}^{-1}\left(\mathfrak{R}=8.314 \times 10^{-3} \mathrm{~kJ} \mathrm{~mol}^{-1} \mathrm{~K}^{-1}\right)$ except for $\mathrm{NH}_{3}$ gas. A power function of temperature is assumed for $\mathrm{NH}_{3}$ gas from Massman (1998): $D$ $=624\left\{\left(T_{\mathrm{C}}+273.15\right) / 273.15\right\}^{1.81}\left(\mathrm{~m}^{2} \mathrm{yr}^{-1}\right)$.

b [1] From Li and Gregory (1974). [2] From Rebreanu et al. (2008). [3] Kanzaki and Murakami (2016). [4] A value of $0.14 \mathrm{~cm}^{2} \mathrm{~s}^{-1}$ is assumed (e.g., Pritchard and Currie, 1982) and apparent activation energy is assumed to be the same as that for $\mathrm{O}_{2}$ gas. [5] Massman (1998). See cation a. [6] Assumed to be the same as $\mathrm{CO}_{2}$ diffusion (e.g., Pritchard and Currie, 1982). [7] Diffusion coefficient of $\mathrm{CO}_{3}^{2-}$ is assumed to be the same as that of aqueous $\mathrm{CO}_{2}$. [8] $\mathrm{NH}_{4}^{+}$ diffusion from Schulz and Zabel (2005). [9] From Schulz and Zabel (2005). 
https://doi.org/10.5194/gmd-2022-8

Preprint. Discussion started: 10 February 2022

(c) Author(s) 2022. CC BY 4.0 License.

(c) (i)

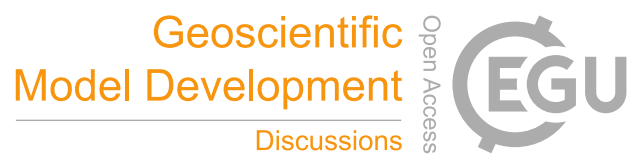

Table 6. Extra reactions and their kinetic laws.

\begin{tabular}{llll}
\hline ID & Reaction & Rate law $^{a}$ & \\
\hline fe2o2 & $\mathrm{Fe}(\mathrm{II})+(1 / 4) \mathrm{O}_{2}+(1 / 2) \mathrm{H}_{2} \mathrm{O}$ & $\phi \sigma \ell\left(4.20 \times 10^{19}\left[\mathrm{OH}^{-}\right]^{2}+5.26 \times 10^{-2}\right) c_{\mathrm{Fe}(\mathrm{II})} p_{\mathrm{O}_{2}}$ & Ref./note $^{\mathrm{b}}$ \\
& $\rightarrow \mathrm{Fe}(\mathrm{III})+\mathrm{OH}$ & & 1 \\
$\mathrm{amo} 2 \mathrm{O}$ & $\mathrm{NH}_{4}^{+}+2 \mathrm{O}_{2} \rightarrow \mathrm{NO}_{3}^{-}+\mathrm{H}_{2} \mathrm{O}+2 \mathrm{H}^{+}$ & $301 c_{\mathrm{NH}_{4}^{+}} /\left(c_{\mathrm{NH}_{4}^{+}}+1.4 \times 10^{-4}\right) H_{\mathrm{O}_{2}} p_{\mathrm{O}_{2}} /\left(H_{\mathrm{O}_{2}} p_{\mathrm{O}_{2}}+2.41 \times 10^{-5}\right) \times \min (2 \sigma, 1) \times \exp \left(-(\mathrm{pH}-7)^{2} / 2\right)$ & 2 \\
$\mathrm{~g} 2 \mathrm{n} 21$ & $2 \mathrm{NO}_{3}^{-}+2 \mathrm{CH}_{2} \mathrm{O}+2 \mathrm{H}^{+}$ & $3.88 m_{\mathrm{gg} 2} /\left(m_{\mathrm{g} 2}+100\right) c_{\mathrm{NO}_{3}^{-}}^{-} /\left(c_{\mathrm{NO}_{3}^{-}}+1.13 \times 10^{-4}\right) \times 2.52 \times 10^{-5} /\left(H_{\mathrm{O}_{2}} p_{\mathrm{O}_{2}}+2.52 \times 10^{-5}\right) \times \min (2 \sigma, 1) \times \exp \left(-(\mathrm{pH}-7)^{2} / 2\right)$ & 2 \\
& $\rightarrow \mathrm{N}_{2} \mathrm{O}+2 \mathrm{CO}_{2}+3 \mathrm{H}_{2} \mathrm{O}$ & & 2 \\
$\mathrm{~g} 2 \mathrm{n} 22$ & $2 \mathrm{~N}_{2} \mathrm{O}+\mathrm{CH}_{2} \mathrm{O} \rightarrow 2 \mathrm{~N}_{2}+\mathrm{CO}_{2}+\mathrm{H}_{2} \mathrm{O}$ & $3.88 m_{\mathrm{g} 2} /\left(m_{\mathrm{g} 2}+100\right) c_{\mathrm{N}_{2} \mathrm{O}} /\left(c_{\mathrm{N}_{2} \mathrm{O}}+1.13 \times 10^{-4}\right) \times 2.52 \times 10^{-5} /\left(c_{\mathrm{NO}_{3}^{-}}+2.52 \times 10^{-5}\right) \times \min (2 \sigma, 1) \times \exp \left(-(\mathrm{pH}-7)^{2} / 2\right)$ & \\
\hline
\end{tabular}

${ }^{\mathrm{a}}$ Given in units of $\mathrm{mol} \mathrm{m}^{-3} \mathrm{yr}^{-1}$.

${ }^{\mathrm{b}}$ [1] Singer and Stumm (1970). [2] After Maggi et al. (2007). A liner pH function is fitted to an exponential function. 
https://doi.org/10.5194/gmd-2022-8

Preprint. Discussion started: 10 February 2022

(c) Author(s) 2022. CC BY 4.0 License.

(c) (i)

Table 7. Boundary conditions for example simulations.

\begin{tabular}{|c|c|c|c|c|c|c|c|c|c|c|c|c|c|c|c|c|}
\hline \multirow[t]{2}{*}{ Figure } & \multicolumn{3}{|l|}{ Chosen species } & \multirow{2}{*}{$\begin{array}{l}\text { Extra } \\
\text { rxn. }{ }^{\text {a }}\end{array}$} & \multicolumn{2}{|c|}{ Rain $\left[\mathrm{g} \mathrm{m}^{-2} \mathrm{yr}^{-1}\right]$} & \multirow[t]{2}{*}{$N^{\mathrm{c}}$} & \multirow{2}{*}{$\begin{array}{l}z_{\text {tot }} \\
{[\mathrm{m}]^{\mathrm{c}}}\end{array}$} & \multirow{2}{*}{$\begin{array}{l}w \\
{\left[10^{-5}\right.} \\
\left.\mathrm{m} \mathrm{yr}^{-1}\right]\end{array}$} & \multirow{2}{*}{$\begin{array}{l}\text { Bio- } \\
\text { mixing } \\
\left(z_{\mathrm{ml}}[\mathrm{m}]\right)\end{array}$} & \multirow{2}{*}{$\begin{array}{l}\log r_{\mathrm{H}} \\
{[\mathrm{m}]^{\mathrm{d}}}\end{array}$} & \multirow{2}{*}{$\begin{array}{l}q \\
{\left[\mathrm{~m} \mathrm{yr}^{-1}\right]}\end{array}$} & \multirow{2}{*}{$\begin{array}{l}z_{\text {sat }} \\
{[\mathrm{m}]^{\mathrm{c}}}\end{array}$} & \multirow[t]{2}{*}{$\sigma_{0}{ }^{\mathrm{c}}$} & \multirow[t]{2}{*}{$\phi_{0}{ }^{\mathrm{c}}$} & \multirow[t]{2}{*}{ Note $^{e}$} \\
\hline & Solid $^{\text {a }}$ & Aqueous & Gas & & $\mathrm{OM}$ & Dust $^{b}$ & & & & & & & & & & \\
\hline 2 & py, gt & $\mathrm{Fe}(\mathrm{II}), \mathrm{Fe}(\mathrm{III}), \mathrm{SO}_{4}$ & $\mathrm{O}_{2}$ & fe 202 & 0 & 0 & 30 & 2 & 5 & No & -5 & 0.01 & 1 & 0.1 & 0.1 & $1,2,4$ \\
\hline 3,4 & $\begin{array}{l}\text { amsi, qrtz, cc, dlm, } \\
\text { kfs, ab, dp, tm, ill, } \\
\text { cabd, ka }\end{array}$ & $\begin{array}{l}\mathrm{Na}, \quad \mathrm{K}, \quad \mathrm{Si}, \quad \mathrm{Al}, \\
\mathrm{Fe}(\mathrm{III}), \mathrm{Ca}, \mathrm{Mg}\end{array}$ & $\mathrm{CO}_{2}$ & & 0 & 0 & 30 & 0.5 & 8.69 & No & -5 & 0.422 & 1000 & 0.501 & 0.5 & $1,2,5$ \\
\hline 6,7 & $\begin{array}{l}\text { amsi, qrtz, cc, dlm, } \\
\text { kfs, ab, dp, tm, ill, } \\
\text { cabd, ka, g2 }\end{array}$ & $\begin{array}{l}\mathrm{Na}, \quad \mathrm{K}, \quad \mathrm{Si}, \quad \mathrm{Al}, \\
\mathrm{Fe}(\mathrm{III}), \mathrm{Ca}, \mathrm{Mg}\end{array}$ & $\begin{array}{l}\mathrm{O}_{2} \\
\mathrm{CO}_{2}\end{array}$ & & 899 & 0 & 30 & 0.5 & 8.69 & $\begin{array}{l}\text { Fickian } \\
(0.25)\end{array}$ & -5 & 0.422 & 1000 & 0.501 & 0.5 & $1,2,5$ \\
\hline 8,9 & $\begin{array}{l}\text { amsi, qrtz, cc, dlm, } \\
\text { kfs, ab, dp, tm, ill, } \\
\text { cabd, ka, g2, fo, fa, } \\
\text { an, gt }\end{array}$ & $\begin{array}{l}\mathrm{Na}, \mathrm{K}, \mathrm{Si}, \mathrm{Al}, \\
\mathrm{Fe}(\mathrm{II}), \mathrm{Fe}(\mathrm{III}), \mathrm{Ca}, \\
\mathrm{Mg}\end{array}$ & $\begin{array}{l}\mathrm{O}_{2} \\
\mathrm{CO}_{2}\end{array}$ & fe 202 & 899 & 4000 & 30 & 0.5 & 8.69 & $\begin{array}{l}\text { Fickian } \\
(0.25)\end{array}$ & -5 & 0.422 & 1000 & 0.501 & 0.5 & $1,2,5$ \\
\hline $10-12$ & $\begin{array}{l}\text { amsi, qrtz, cc, dlm, } \\
\text { kfs, ab, dp, tm, ill, }\end{array}$ & $\begin{array}{l}\mathrm{Na}, \quad \mathrm{K}, \quad \mathrm{Si}, \quad \mathrm{Al}, \\
\mathrm{Fe}(\mathrm{II}), \mathrm{Fe}(\mathrm{III}), \mathrm{Ca},\end{array}$ & $\begin{array}{l}\mathrm{O}_{2} \\
\mathrm{CO}_{2}\end{array}$ & fe 202 & 899 & 4000 & 30 & 0.5 & 8.69 & $\begin{array}{l}\text { Fickian } \\
(0.25)\end{array}$ & $\begin{array}{l}-5 \\
\text { (PSD) }\end{array}$ & 0.422 & 1000 & 0.501 & 0.5 & $1,2,5,6$ \\
\hline
\end{tabular}

cabd, ka, g2, fo, fa, $\mathrm{Mg}$

an, gt

${ }^{a}$ Only IDs of solid species and extra reactions are denoted (Tables 1 and 6).

${ }^{\mathrm{b}}$ Composition of dust is assumed to be the basalt composition by Beerling et al. (2020).

${ }^{\mathrm{c}} N$ is the number of grid points, $z_{\text {tot }}$ is the bottom depth of simulated soil, $z_{\text {sat }}$ is the depth of water table, $\sigma_{0}$ is the surface water saturation ratio and $\phi_{0}$ is the initial porosity.

${ }^{\mathrm{d}}$ When surface area is calculated based on tracked particle size distributions, 'PSD' is denoted.

${ }^{\text {e }}$ [1] Rainwater composition is assumed to be those of pure water saturated with respect to atmospheric $\mathrm{CO}_{2}$ and $\mathrm{O}_{2}$. [2] Atmospheric $\mathrm{CO}_{2}$ and $\mathrm{O}_{2}$ are assumed to be $3.16 \times 10^{-4}$ and $0.21 \mathrm{~atm}$, respectively. [3] Parent rock concentrations of albite and kaolinite are 10 and $10^{-3}$ wt $\%$, respectively. [4] Parent rock concentrations of pyrite and goethite are 0.56 and $10^{-3} \mathrm{wt} \%$, respectively. [5] Parent rock concentrations of solid species are from those for Site 1 in Table 8. [6] Abiotic weathering, biotic weathering and basalt application experiments in Figs. 3, 4 and 6-8 are repeated with surface area parameterization based on tracked particle size distributions for bulk soil (Fig. 10). The same basalt application experiment was conducted except with tracking PSDs for individual solid species and calculating corresponding specific surface areas (Figs. 11 and 12). 
https://doi.org/10.5194/gmd-2022-8

Preprint. Discussion started: 10 February 2022

(c) Author(s) 2022. CC BY 4.0 License.

(c) (i)

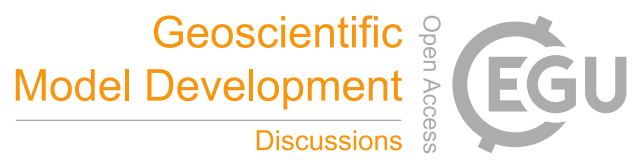

Table 8. Boundary conditions for natural weathering sites.

\begin{tabular}{|c|c|c|c|c|c|c|c|c|c|c|c|c|c|c|c|c|c|c|c|}
\hline \multirow{2}{*}{$\begin{array}{l}\text { Site } \\
\text { ID }\end{array}$} & \multicolumn{14}{|c|}{ Solid species $[\mathrm{wt} \%]^{\mathrm{a}}$} & \multirow{2}{*}{$w^{\mathrm{b}}$} & \multirow{2}{*}{$q^{\mathrm{b}}$} & \multirow{2}{*}{$\sigma_{0}{ }^{\mathrm{b}}$} & \multirow{2}{*}{$T_{\mathrm{C}}^{\mathrm{b}}$} & \multirow{2}{*}{$\begin{array}{l}\text { OM } \\
\text { rain } \\
b, c\end{array}$} \\
\hline & amsi & $\arg$ & $\mathrm{cc}$ & $\mathrm{dlm}$ & $\mathrm{hm}$ & $\mathrm{tm}$ & ka & $\mathrm{dp}$ & qrtz & ill & cabd & $\mathrm{kfs}$ & $a b$ & anl & & & & & \\
\hline 1 & 33.286 & 0.000 & 4.853 & 2.315 & 0.000 & 2.338 & 3.138 & 12.826 & 26.886 & 10.067 & 1.396 & 4.735 & 19.266 & 0.000 & 8.69 & 0.422 & 0.501 & 5.969 & 899 \\
\hline 2 & 18.854 & 0.645 & 4.901 & 3.861 & 1.698 & 2.508 & 3.776 & 5.482 & 64.426 & 19.885 & 3.640 & 0.454 & 2.118 & 1.240 & 4.17 & 0.498 & 0.624 & 7.594 & 936 \\
\hline 3 & 38.390 & 0.000 & 5.533 & 3.461 & 0.466 & 0.605 & 2.548 & 4.957 & 31.607 & 12.949 & 2.696 & 2.503 & 10.525 & 1.301 & 7.67 & 0.211 & 0.420 & 3.655 & 797 \\
\hline
\end{tabular}

${ }^{\text {a }}$ Solid species denoted as amorphous, hornblende, pyroxene, $10 \AA$ clay, $14 \AA$ clay, plagioclase and zeolite phases in the original data are assumed to be amorphous $\mathrm{Si}$, tremolite, diopside, illite, Ca-beidellite, albite and analcime, respectively. Solid species are denoted with ID in Table 1.

${ }^{\mathrm{b}} w$ is the uplift rate in units of $10^{-5} \mathrm{~m} \mathrm{yr}^{-1}$ (Larsen et al., 2014), $q$ is the net water flux to sites in units of $\mathrm{m} \mathrm{yr}^{-1}$ (Fekete et al., 2002), $\sigma_{0}$ is the surface water saturation ratio, $T_{\mathrm{C}}$ is temperature in ${ }^{\circ} \mathrm{C}$ (Fick and Hijimans, 2017) and $\mathrm{OM}$ rain value is provided with units of $\mathrm{g} \mathrm{C} \mathrm{m}^{-2} \mathrm{yr}^{-1}$.

${ }^{\mathrm{c}}$ Obtained as 1.5 times the net primary production following Beerling et al. (2020). 
https://doi.org/10.5194/gmd-2022-8

Preprint. Discussion started: 10 February 2022

(C) Author(s) 2022. CC BY 4.0 License.

(c) (i)

Table 9. Observed soil depth profiles of $\mathrm{OM}$ and $\mathrm{pH}^{*}$.

\begin{tabular}{rrrrr}
\hline \multirow{2}{*}{ Depth $[\mathrm{m}]$} & \multicolumn{2}{c}{ OM [wt\%] } & \multicolumn{2}{c}{$\mathrm{pH}$} \\
\cline { 2 - 5 } & Site 2 & \multicolumn{1}{c}{ Site 3 } & Site 2 & Site 3 \\
\hline 0.00 & 26.5 & 0.0534 & 4.46 & 8.17 \\
0.05 & 12.0 & 0.515 & 4.37 & 8.22 \\
0.15 & 4.43 & 0.477 & 4.47 & 8.21 \\
0.30 & 1.65 & 0.284 & 4.76 & 8.29 \\
0.60 & 1.00 & 0.165 & 4.85 & 8.38 \\
1.00 & 0.797 & 0.0411 & 4.91 & 8.40 \\
2.00 & 0.767 & 0.0171 & 5.04 & 8.42
\end{tabular}

* From Hengl et al. (2017). 

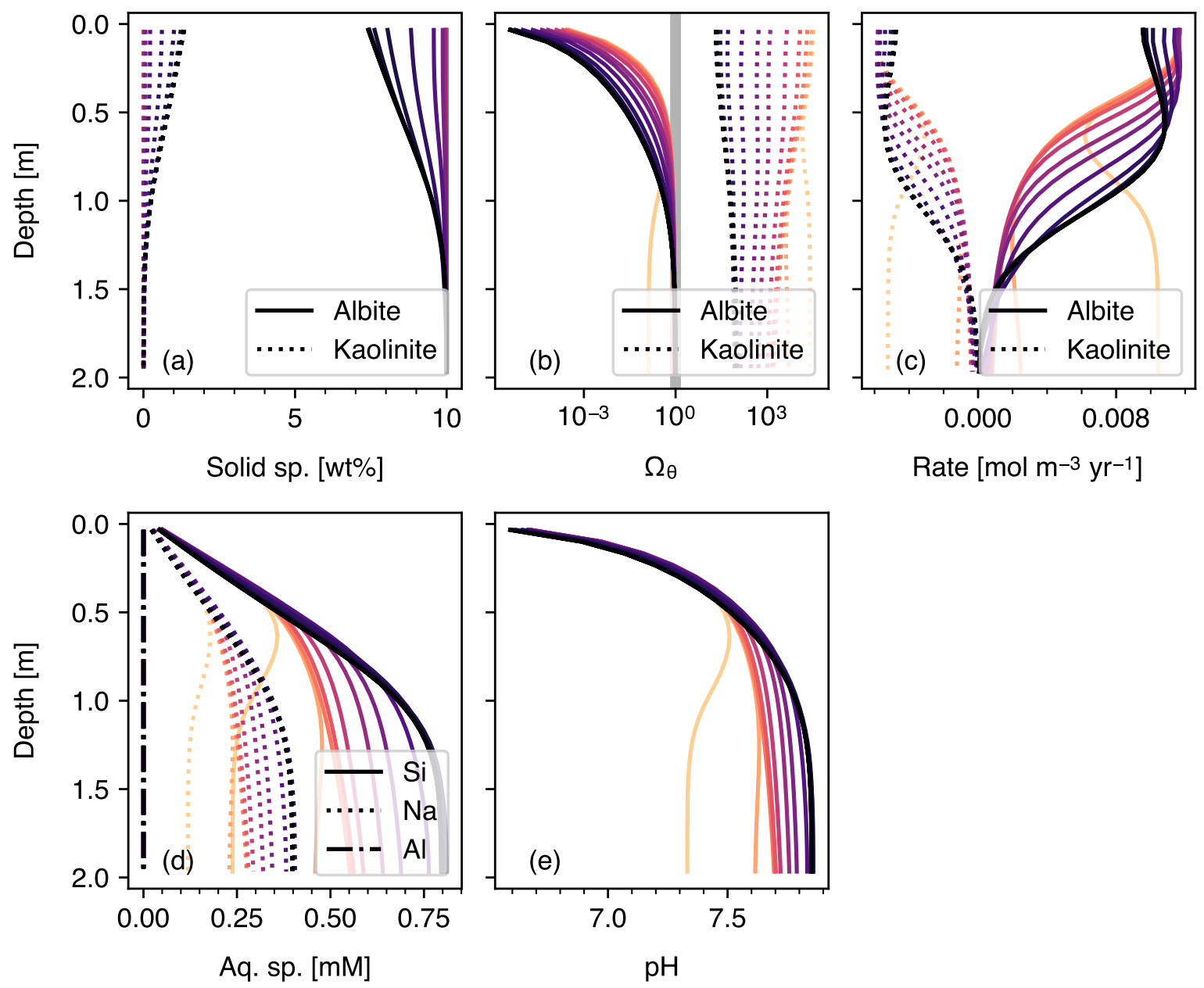

Rate [mol m-3 $\mathrm{yr}^{-1}$ ]

Aq. sp. [mM]
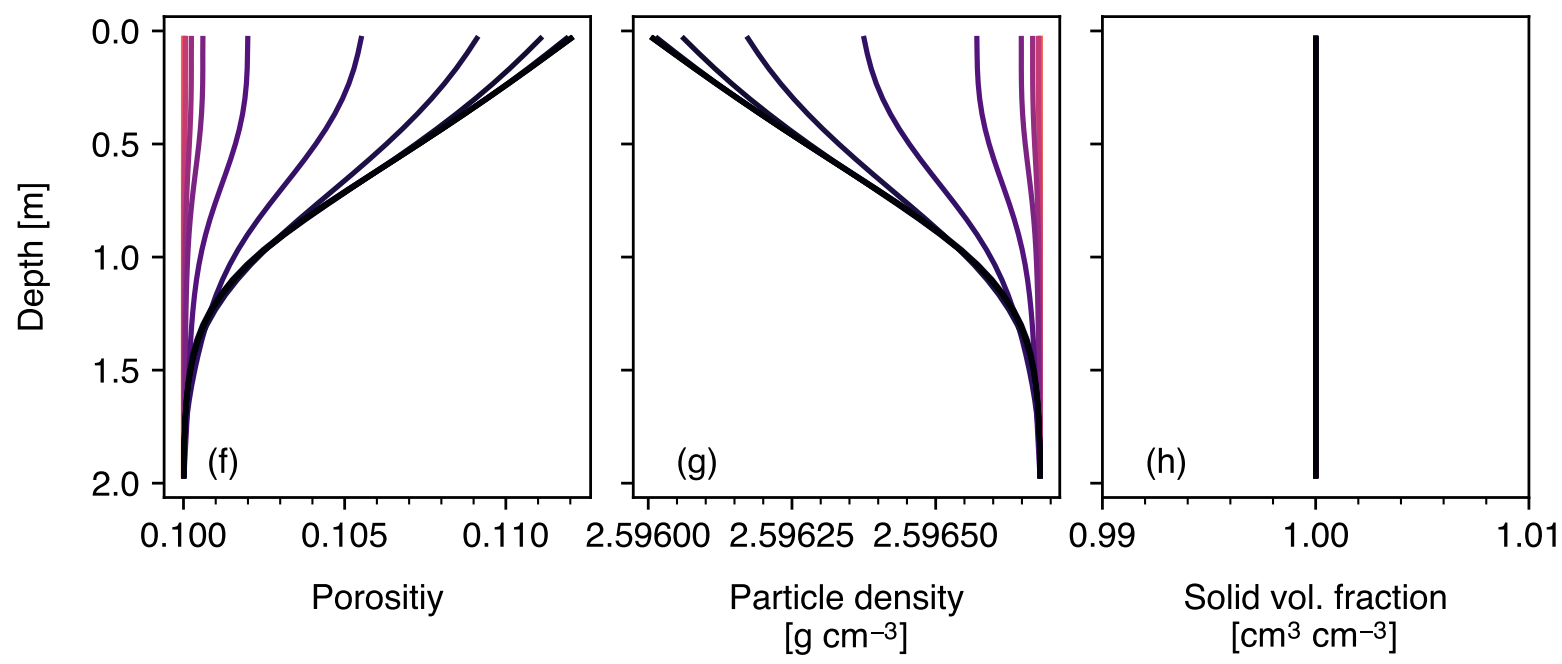

Figure 1: Simulation of abiotic weathering of albite. Soil concentrations, saturation states and dissolution/precipitation rates of solid species are plotted in a-c, respectively; porewater concentrations of aqueous species and $\mathrm{pH}$ in $\mathrm{d}$ and e, respectively; soil porosity and particle density in $\mathrm{f}$ and $\mathrm{g}$, respectively; and ratio of total volume of solid species against solid space specified with porosity in $h$. See Table 7 for the details on the boundary conditions of the simulation. 

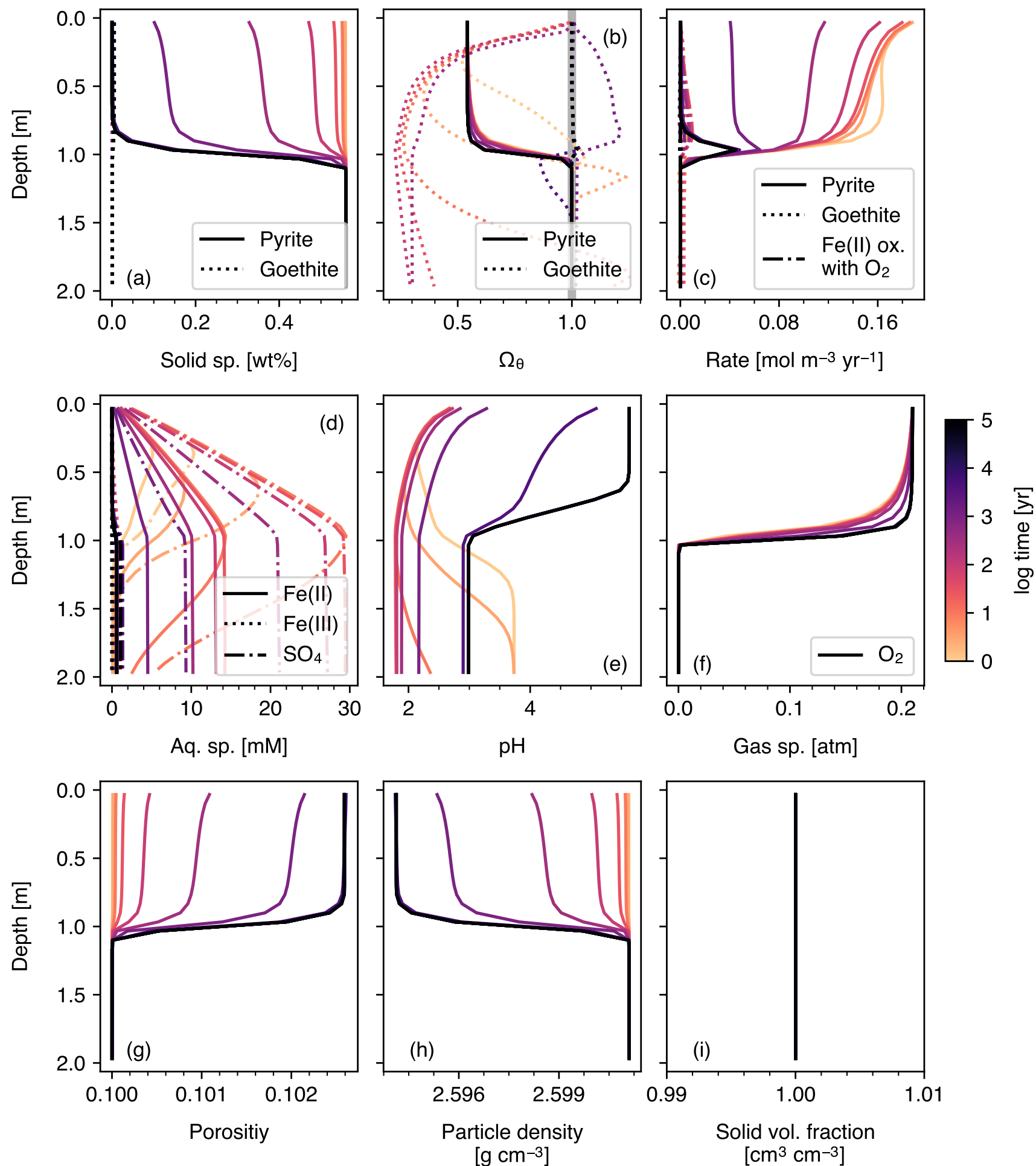

Figure 2: Simulation of abiotic weathering of pyrite. Soil concentrations and saturation states of solid species are plotted in a and $\mathrm{b}$, respectively; rate profile of reactions within soil in c; porewater concentrations of aqueous species and $\mathrm{pH}$ in $\mathrm{d}$ and $\mathrm{e}$, respectively; concentrations of soil gases in $f$; soil porosity and particle density in $g$ and $h$, respectively; and ratio of total volume of solid species against solid space specified with porosity in i. See Table 7 for the details on the boundary conditions of the simulation. 
https://doi.org/10.5194/gmd-2022-8

Preprint. Discussion started: 10 February 2022

(c) Author(s) 2022. CC BY 4.0 License.

(C) (1)
Geoscientific

Model Development

Discussions
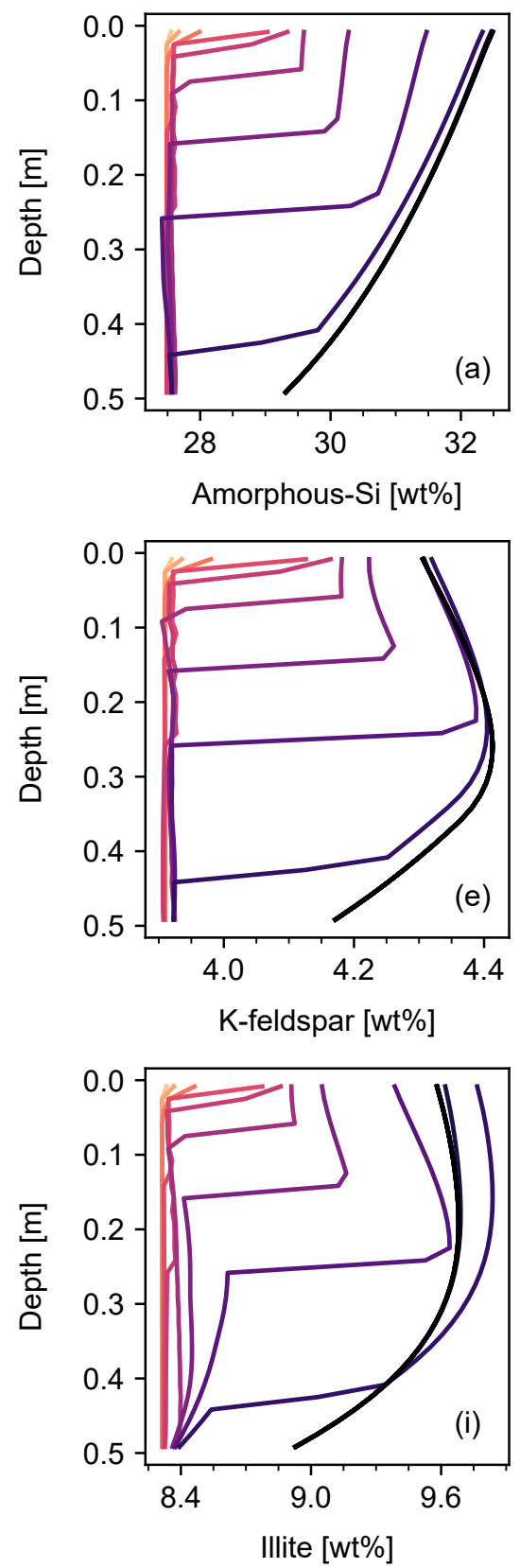
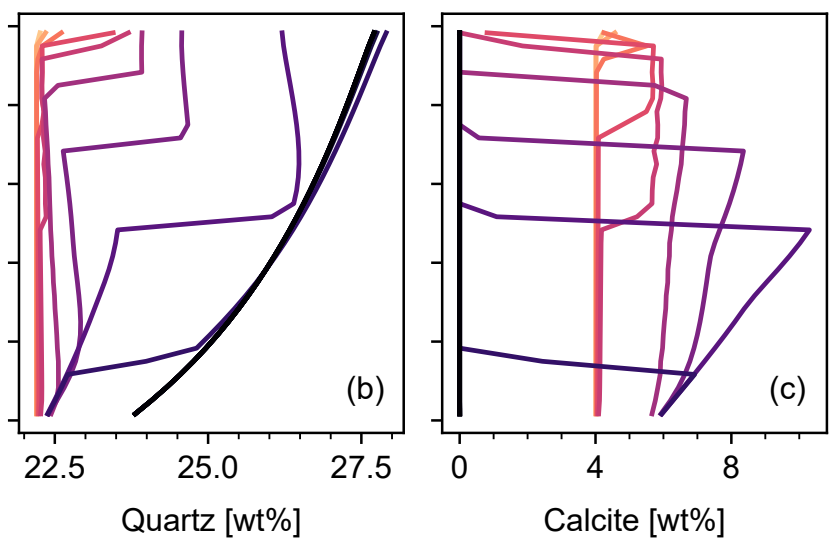

(c)
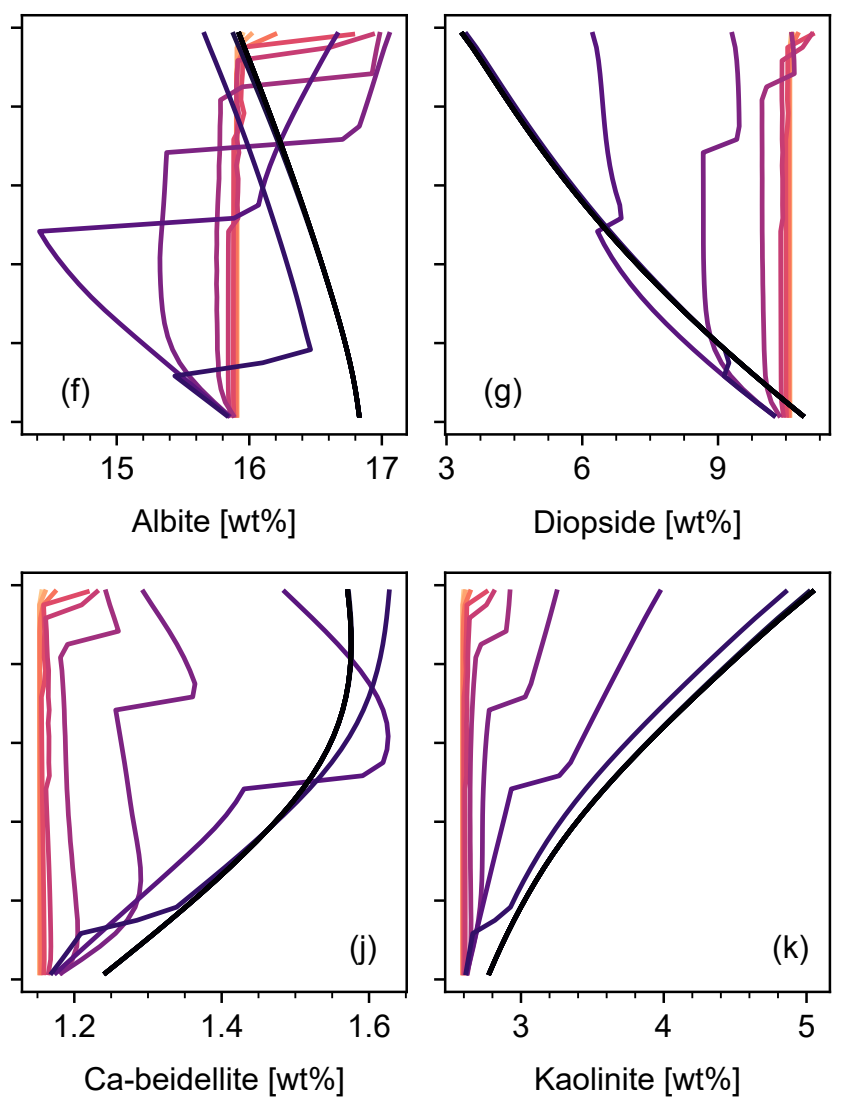
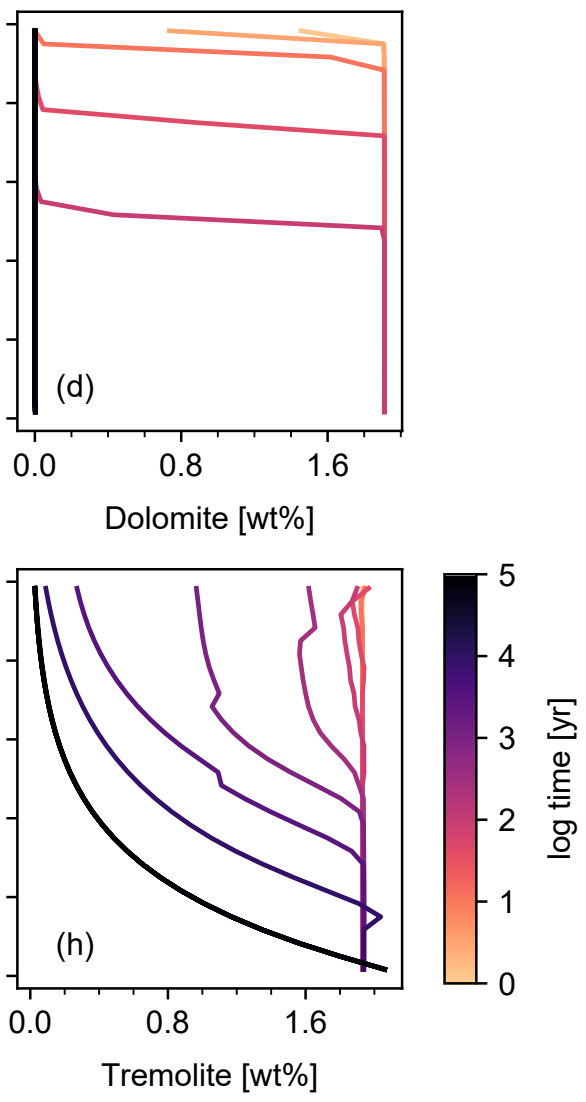

Figure 3: Soil concentrations of solid species in simulation of abiotic weathering at Site 1 in Table 8 . See Table 7 for the details on the boundary conditions of the simulation. 


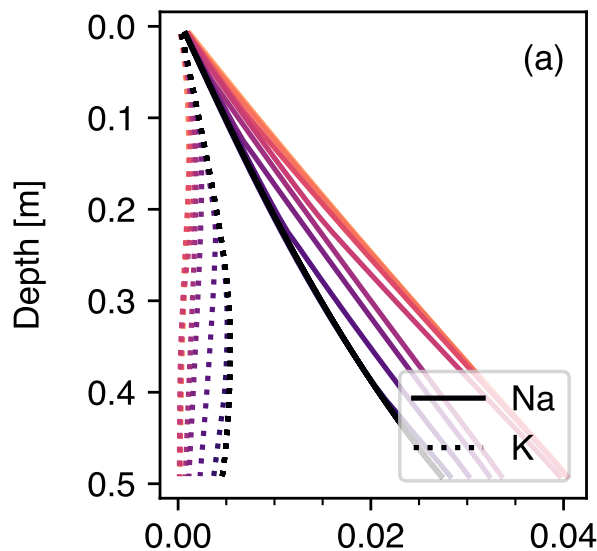

Aq. sp. $[\mathrm{mM}]$

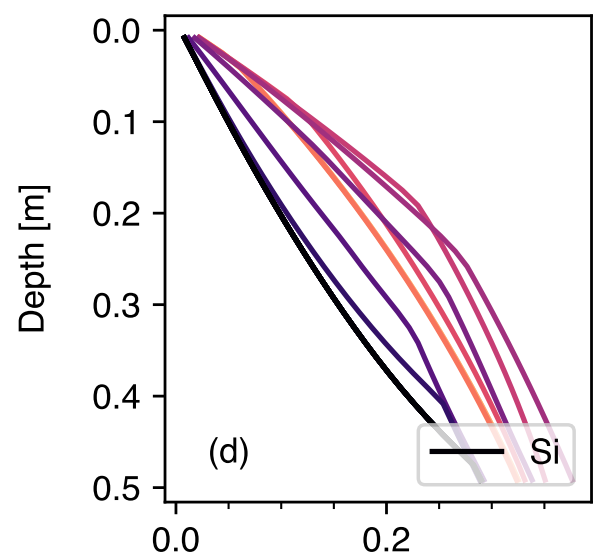

Aq. sp. [mM]

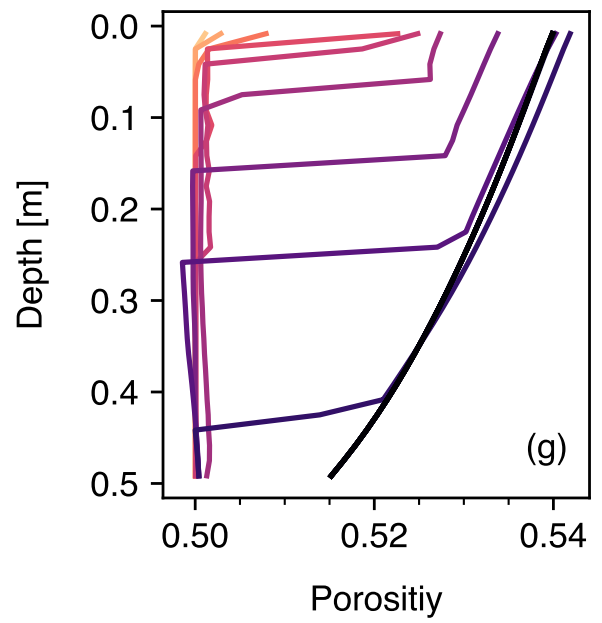

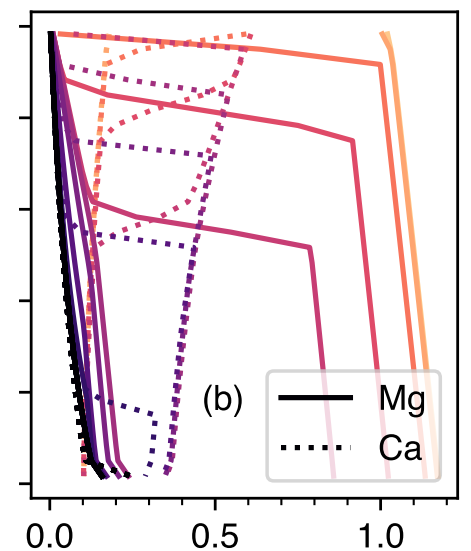

Aq. sp. [mM]

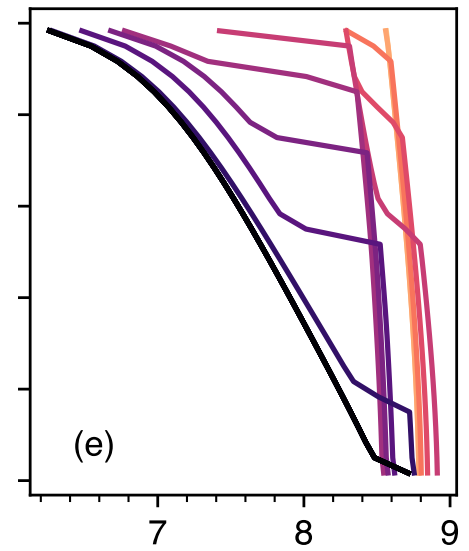

$\mathrm{pH}$

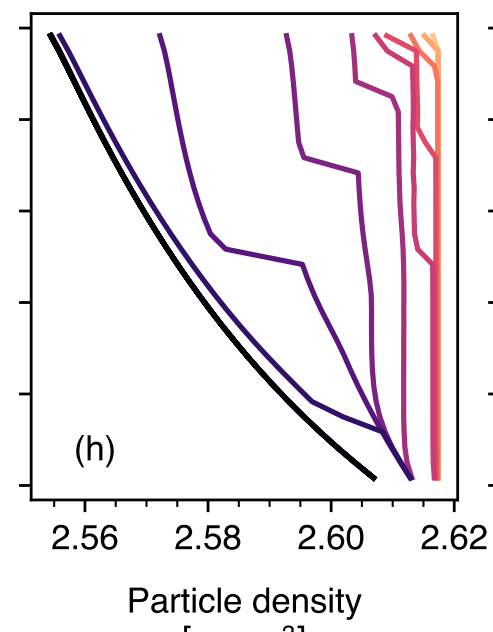

$\left[\mathrm{g} \mathrm{cm}^{-3}\right]$

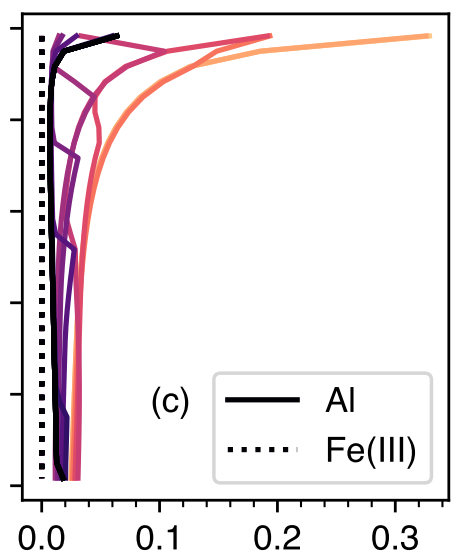

Aq. sp. $[\mu \mathrm{M}]$

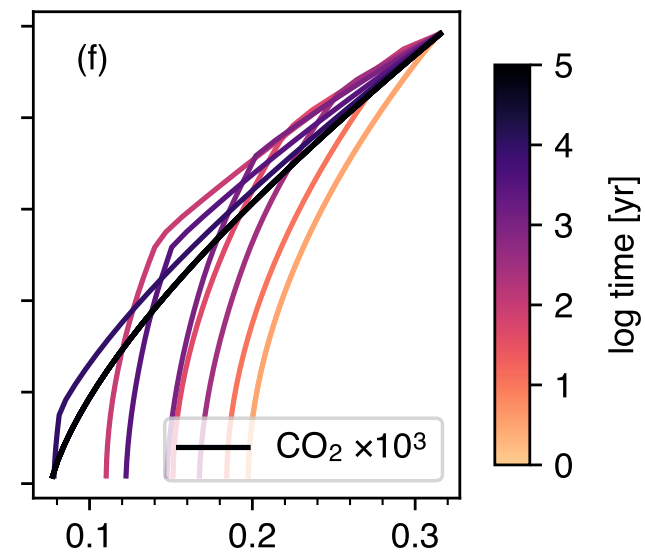

Gas sp. [atm]

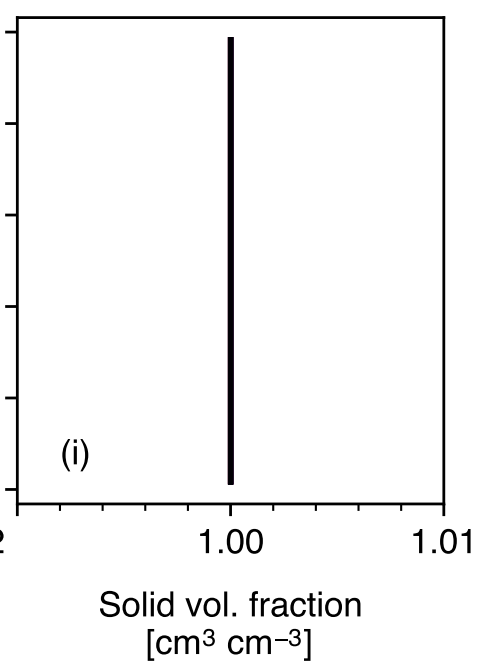

Figure 4: Simulation of abiotic weathering at Site 1 in Table 8. Porewater concentrations of aqueous species and pH are plotted in a-d and e, respectively; concentrations of soil gases in $f$; soil porosity and particle density in $f$ and g, respectively; and ratio of total volume of solid species against solid space specified with porosity in $h$. See Table 7 for the details on the boundary conditions of the simulation. 
https://doi.org/10.5194/gmd-2022-8

Preprint. Discussion started: 10 February 2022

(c) Author(s) 2022. CC BY 4.0 License.

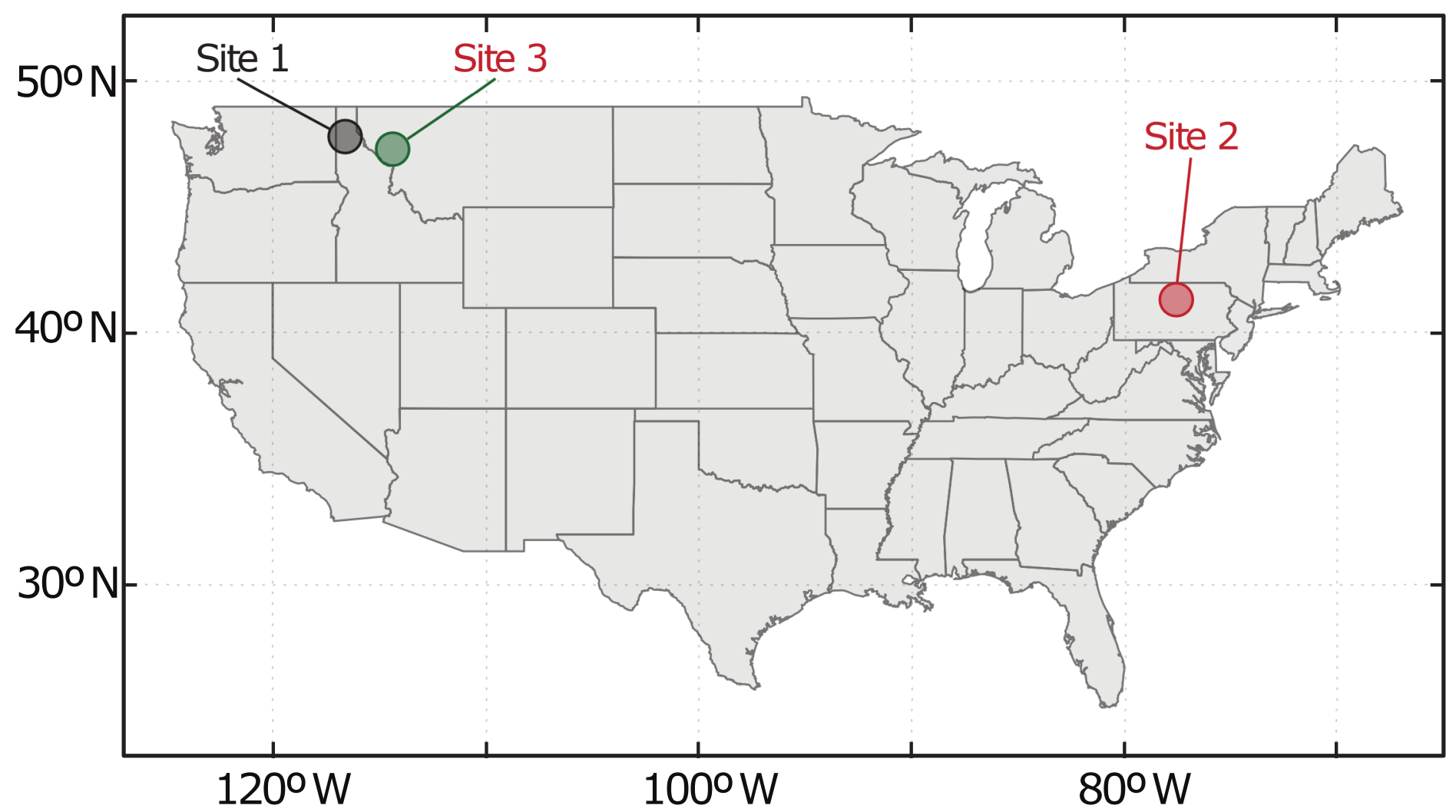

Figure 5: Locations of natural weathering sites whose boundary conditions are tabulated in Table 8 and utilized for example simulations in Section 3. 
https://doi.org/10.5194/gmd-2022-8

Preprint. Discussion started: 10 February 2022

(c) Author(s) 2022. CC BY 4.0 License.

(c) (1)
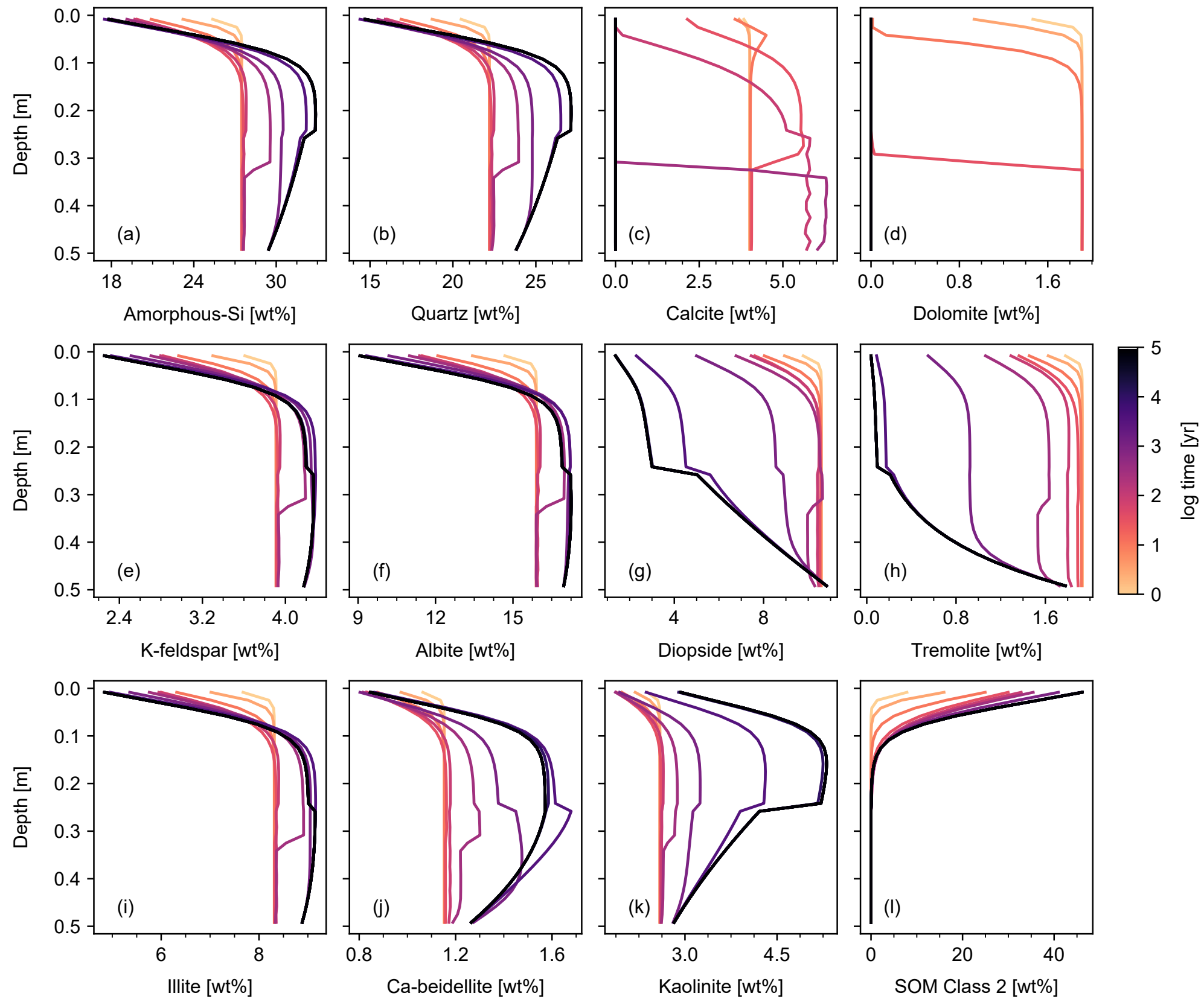

Figure 6: Simulation of biotic weathering at Site 1 in Table 8. Shown are concentrations of simulated solid species. Note that the model configuration is the same as that for Fig. 3 except that soil respiration and bio-mixing are included. 


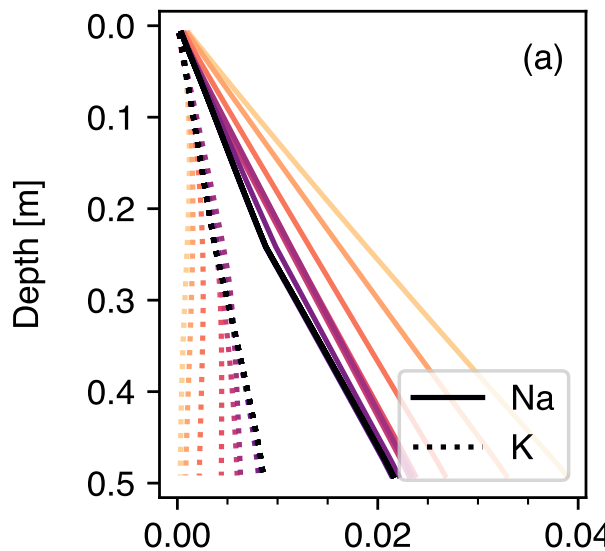

Aq. sp. [mM]

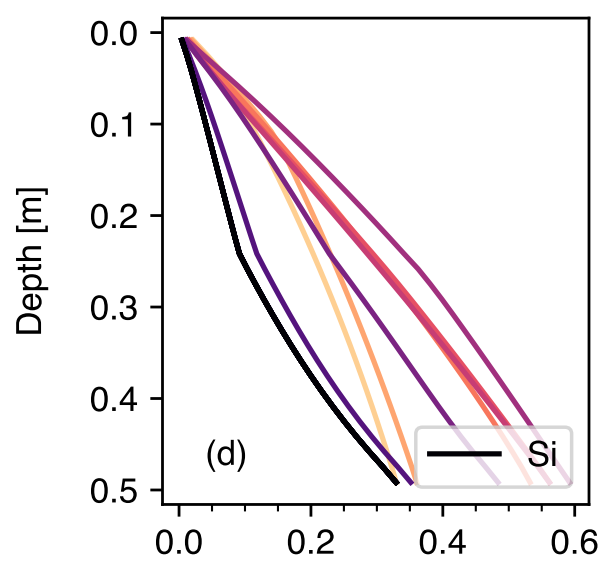

Aq. sp. [mM]

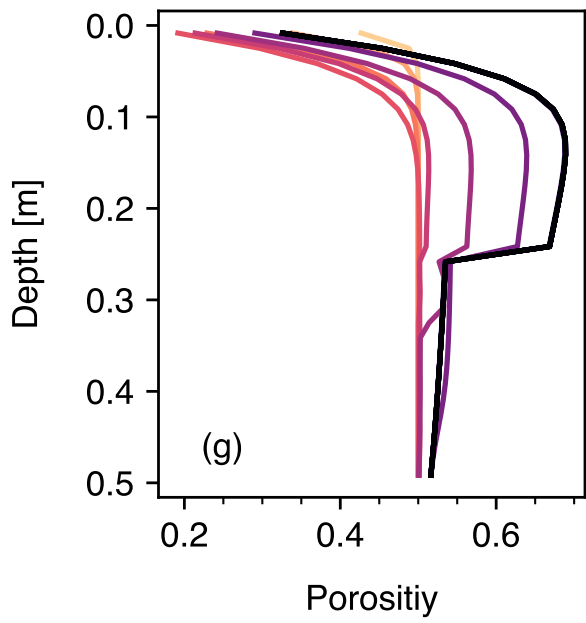

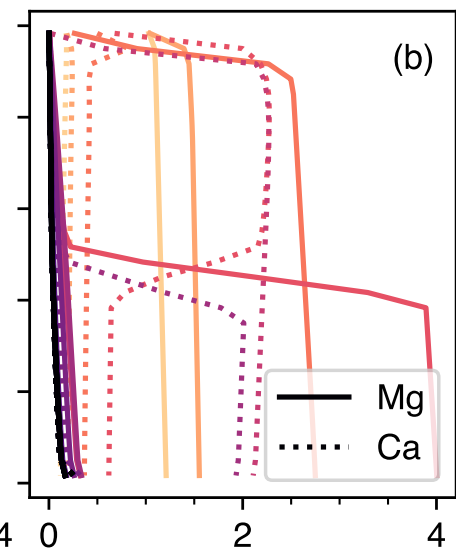

Aq. sp. [mM]

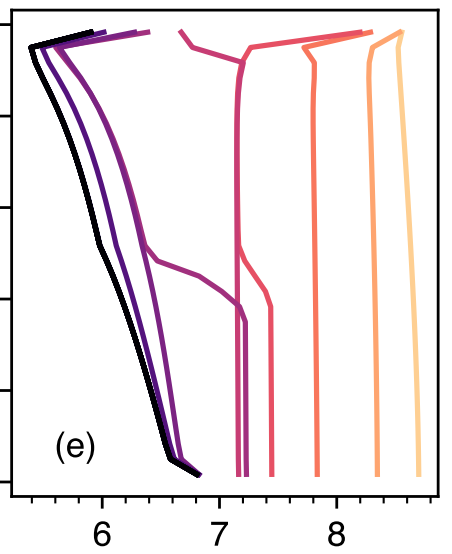

$\mathrm{pH}$

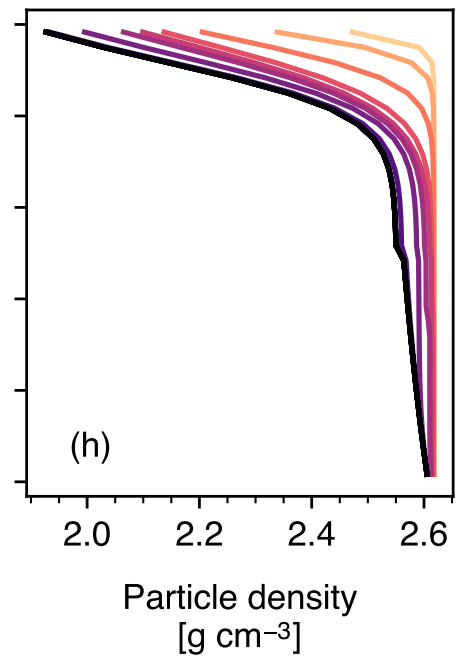

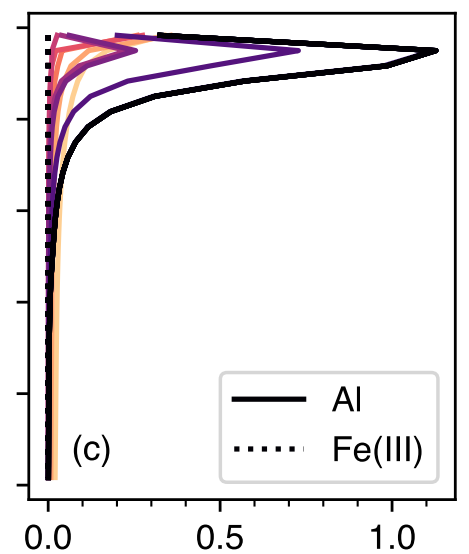

Aq. sp. $[\mu \mathrm{M}]$

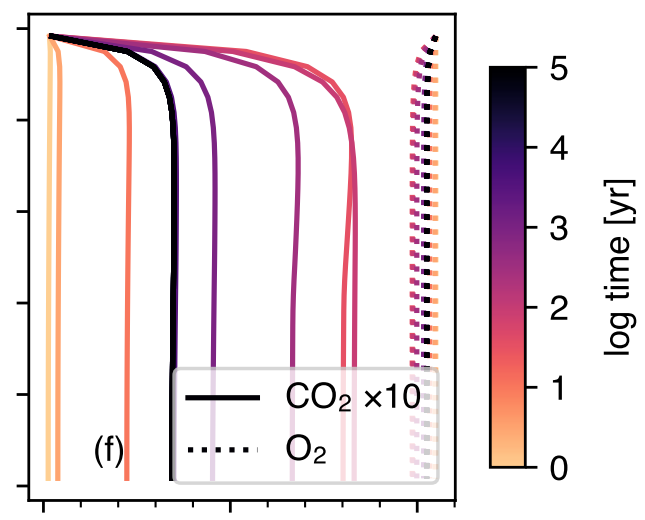

Gas sp. [atm]

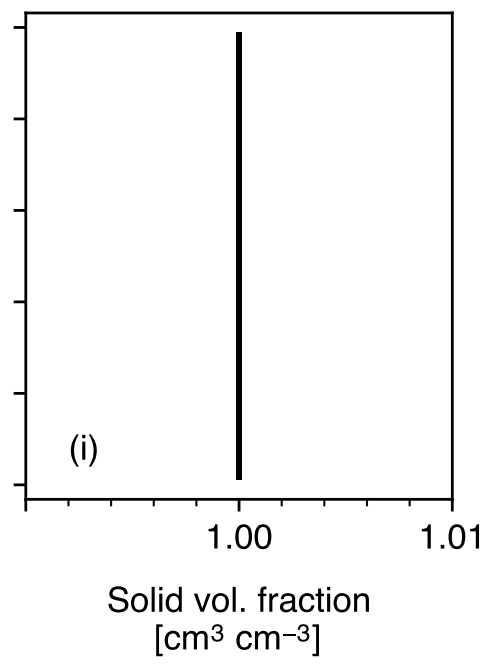

Figure 7: Simulation of biotic weathering at Site 1 in Table 8. Panels show the depth profiles of aqueous and gas species and soil physical properties as in Fig. 4 except that simulation includes soil respiration and bio-mixing. 
https://doi.org/10.5194/gmd-2022-8

Preprint. Discussion started: 10 February 2022

(c) Author(s) 2022. CC BY 4.0 License.

\section{(c) (1)}

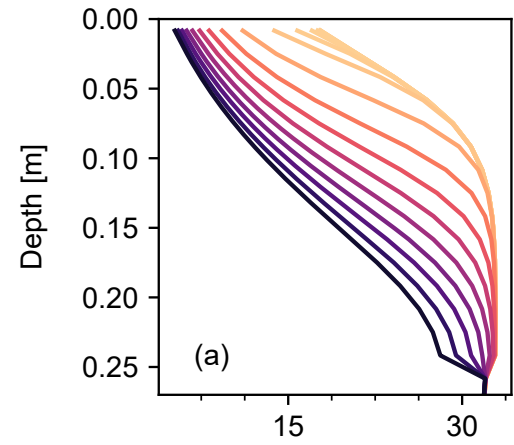

Amorphous-Si [wt\%]
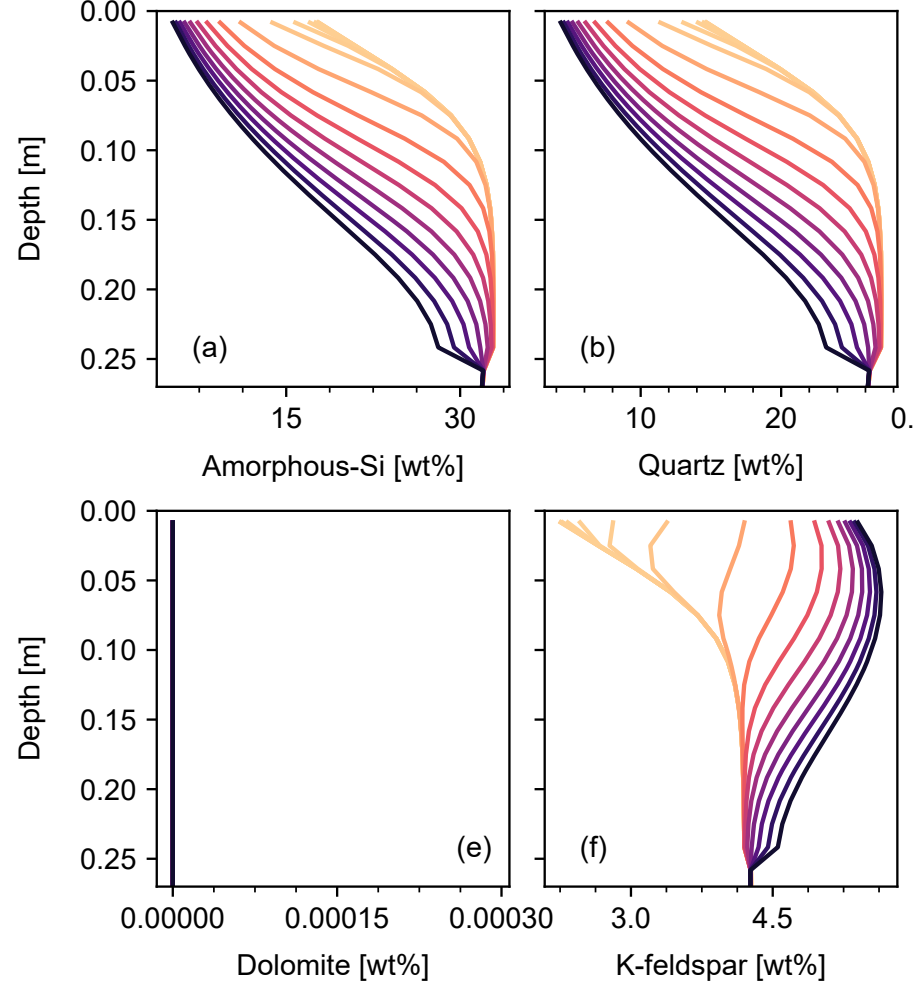

Quartz [wt \%]
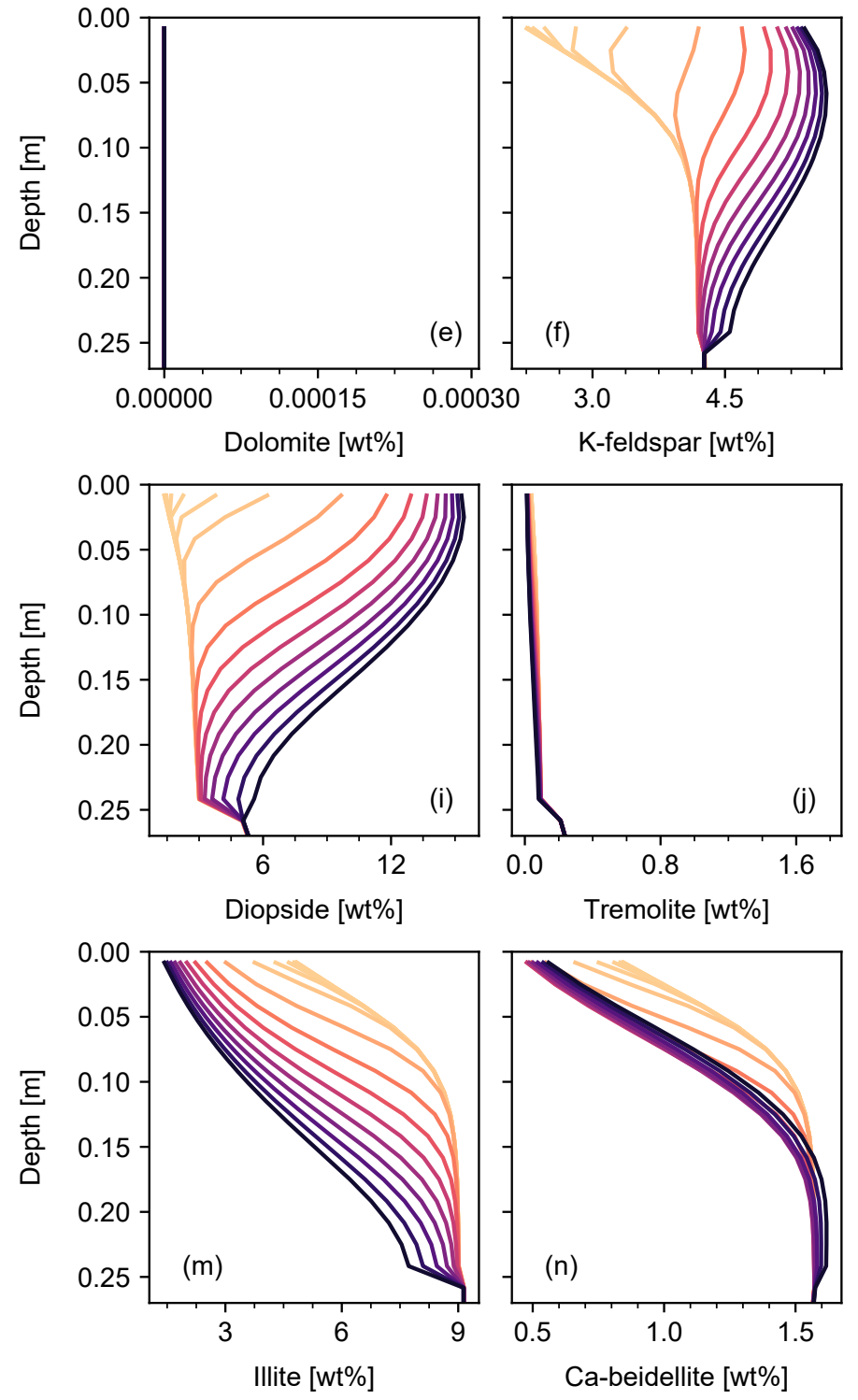

Tremolite [wt\%]

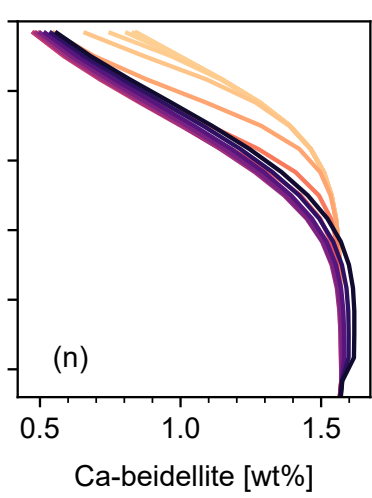

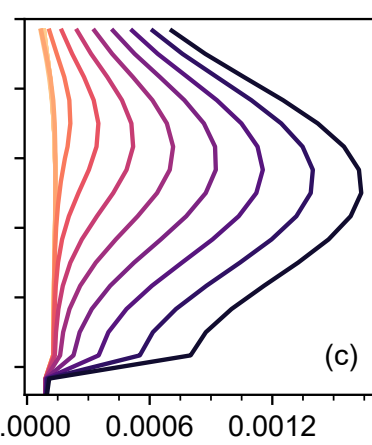

Goethite [wt $\%$ ]
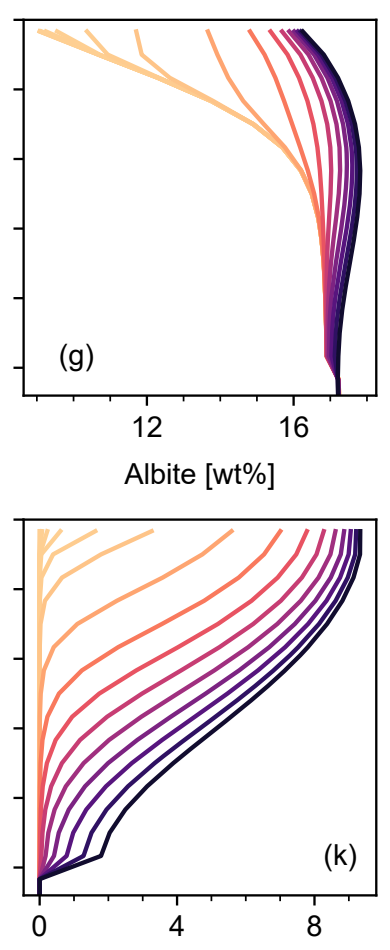

Foresterite [wt\%]

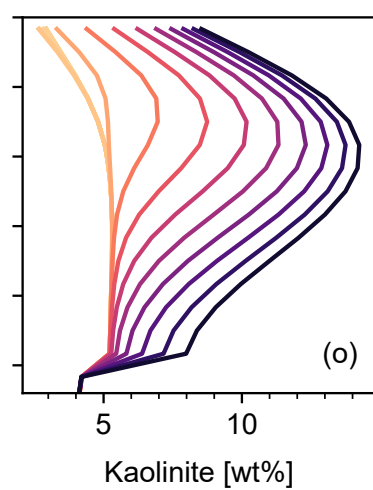

Geoscientific o Model Development $\stackrel{\text { I }}{\overrightarrow{3}}$ GU

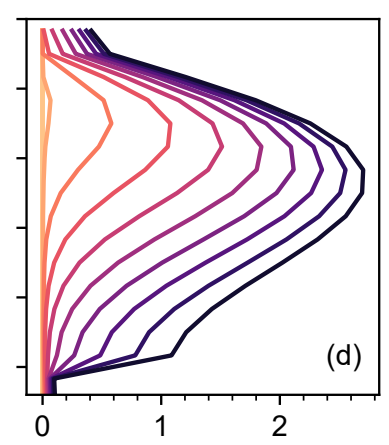

Calcite [wt\%]

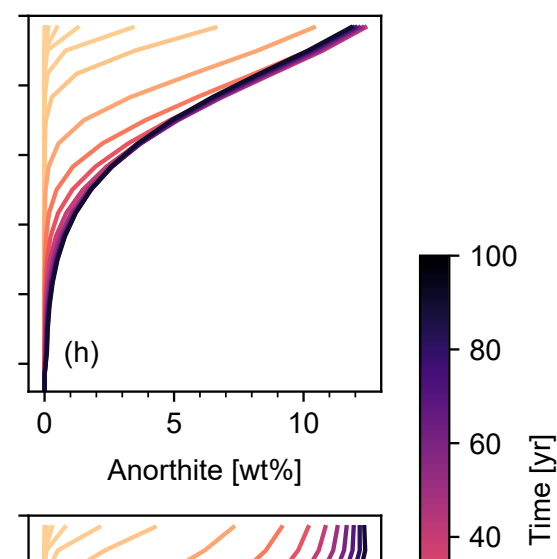

$-20$

Figure 8: Basalt powder application at Site 1 in Table 8. Panels show the depth profiles of simulated solid species as in Fig. 6 except that basalt powder is continuously added at a rate of $40 \mathrm{t} \mathrm{ha}^{-1} \mathrm{yr}^{-1}$ and plots are focused on soil mixed layer (0-25 cm). 


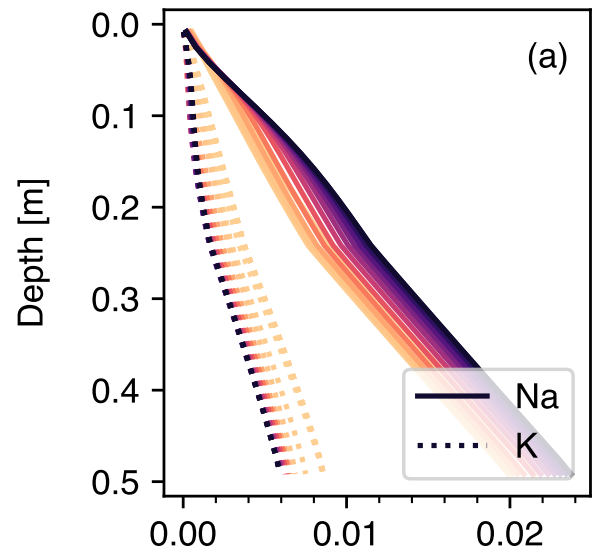

Aq. sp. [mM]

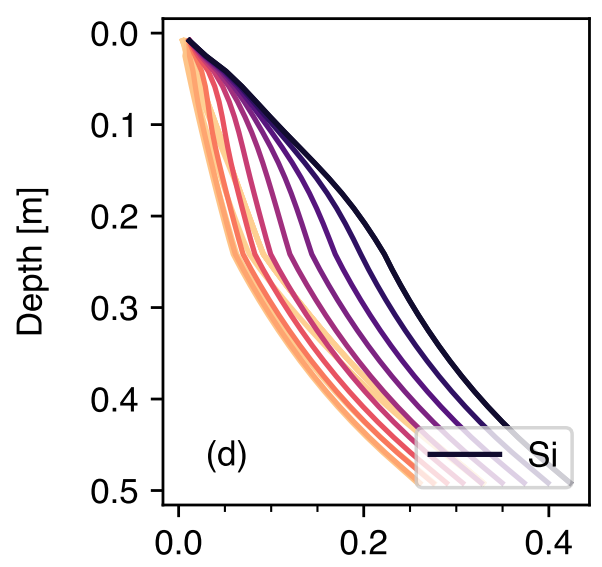

Aq. sp. [mM]

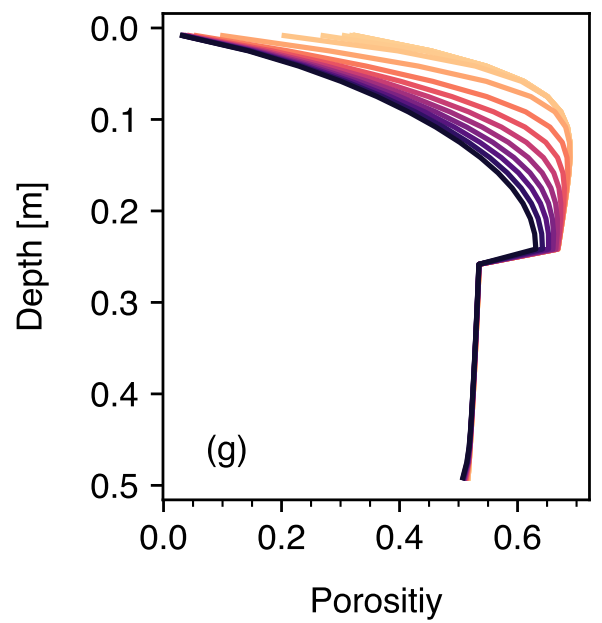

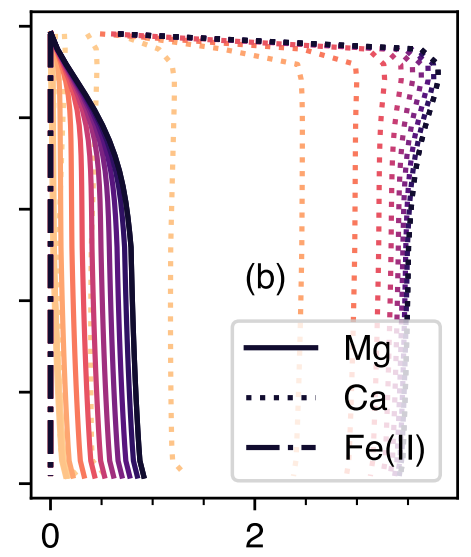

Aq. sp. [mM]

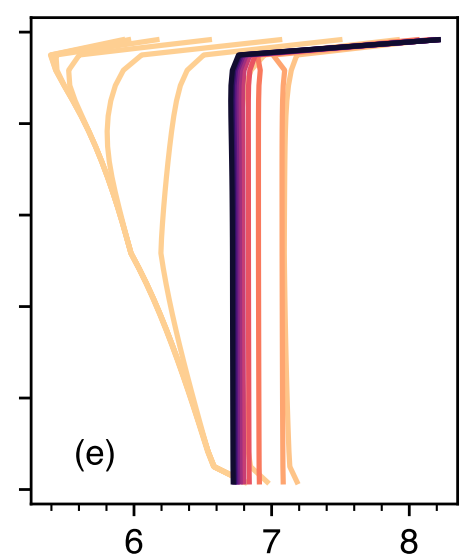

$\mathrm{pH}$

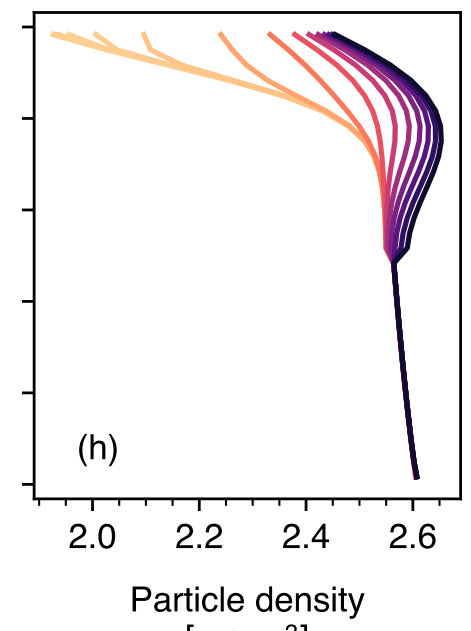

[g cm-3]

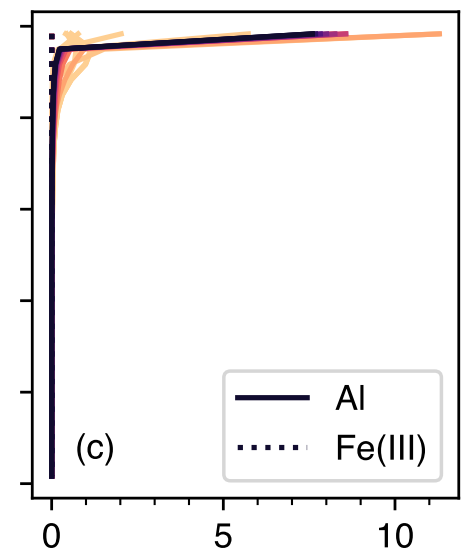

Aq. sp. $[\mu \mathrm{M}]$

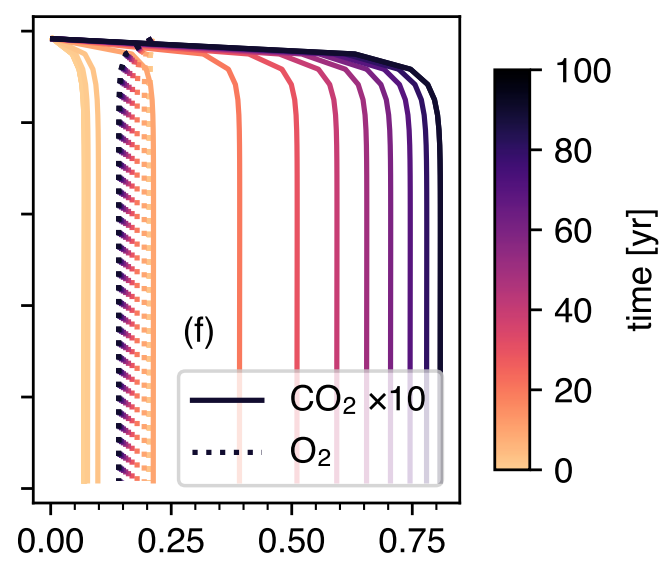

Gas sp. [atm]

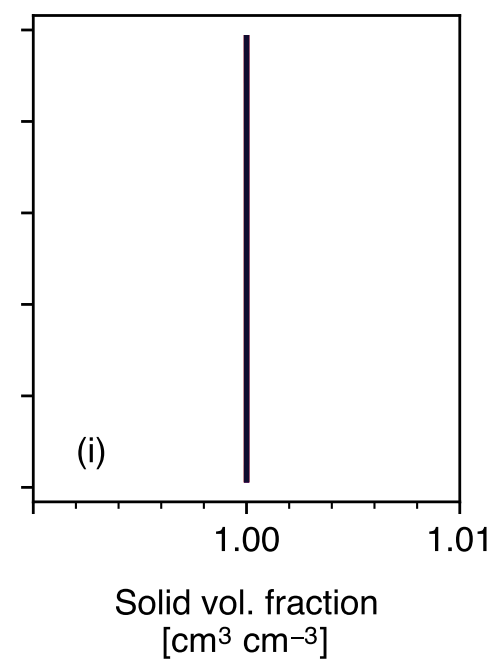

Figure 9: Basalt powder application at Site 1 in Table 8. Panels show the depth profiles of aqueous and gas species and soil physical properties as in Fig. 4 except that basalt powder is continuously added at a rate of $40 \mathrm{tha}^{-1} \mathrm{yr}^{-1}$. 
https://doi.org/10.5194/gmd-2022-8

Preprint. Discussion started: 10 February 2022

(c) Author(s) 2022. CC BY 4.0 License.

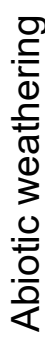

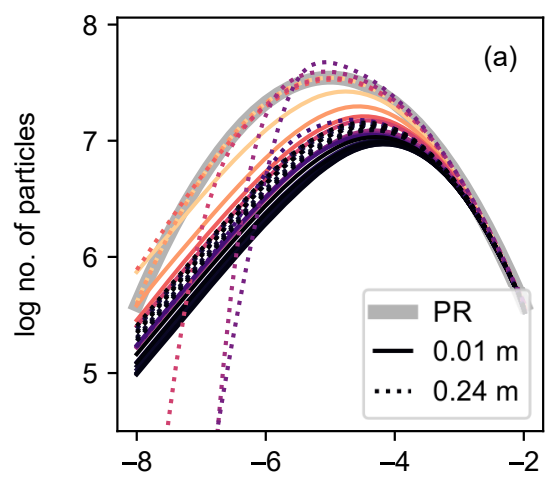

log radius $[\mathrm{m}]$

O্c

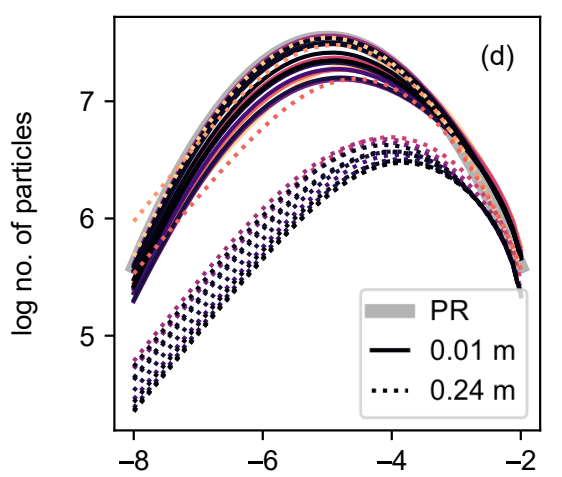

log radius $[\mathrm{m}]$

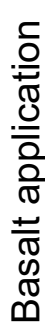

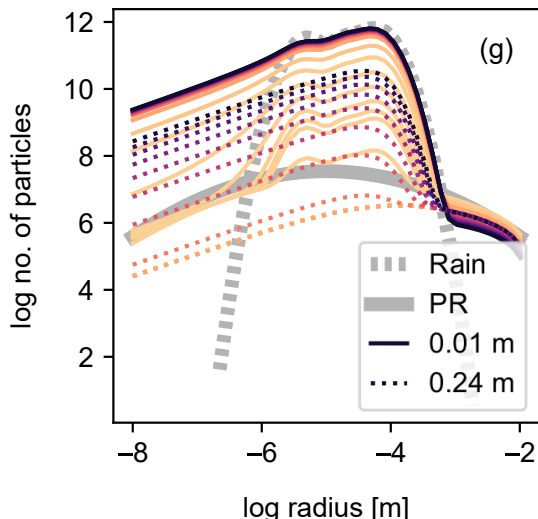

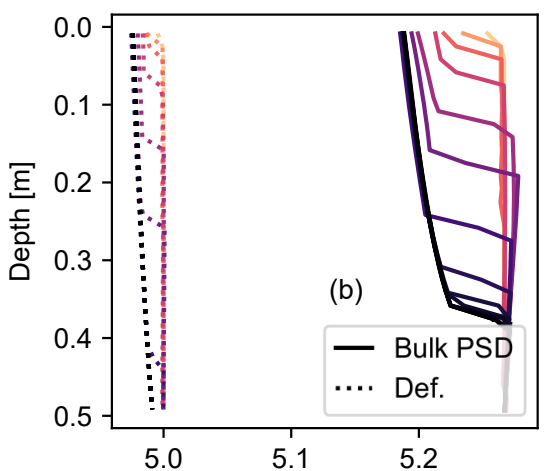

$\log \mathrm{SA}\left[\mathrm{m}^{2} \mathrm{~m}^{-3}\right]$
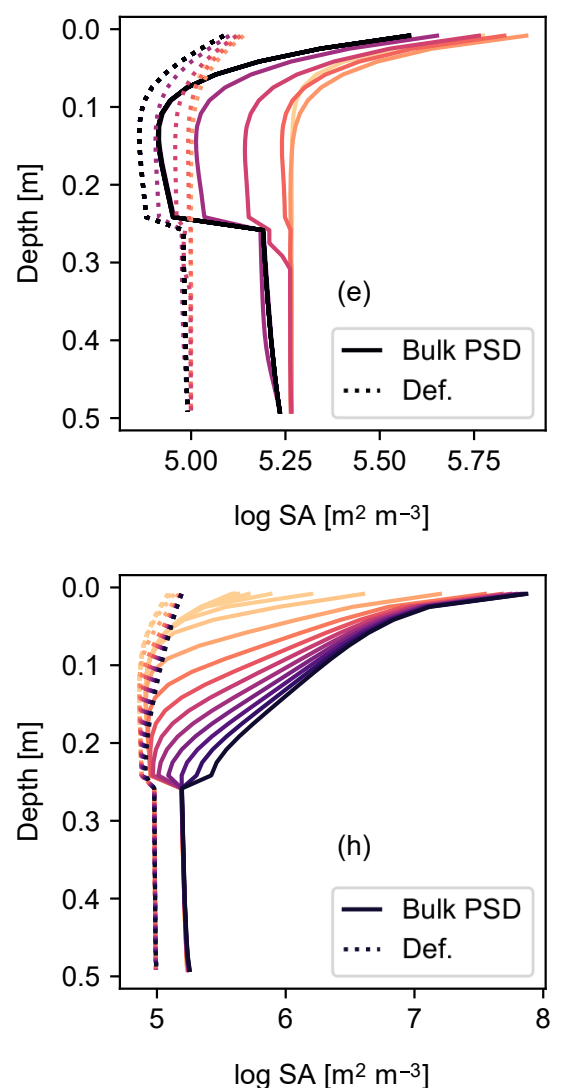

Geoscientific o Model Development

Discussions
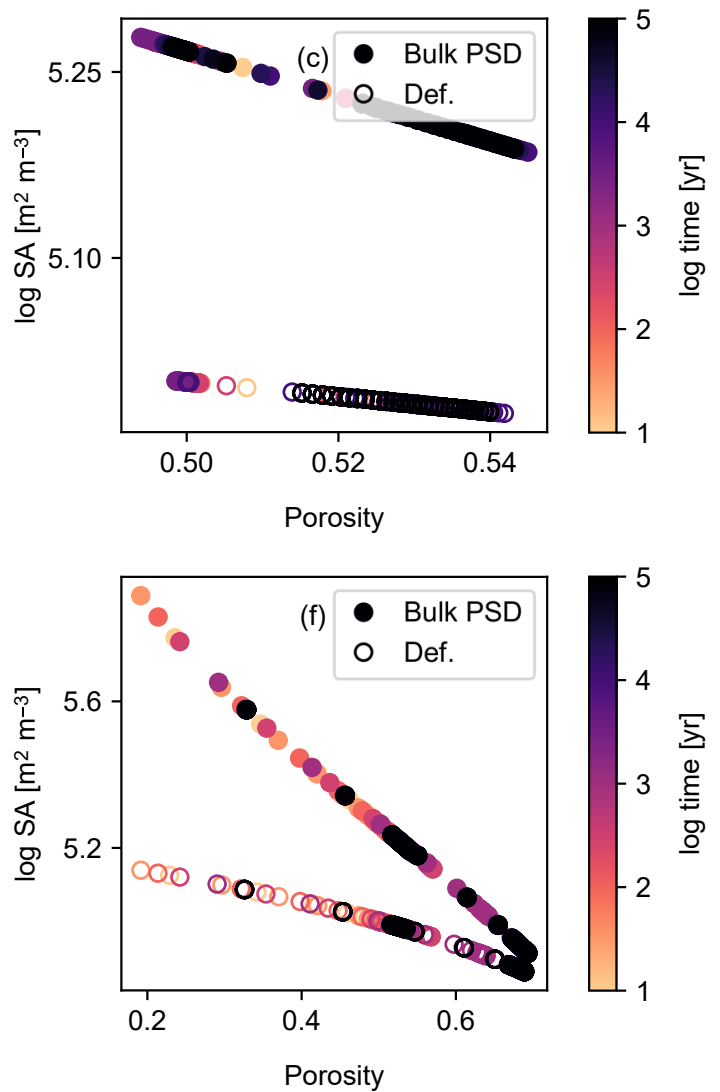

Porosity

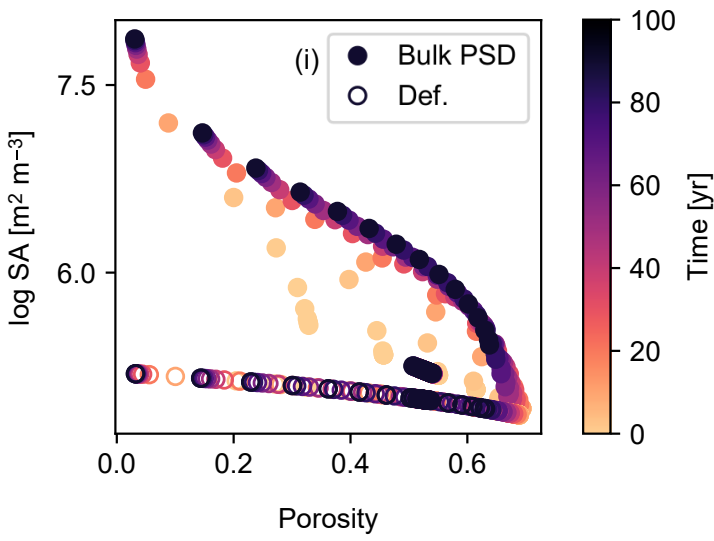

Figure 10: Simulations of abiotic weathering (a-c), biotic weathering (d-f) and basalt powder application (g-i) at Site 1 in Table 8 with surface area calculated based on tracked particle size distribution (PSD) for bulk soil. PSDs at surface and bottom of soil mixed layer are shown in a, $d$ and g. Pore surface area per unit pore volume is plotted against depth (b, e and $h$ ) or porosity (c, $f$ and i) and compared to the calculation with the default surface area parameterization. See Section 3.1.4 and Table 7 for the details on the boundary conditions of the simulations. 
https://doi.org/10.5194/gmd-2022-8

Preprint. Discussion started: 10 February 2022

(c) Author(s) 2022. CC BY 4.0 License.

(c) (i)

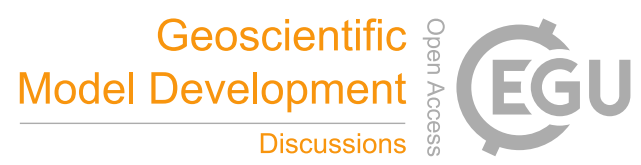

(a) Amorphous-Si

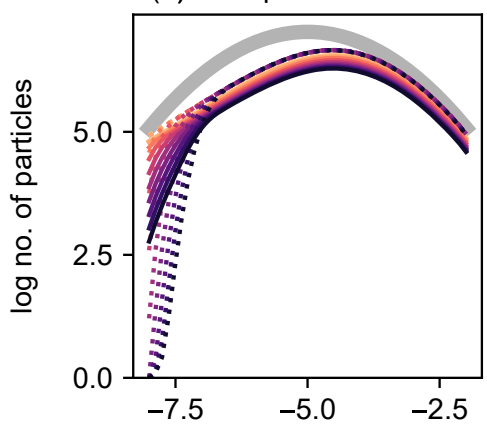

(e) Dolomite

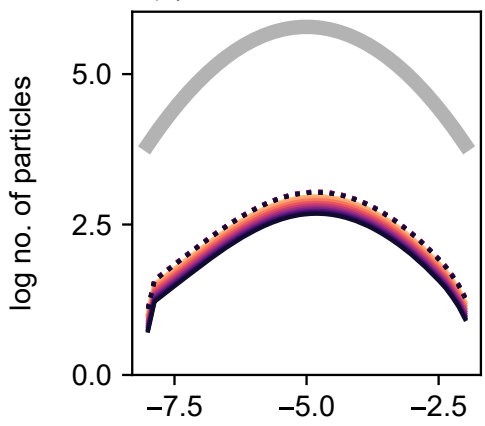

(i) Diopside

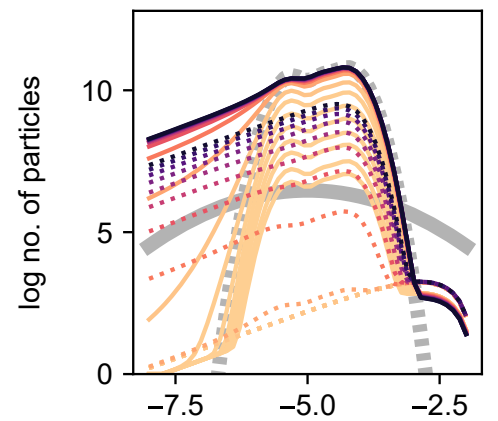

(m) Illite

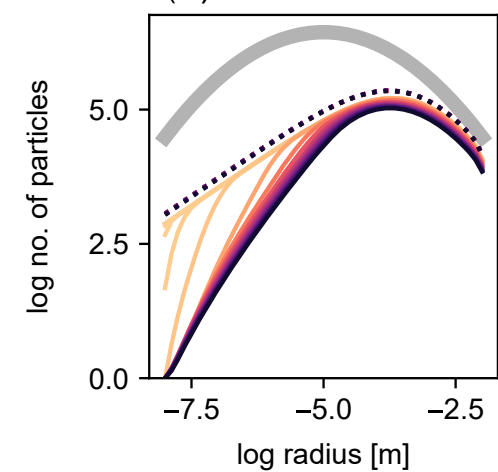

(b) Quartz

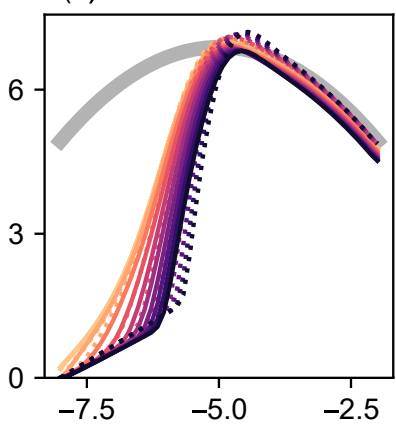

(f) K-feldsper

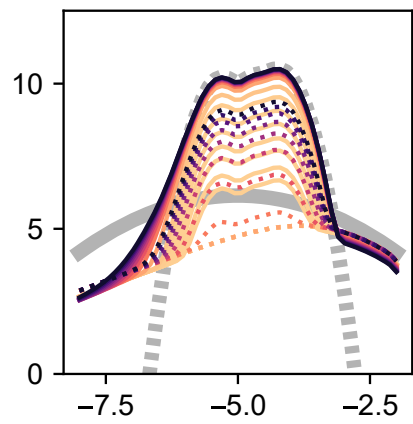

(j) Tremolite

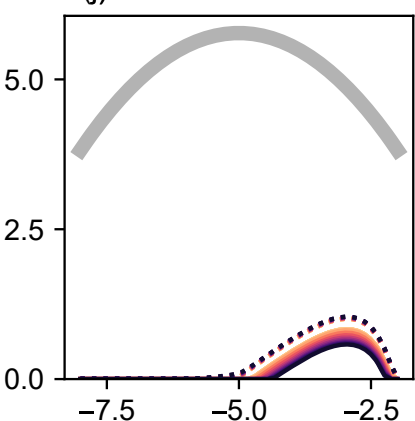

(n) Ca-beidellite

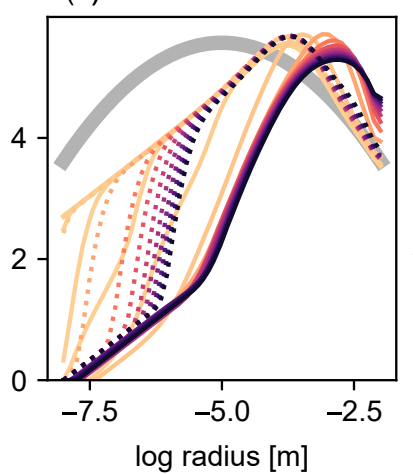

(c) Goethite

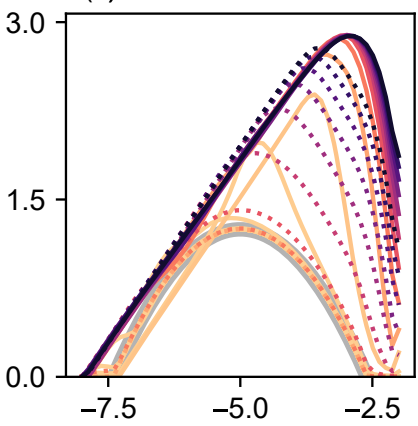

(g) Albite

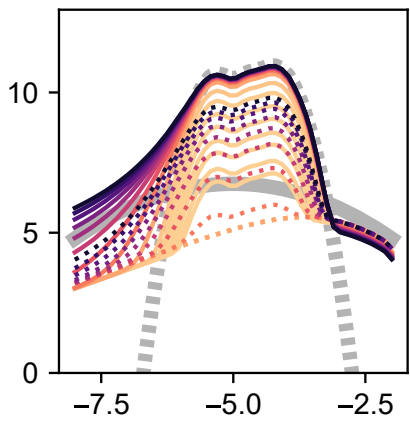

(k) Foresterite

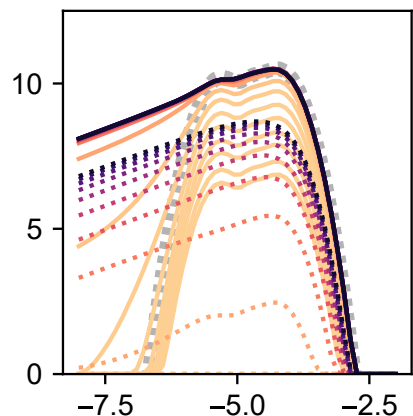

(o) Kaolinite

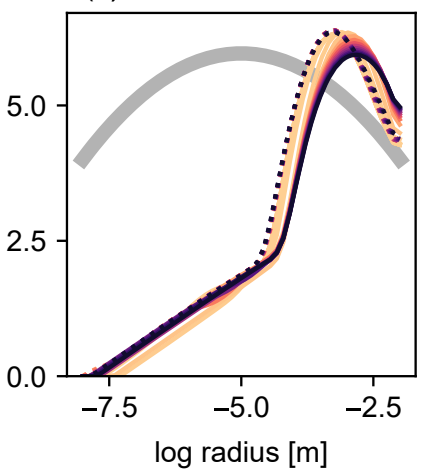

(d) Calcite

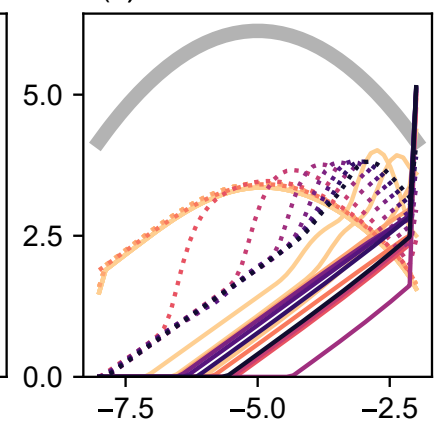

(h) Anorthite

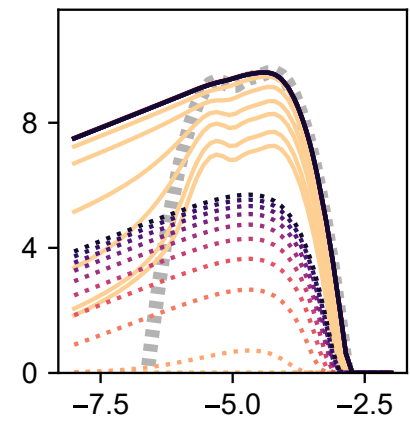

(I) Fayarite

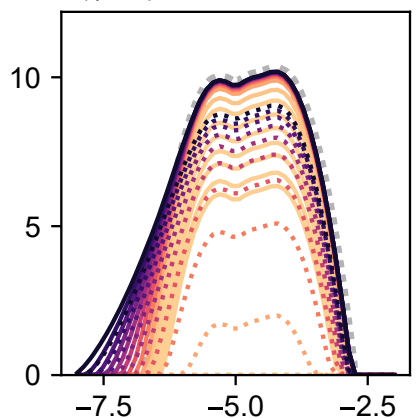

$-20$

Figure 11: Particle size distributions (PSDs) at surface and bottom of soil mixed layer for individual solid species in simulation of basalt powder application at Site 1 in Table 8 with the surface area calculated based on tracked PSDs for individual solid species. See Section 3.1.4 and Table 7 for the details on the boundary conditions of the simulation. 
https://doi.org/10.5194/gmd-2022-8

Preprint. Discussion started: 10 February 2022

(c) Author(s) 2022. CC BY 4.0 License.

(c) (1)
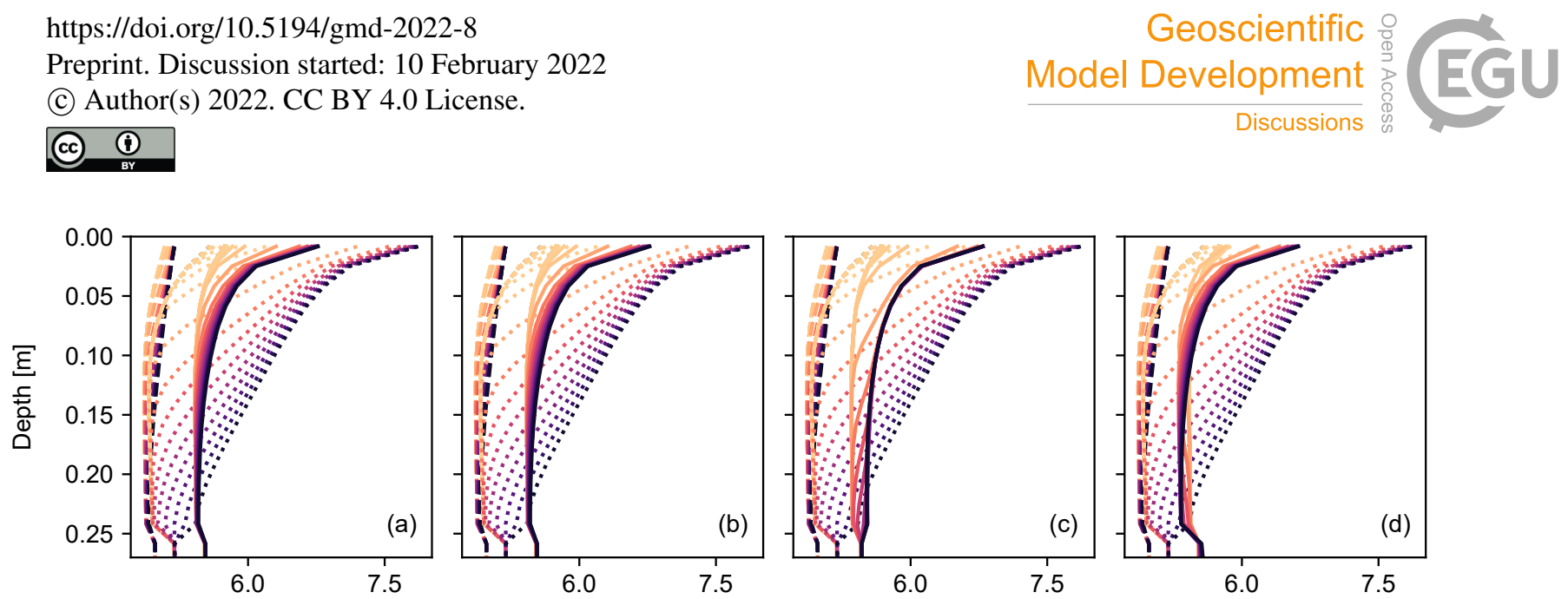

Amorphous-Si $\left[\log \mathrm{m}^{2} \mathrm{~m}^{-3}\right]$

Quartz [log $\mathrm{m}^{2} \mathrm{~m}^{-3}$ ]

Goethite [log $\mathrm{m}^{2} \mathrm{~m}^{-3}$ ]
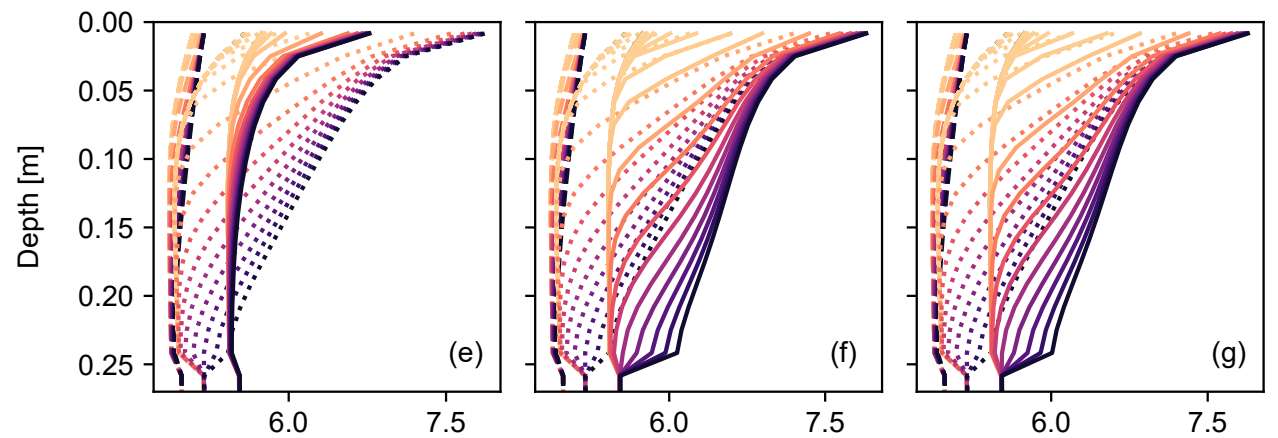

\section{Calcite [log $\mathrm{m}^{2} \mathrm{~m}^{-3}$ ]}

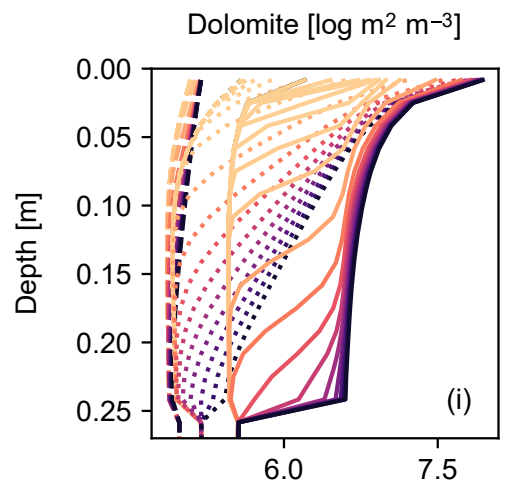

K-feldspar [log $\mathrm{m}^{2} \mathrm{~m}^{-3}$ ]
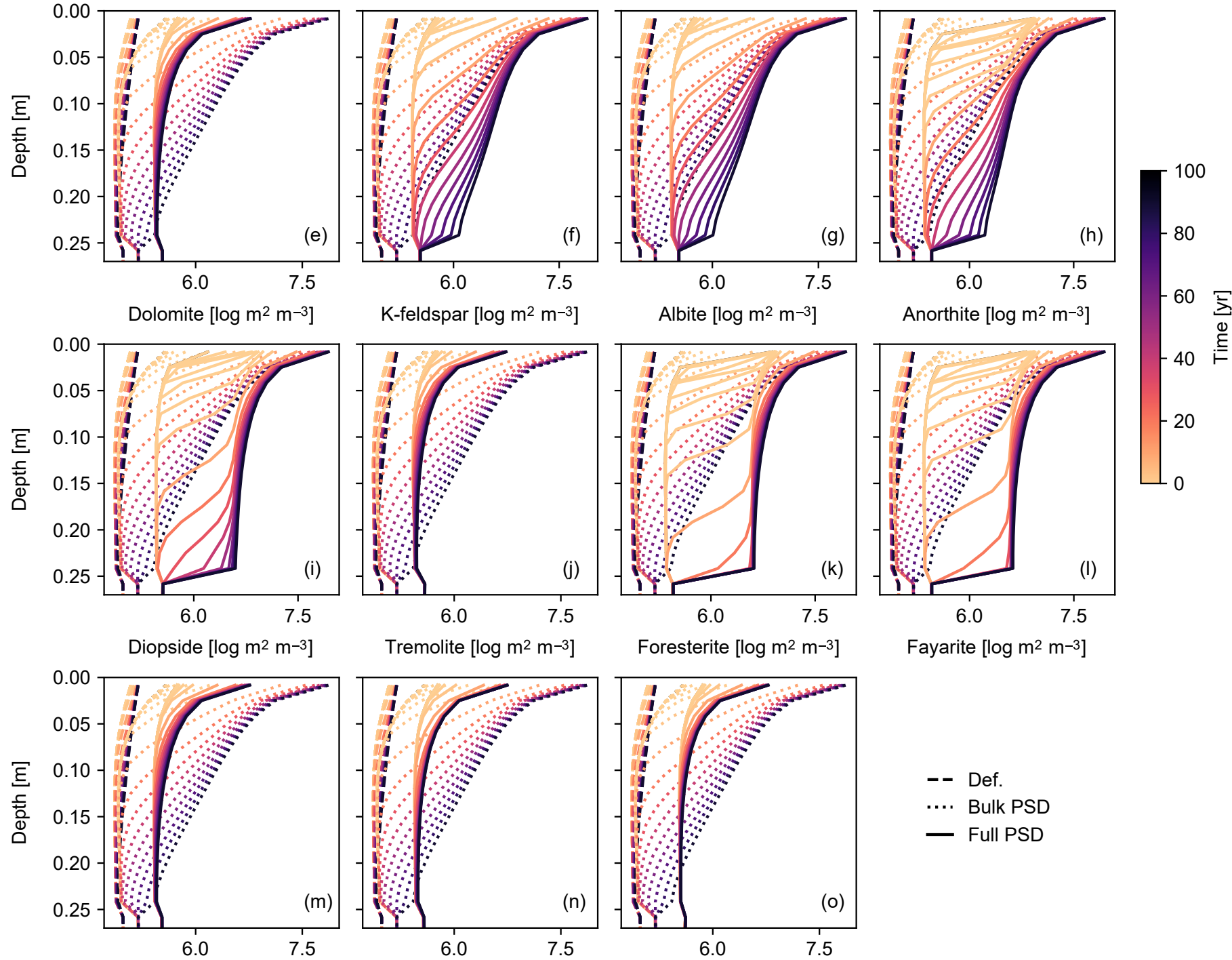

Tremolite $\left[\log \mathrm{m}^{2} \mathrm{~m}^{-3}\right]$

Foresterite [log $\mathrm{m}^{2} \mathrm{~m}^{-3}$ ]
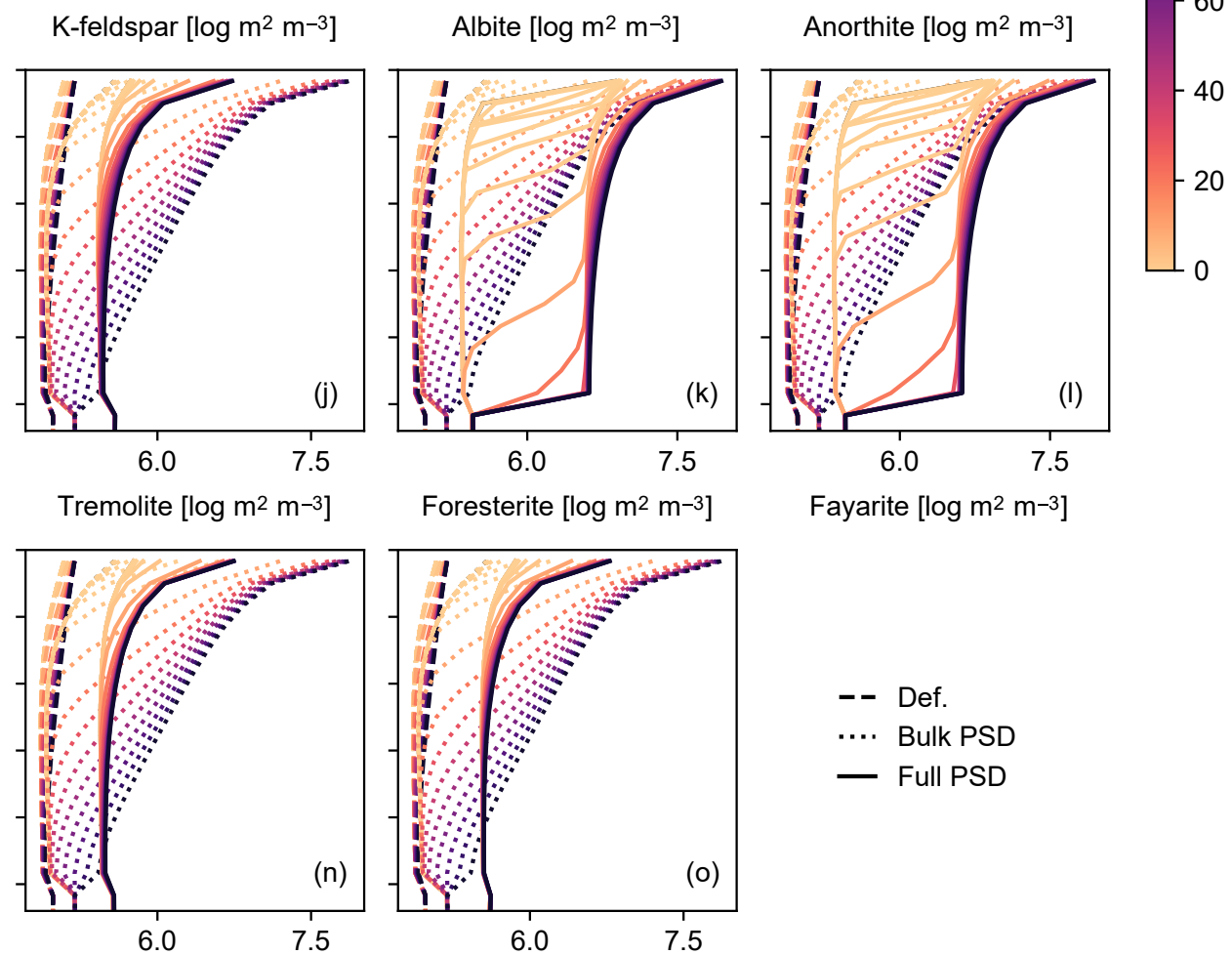

Fayarite $\left[\log \mathrm{m}^{2} \mathrm{~m}^{-3}\right.$ ]

Illite [log $\mathrm{m}^{2} \mathrm{~m}^{-3}$ ]

Ca-beidellite [log $\mathrm{m}^{2} \mathrm{~m}^{-3}$ ]

Kaolinite $\left[\log \mathrm{m}^{2} \mathrm{~m}^{-3}\right.$ ]

Figure 12: Surface area of individual solid species per unit pore volume plotted against depth (focused on mixed layer; 0-25 $\mathrm{cm}$ ) in simulation of basalt powder application at Site 1 in Table 8 with the surface area calculated based on tracked PSDs for individual solid species ('Full PSD'). The pore surface areas per unit pore volume calculated with the default parameterization ('Def.') and based on PSD for bulk soil ('Bulk PSD') are also plotted for comparison. See Section 3.1.4 and Table 7 for the details on the boundary conditions of the simulation. 

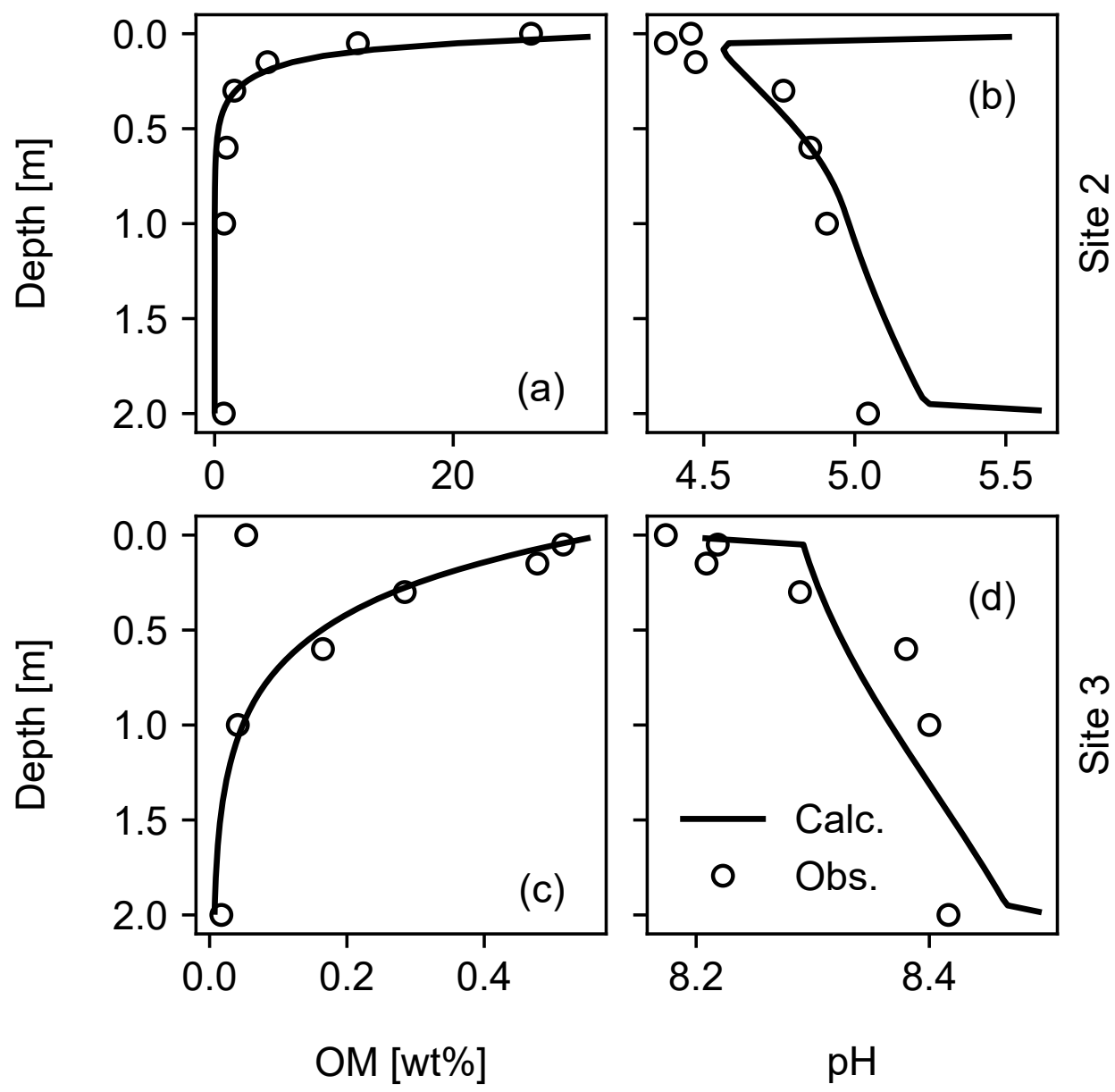

Figure 13: Model fit to observed depth profiles of soil OM and pH for Sites 2 and 3 in Table 8. See Section 3.2.1 for the details. 

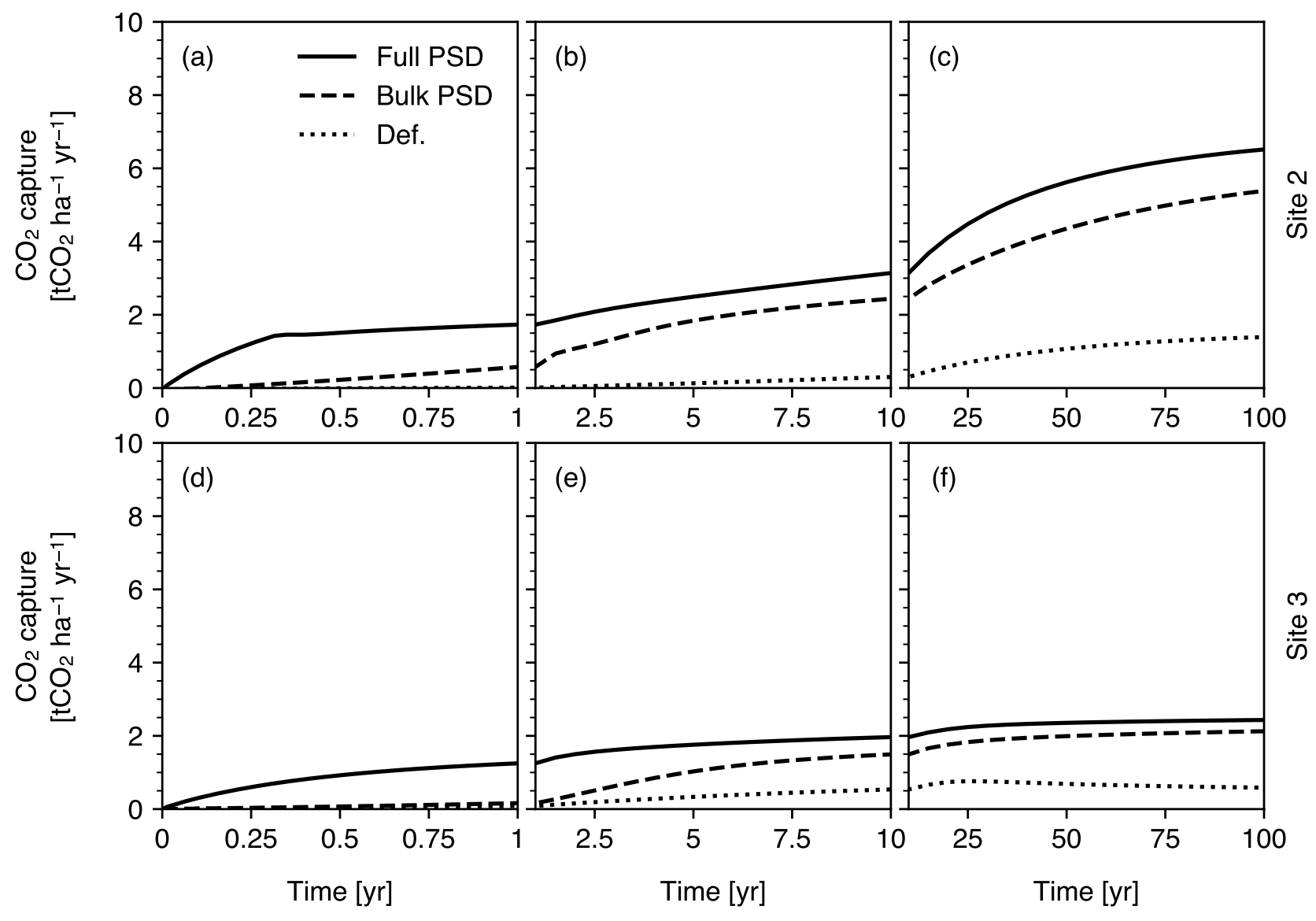

Figure 14: $\mathrm{CO}_{2}$ capture predicted in simulations of continuous basalt powder application at Sites 2 and 3 in Table 8 with the surface area calculation based on assumed hydraulic radius ('Def.'), tracked PSD for bulk soil ('Bulk PSD') and tracked PSDs for individual solid species ('Full PSD'). See Section 3.2.2 for the details. 

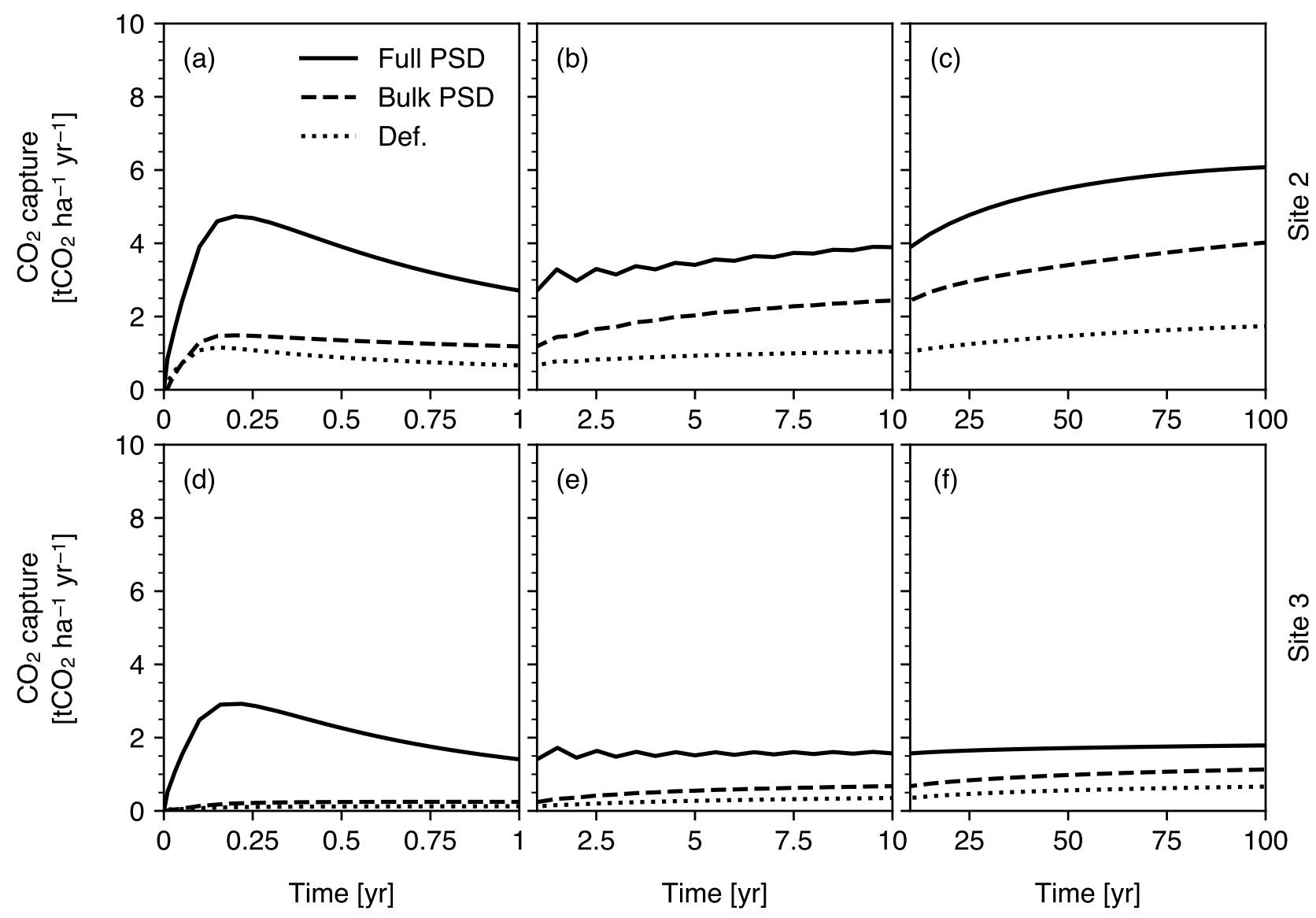

Figure 15: $\mathrm{CO}_{2}$ capture predicted in simulations of pulsative basalt application at Sites 2 and 3 in Table 8 . Milled basalt (dominated by $5,20,50$ and $70 \mu \mathrm{m}$ particles) is applied non-continuously and homogeneously mixed at the soil surface. See Section 3.2.2 for the details. 